\title{
3 Clemens Alexandrinus
}

\subsection{Einleitung}

Der zweite Kirchenschriftsteller, dessen Position untersucht werden soll, ist Titus Flavius Clemens, besser bekannt als Clemens von Alexandria oder Clemens Alexandrinus. Dieser wirkte in etwa zeitgleich mit Tertullian ${ }^{1}$, wahrscheinlich sogar etwas früher, in Alexandria. ${ }^{2}$

Überblickt man die moderne Forschung zur Frage von ,Christentum und Soldatenstand' in vorkonstantinischer Zeit, so entdeckt man ein deutliches Ungleichgewicht in der Behandlung des Clemens. Während er für einige Autoren bei der Untersuchung des Problems eine wichtige Rolle spielt, wird er von anderen weitgehend ignoriert. So betrachtet ihn einerseits R. Riesner ${ }^{3}$ als den Vertreter einer paradigma-

1 Das Leben des Clemens wird meist zwischen ca. 150 n.Chr. und vor 216/220 n. Chr. angesetzt; vgl. MÉHAT, André, s.v. Clemens von Alexandrien. In: TRE 8, (1981), 101-113, hier 101-102; NeYMEYr, Lehrer, 45-50; FeulNER, Rüdiger, Clemens von Alexandrien - Sein Leben, Werk und philosophischtheologisches Denken, (Bamberger theologische Studien), Frankfurt am Main, Berlin, Bern, Wien 2006, 22-27. KöNIG, Hildegard, „Dass du dich retten lässt, das drängt mich sehr!“ Clemens von Alexandrien als Seelsorger - Ein wenig beachteter Zugang zu Person und Werk, Habil. Univ. Bonn 2005, publ. auf dem Hochschulserver der ULB, Bonn 2010, 43, setzt seinen Tod etwas vorsichtiger vor $230 \mathrm{n}$. Chr. an. Den Höhepunkt seines Wirkens erlebte er wohl in den Jahren zwischen 190 und etwa 210 n.Chr. (vgl. MÉHAT, s.v. Clemens (TRE), 101; FeulnER, Clemens, 22, die mit Euseb., praef. Chron. can. S. 211 [Helm/ Treu] = S. 223 [Karst] seine ơk $\mu \eta ́$, in das Jahr 193 n.Chr. datieren). Um 202-203 n.Chr. oder vielleicht etwas später hat er Alexandria verlassen, um sich bei Alexander (Bischof von zuerst Cäsarea in Kappadokien und dann Jerusalem) niederzulassen. Der Grund dafür ist unklar. Für alternative Erklärungen vgl. u.a. NeYmEYR, Lehrer, 49; OsBoRn, Eric F., Clement of Alexandria, Cambridge 2005, 22; Rankin, David, From Clement to Origen - The Social and Historical Context of the Church Fathers, Aldershot 2006, 125; FeULnER, Clemens, 26; sowie andererseits NAutin, Pierre, Origène - Sa vie et son oeuvre, (Christianisme Antique 1), Paris 1977, 54; Wyrwa, Dietmar, s.v. Clemens von Alexandrien. In: DöPP/GeERLINGS (Hrsg.), LACL, 152-154, hier 152; MÉHAT, s.v. Clemens (TRE), 102.

2 Für einen Überblick über das kaiserzeitliche Ägypten vgl. MoDRzEJEwSKI, Joseph Mélèze, Ägypten. In: Lepelley, Claude (Hrsg.), Rom und das Reich - Die Regionen des Reiches, (genehmigte Lizenzausg.), Hamburg 2006, 457-518. Für Alexandria, das, wie schon der Titel des Statthalter (praefectus Alexandriae et Aegypti) sowie die Bezeichnung Alexandria ad Aegyptum erkennen lassen, kein Teil der Provinz, sondern eine eigenständige Polis war, vgl. z. B. kurz MÜLLER, Caspar D.G.; WEISs, Hans-Friedrich, s.v. Alexandria. In: TRE 2, (1978), 248-264; JANSEN-WinkELn, Karl, s.v. Alexandreia [1]. In: DNP 1, (1996), 463-465; sowie ausführlich ClAuss, Manfred, Alexandria - Schicksale einer antiken Weltstadt, Stuttgart 2003, hier v. a. 121-219. Zur Bevölkerung Alexandrias vgl. DeLIA, Diana, The Population of Roman Alexandria. In: TAPhA 118, (1988), 275-292. Zu Alexandria selbst als einem Zentrum antiker Gelehrsamkeit, das als solches einen wichtigen Hintergrund für die Entstehung speziell christlicher Gelehrsamkeit bildet, vgl. ausführlich WATTS, Edward Jay, City and School in Late Antique Athens and Alexandria, (The Joan Palevsky imprint in classical literature 41), Berkeley 2006, 143-168; außerdem HeINE, Origen, 1-25.

3 RIESNER, Militia Christi; vgl. den Untertitel: „Tertullian und Clemens Alexandrinus als paradigmatische Positionen in der Alten Kirche“.

Ә OpenAccess. (c) 2021 Andreas Gerstacker, publiziert von De Gruyter. (cc))BY-NC-ND Dieses Werk ist lizenziert unter einer Creative Commons Namensnennung - 4.0 International Lizenz. 
tischen Gegenposition in der Soldatenfrage zu dem vorgeblichen Rigoristen Tertullian. ${ }^{4}$ Auch für R. Klein ${ }^{5}$ übernimmt Clemens die Rolle des Vertreters einer von zwei konträren Positionen, hier aber gegenüber Origenes. Beide lassen erkennen, welche Bedeutung der Alexandriner für diese Frage haben könnte. Bei J. Cadoux, R. Bainton, B. Schöpf, L. Swift und J. Helgeland nimmt die Besprechung des Clemens ebenfalls gemessen am Umfang der jeweiligen Studien verhältnismäßig weiten Raum ein. ${ }^{6}$ Andererseits kommen beispielsweise A. Bigelmaier, E. Ryan, H. Karpp, W. Geerlings, D. Hunter und J. Shean völlig ohne beziehungsweise nur mit einer vergleichsweise knappen Diskussion des Clemens aus. ${ }^{7}$ Es wird sich im Lauf der Analyse zeigen, dass Clemens in der Tat einen substantiellen Beitrag für die vorliegende Untersuchung zu leisten hat.

Das Kapitel ist wie folgt aufgebaut: Nach einem kurzen, auf die vorliegende Fragestellung bezogenen Überblick über Leben und Werk werden zuerst drei Texte besprochen, in denen Clemens direkt auf Soldaten zu sprechen kommt. Im Anschluss daran sollen einige weitere Textstellen untersucht werden, in denen er das Thema Krieg abhandelt und die in der Forschung des Öfteren für die hier untersuchte Fragestellung herangezogen werden. Am Ende werden wieder eine Zusammenschau der Texte und die Frage nach einer einheitlichen Position des Clemens stehen.

\subsection{Leben und Werk}

\subsubsection{Leben}

Über Clemens Leben ${ }^{8}$ ist nur wenig bekannt, so dass H. König mit Recht festhält:

\footnotetext{
4 Dass man Clemens auch schon ganz anders verstanden hat, zeigt eine Bemerkung bei RAMSAY, William M., The Cities and Bishoprics of Phrygia - Being an Essay of the Local History of Phrygia from the Earliest Time to the Turkish Conquest, Bd. 1,2: West and West-Central Phrygia, Oxford 1897, 718: „Hence many authorities, such as Tertullian and Clement of Alexandria, absolutely forbade that Christians should be soldiers or bear arms; but the Church as a whole never sanctioned this prohibition [...].“ Dieses Verständnis wird weder den Texten bei Clemens gerecht, noch, wie festgestellt, der Haltung Tertullians.

5 KLEIN, Tertullian, 107.

6 Cadoux, Christian Attitude; siehe im Register für die verstreuten Bezugnahmen; BaInTon, Early Church (= Kirche und Krieg) passim; BAINTON, Attitudes passim; ScHöPF, Tötungsrecht, passim; SwIFT, War (ANRW), passim; wesentlich kürzer ist die Diskussion bei Swift, Views; HeLgeland, Christians (ANRW); in HELgeLAND, ET AL., Christians and the Military, spielt er dagegen keine Rolle. 7 Bigelmair, Beteiligung, 181; Ryan, Rejection, kommt völlig ohne eine Diskussion des Clemens aus; KarpP, Stellung, 506; GeErLings, vorkonstantinische Kirche, 10; Hunter, Research, 90; Hunter, Church, 172, Anm. 29; SHEAN, Soldiering, 100-101.

8 Vgl. dazu knapp MÉHat, s.v. Clemens (TRE) 101-102; NEYMEYR, Lehrer, 45-50; WyRWA, s.v. Clemens (LACL), 152; FeUlNER, Clemens, 21-27. Ausführlich sind OsBorn, Clement, 1-27; und KöNIG, Clemens, 29-88; Wyrwa, Dietmar, Clemens von Alexandrien. In: Riedeweg/Horn/Wyrwa (Hrsg.), Philosophie der Kaiserzeit, 927-957, hier 927-928. Zur älteren Forschung vgl. HARNACK, Geschichte, 3-23; CAM-
} 
„Clemens von Alexandrien ist nicht leicht beizukommen: Zu wenig wird über ihn durch zeitgenössische Zeugen bekannt, nicht viel gibt er selbst in seinem beträchtlichen Werk von sich preis.“`

Viel hängt davon ab, wie viel Zutrauen man in die Angaben des Eusebius hat, der als erster substantiellere Nachrichten bietet. ${ }^{10}$ Im Anschluss an A. van den Hoek, E. Osborn und H. König ${ }^{11}$ wird hier „Euseb als ein Informant betrachtet, der vor allem das Wissen, welches in der ersten Hälfte des 4. Jahrhunderts über Clemens und die Kirche von Alexandria zugänglich war, überliefert"12 und bei aller Notwendigkeit einer kritischen Lektüre doch einiges Vertrauen in die grundsätzliche Zuverlässigkeit seiner Angaben verdient.

Der aus einem nicht-christlichen Elternhaus ${ }^{13}$ stammende Clemens hatte sich nach seiner Hinwendung zum christlichen Glauben und einer längeren Bildungsreise $\mathrm{zu}$ verschiedenen christlichen Lehrern vor allem des östliche Mittelmeergebietes ${ }^{14}$ in Alexandria niedergelassen und wirkte dort als christlicher Lehrer. ${ }^{15}$

Von besonderem Interesse für diese Arbeit ist die Stellung des Clemens zur christlichen Gemeinde Alexandrias. Diese Frage ist eng mit derjenigen nach der sogenannten alexandrinischen Katechetenschule verbunden, deren Leiter Clemens gewesen sein soll. ${ }^{16}$ Dabei interessiert an dieser Stelle vor allem, inwieweit das, was Clemens zur ,Soldatenfrage‘ zu sagen hat, repräsentativ für die alexandrinische Gemeinde sein kann. Dabei kann, was J. Tloka für die alexandrinische Schule unter Origenes festhält, genauso auch für Clemens gelten:

PENHAUSEn, Hans von, Griechische Kirchenväter, (Urban-Taschenbücher), 8. Aufl., Stuttgart 1993, $32-42$.

9 KÖNIG, Clemens, 26. Eine ausführliche Auflistung aller Quellen bietet FEULNER, Clemens, 21; außerdem HARNACK, Geschichte, 6-9. Gründlich besprochen werden die wichtigsten davon bei KöNIG, Clemens, 29-44.

10 Sehr skeptisch sind z. B. GRANT, Robert M., Early Alexandrian Christianity. In: ChHist 40/2, (1971), 133-144; NeYMEYR, Lehrer, 42-50; VAN DEN BROEK, Roelof, The Christian „School“ of Alexandria in the Second and Third Centuries. In: van den Broek, Roelof (Hrsg.), Studies in Gnosticism and Alexandrian Christianity, (Nag Hammadi and Manichaean Studies 39), Leiden 1996, 197-205. Deutlich optimistischer sind Scholten, Clemens, Die alexandrinische Katechetenschule. In: JbAC 38, (1995), 16-37; vAN DEN HoEK, Annewies, How Alexandrian was Clement of Alexandria? - Reflections on Clement and his Alexandrian Background. In: HeyJ (The Heythrop Journal) 31/2, (1990), 179-194; und noch stärker DIEs., The „Catechetical“ School of Early Christian Alexandria and Its Philonic Heritage. In: HThR 90/1, (1997), 59-87, zusammenfassend ebd., 85-86; außerdem OsBoRN, Clement, 19-24; Wyrwa, s.v. Clemens (LACL), 152; KöNIG, Clemens, 36-44 und v. a. 45-77.

11 Belege siehe oben, Anm. 10.

12 KöNIG, Clemens, 28.

13 Euseb. praep. Ev. 2,2,64; Beleg nach FeulnER, Clemens, 25.

14 Strom. 1,11,2. Eine ausführliche Diskussion der möglichen Kandidaten bietet KöNIG, Clemens, 44-74; für eine kurze Übersicht vgl. MÉHAT, s.v. Clemens (TRE), 101; FEULnER, Clemens, 25-26.

15 Strom. 1,11,1-3.

16 Die frühesten Belege finden sich bei Euseb. hist. eccl. 5,10,1-11,5 ; 6,3,3; 6,6. Zur weiteren Quellenlage vgl. z. B. VAN DEN BROEK, School, 198-199. 
„Die sogenannte alexandrinische Katechetenschule zur Zeit des Origenes ist insbesondere in der jüngeren Forschungsgeschichte Gegenstand einer intensiven Diskussion, so daß sie geradezu ausund überinterpretiert scheint.“"17

Daher sollen hier auch nur einige wenige, für die vorliegende Fragestellung relevante Aspekte kurz angeschnitten werden, ansonsten wird auf die wichtigste Literatur verwiesen. ${ }^{18}$

In der älteren Forschung wurde spätestens seit G. Bardys ${ }^{19}$ Kritik an Eusebius die Existenz einer kirchlich eingebundenen Schule bestritten ${ }^{20}$ und Clemens selbst mit seinem Lehrbetrieb immer weiter von der christlichen Gemeinde Alexandrias weggerückt ${ }^{21}$. In der neueren Forschung wurde er dagegen wieder deutlich der christli-

17 TloKA, Jutta, Griechische Christen - Christliche Griechen: Plausibilisierungsstrategien des antiken Christentums bei Origenes und Johannes Chrysostomos, (Studien und Texte zu Antike und Christentum 30), Tübingen 2005, 112.

$18 \mathrm{Zu}$ den miteinander verbundenen Fragen nach Clemens, seiner Stellung zur Gemeinde und der alexandrinischen Katechetenschule vgl. aus der umfangreichen Literatur BARDY, Gustave, Aux origines de l'École d'Alexandrie. In: RSR 27, (1937), 65-90; BARDY, Gustave, Pour l'histoire de l'École d'Alexandrie. In: VivPen 2, (1942), 80 - 109; KNAUBER, Adolf, Katechetenschule oder Schulkatechumenat? Um die rechte Deutung des „Unternehmens“ der ersten großen Alexandriner. In: TThZ 60, (1951), 243-266; Hornschun, Manfred, Das Leben des Origenes und die Entstehung der alexandrinischen Schule. In: ZKG 71, (1960), 1-25, 193-214; MÜLLER, Caspar D.G., s.v. Alexandrien I: Historisch. In: TRE 2, (1978), 248-261, hier 253-254; MEEs, Michael, Die frühe Christengemeinde von Alexandrien und die Theologie des Klemens von Alexandrien. In: Lateranum N.S. 50, (1984), 114-126; NEYMEYR, Lehrer, 42-45 und 86-95; vAN DEN HoEK, How Alexandrian; SCHOLten, Katechetenschule; vAN DEN BROEK, Roelof, Juden und Christen in Alexandrien im 2. und 3. Jahrhundert. In: van den Broek (Hrsg.), Studies in Gnosticism, 181-196; van Den BRoeK, School; van Den Hoek, School; Le Boulluec, Alain, Die „Schule“ von Alexandrien. In: Pietri, Luce (Hrsg.), Die Geschichte des Christentums: Religion, Politik, Kultur - Bd. 1: Die Zeit des Anfangs (bis 250), (Die Geschichte des Christentums von den Anfängen bis zur Gegenwart 1), Freiburg i. Br. 2003, 576 - 621; JAKAB, Ecclesia alexandrina, 91-106; WYRWA, Lernen, hier v.a. 279-302; TloKA, Griechische Christen, 112-124; OsBorn, Clement, 19-24; HäGG, Henny Fiskå, Clement of Alexandria and the Beginnings of Christian Apophaticism, (Oxford Early Christian Studies), Oxford, Bergen 2006, 55-60; KöNIG, Clemens, 75-88 und 184-197; ITTER, Andrew C., Esoteric Teaching in the Stromateis of Clement of Alexandria, (Supplements to Vigiliae Christianae 97), Leiden, Boston 2009, 7-15; HeINE, Origen, 48-51 und 54-56.

19 BARDY, origines; DERS, l'histoire. Einen guten Überblick über die Literatur bieten z.B. NEYMEYR, Lehrer, 42-45; Scholten, Katechetenschule, 17 mit Anm. 3; van Den Hoek, School, 59-60, Anm. 1. 20 Vgl. z.B. schon Munck, Johannes, Untersuchungen über Clemens von Alexandria, (Forschungen zur Kirchen- und Geistesgeschichte 2), Stuttgart 1933, 173-175, 185 und 227-228. Zum Einfluss G. Bardys siehe NEYmeYr, Lehrer, 44, der im ausdrücklichen Anschluss meint „daß sich die Vorstellung einer institutionalisierten ,alexandrinischen Katechetenschule‘ als ein Konstrukt des Eusebius zu erkennen gibt.“ Zusammengefasst werden die wichtigsten Argumente gegen die Annahme einer gemeindlichen ,Schule“ bei NeymeYr, Lehrer, 42-45; van den BRoEK, School, 199-202; vgl. auch HeINE, Origen, 48-51 und 57-60.

21 Zur Distanz zwischen Clemens und der christlichen Gemeinde vgl. die Darstellung dieser von ihm aber abgelehnten Position bei Neymeyr, Lehrer, 86-87. Repräsentative Beispiele sind Munck, Clemens, 173-175 und 185; sowie HoRNSCHUH, Leben, 199, Anm. 74: „An der verfassten Kirche, ihren Ämtern und Gottesdiensten, lebte Klemens im Grunde vorbei.“; außerdem CAMPENHAUSEN, Griechi- 
chen Gemeinde angenähert. ${ }^{22}$ In unterschiedlicher Akzentuierung lässt man ihn wieder in großer Nähe zur alexandrinischen Gemeinde lehren. ${ }^{23}$ Selbst der Gedanke eines der Gemeinde verbundenen Schulwesens findet seit den wichtigen Studien von A. van den Hoek wieder Vertreter. ${ }^{24}$ A. Le Boulluec formuliert pointiert: „Seine Rolle als Lehrer übte er nicht in einer privaten, unabhängigen Schule aus, da sich diese nicht von der institutionellen Kirche trennen lässt." ${ }^{25}$ Insgesamt ist das Bild, das A. van den Hoek entwirft, von beeindruckender Schlüssigkeit und sie dürfte weitgehend im Recht sein. ${ }^{26}$ Nach A. van den Hoek haben beispielsweise auch A. Le Boulluec, D. Wyrwa, H. Hägg und H. König ${ }^{27}$ das Bild des Clemens als eines von Seiten der Gemeinde anerkannten Lehrers innerhalb eines gewissen institutionell-kirchlichen Rahmens weiter bekräftigt.

Ob man nun in Clemens einen der alexandrinischen Gemeinde nur nahestehenden Lehrer sieht oder ob man ihn sogar innerhalb des institutionellen Rahmens dieser Gemeinde lehren lässt, für die vorliegende Fragestellung ist als positiver Ertrag festzuhalten: Es kann als plausibel angenommen werden, dass die Haltung des Clemens zur ,Soldatenfrage“ sich innerhalb des in der alexandrinischen Christengemeinde

sche Kirchenväter, 33 und 42: „Klemens [ist] unter allen Kirchenvätern ohne Zweifel der ,unkirchlichste`, d.h. der organisierten Kirche gegenüber gleichgültigste gewesen [...]“; CHADwick, Kirche, $110-111$.

22 Vgl. z.B. MeEs, Christengemeinde; Neymeyr, Lehrer, 86-95; van DEN Hoek, How Alexandrian; Scholten, Katechetenschule, 35; van DEN Broek, School; van den HoEK, School; Le Boulluec, Schule, hier v.a. 583-586; OsBoRn, Clement, 19-24; JAKAB, Ecclesia alexandrina, 131-133; TLoKA, Griechische Christen, 114; WYRWA, Lernen, 291-301; KöNIG, Clemens, 75- 88 und 184-197.

23 Vgl. exemplarisch NeymeYr, Lehrer, 95: „Clemens [...] übte seine Lehrtätigkeit in lebendigem Kontakt mit der christlichen Gemeinde aus. Er unterrichtete nicht im Rahmen einer privaten Schule, doch bleibt offen, in welchem konkreten Verhältnis er zur christlichen Gemeinde stand [...].“ Ähnlich auch van DEN BRoek, School, 200 -202; TlokA, Griechische Christen, 114; Scholten, Katechetenschule, 35. Zur Kritik an C. Scholten vgl. aber FüRST, Alfons, Von Origenes und Hieronymus zu Augustinus - Studien zur antiken Theologiegeschichte, (Arbeiten zur Kirchengeschichte 115), Berlin, Boston 2011, 73.

24 VAN DEN HoEK, How Alexandrian, zusammenfassend z. B. 108; DIES., School., zusammenfassend z.B. $85-86$.

25 LE Boulluec, Schule, 584.

26 Vgl. aus einer anderen Richtung kommend auch noch einmal ScHoLten, Katechetenschule, 35, zur Möglichkeit einer kirchlichen Beauftragung des Clemens. Sein Gedankengang ist auch im Rahmen der Thesen von A. van den Hoek noch immer richtig. Allerdings erscheint es z. B. trotz vAN DEN HoEK, School, 77-79; und LE Boulluec, Schule, 585-586, weiterhin unwahrscheinlich, dass Clemens das Amt eines Presbyters bereits in Alexandria ausgeübt hat. Hier ist auch z. B. WYRWA, Lernen, 298, sehr kritisch und stellt das zu Recht in Frage. Vgl. auch die Diskussion bei JAKAB, Ecclesia alexandrina, 125, sieht eine Leserschaft, die sehr uneinheitlich ist und sowohl aus dem Christentum nahestehenden Heiden wie auch aus dem „l'esprit grecs“ etwas zu sehr zugetane Christen besteht.

27 Le Boulluec, Schule, 579-586; Wyrwa, Lernen, 296 -301; vgl. z. B. ebd., 298; außerdem Wyrwa, Dietmar, Das alexandrinische Christentum: Überblick. In: Riedeweg/Horn/Wyrwa (Hrsg.), Philosophie der Kaiserzeit, 924-927, hier 925; HäGG, Clement, 57-59; KöNIG, Clemens, 151, 157-159 und 184-189 mit Anm. 166 und Anm. 175. 
Vertretbaren befunden, wenn nicht sogar deren Standpunkt entsprochen haben dürfte. ${ }^{28}$

\subsubsection{Werk}

Die Hauptwerke des Clemens, die auch das hier behandelte Quellenmaterial liefern, sind der Protrepticus, der Paedagogus und die Stromata. ${ }^{29}$ Sie sollen im Folgenden bereits vor der Interpretation einführend betrachtet werden, da es sich aufgrund des Charakters der Belege empfiehlt, die einzelnen Texte nach ihrem inhaltlichen Gewicht für die vorliegende Fragestellung anzuordnen, nicht nach ihrer Zugehörigkeit zu den jeweiligen Schriften.

\section{Protrepticus}

Beim etwa um das Jahr 195 n. Chr. zu datierenden Protrepticus ${ }^{30}$ - O. Stählin übersetzt „Mahnrede an die Heiden“31 - handelt es sich um eine protreptische, das heißt werbende Schrift. Sie gehört in rhetorischer Hinsicht zum genus deliberativum, der beratenden Beredsamkeit. ${ }^{32}$ Dieses genus der Rede kam vor allem im politischen Bereich

28 Bei der Frage, ob die Lehrtätigkeit des Clemens v.a. eine ,wissenschaftliche‘ Betätigung als „Hochschullehrer‘ war (vgl. ScHoLten, Katechetenschule, 35-37; (vorsichtiger) MARKSCHIES, Lehrer, 117-118; FÜRST, Origenes, 63-65) oder ob er in seiner Schule in Anlehnung an paed. 1,3,3 eine sehr breite Lehrtätigkeit entfaltet hat (vgl. MEEs, Christengemeinde, 119-120; NEYMEYR, Lehrer, 50 - 96, v. a. 87 und 95; VAN DEN HoEk, School, 67-79, v. a. 71; Le Boulluec, Schule, 580 - 581 und 584; WyRWA, Lernen, 287-291 und 297-298; KöNIG, Clemens, 75-88, 89-105 und 155-159), sollte der Annahme einer weitgefächerten Lehrtätigkeit der Vorzug gegeben werden.

$29 \mathrm{Zu}$ weiteren Werken des Clemens vgl. u.a. Des Clemens von Alexandreia Mahnrede an die Heiden, Der Erzieher Buch I, aus dem Griech. übers. von Otto StÄHLIN, (BKV 2. Reihe, Bd. 7), München 19, 20 - 41; HARNACK, Geschichte, 3-23; MÉHAT, s.v. Clemens (TRE), 103; NEYMEYR, Lehrer, 81-84; WYRWA, s.v. Clemens (LACL), 152-153; Osborn, Clement, 5; Feulner, Clemens, 34-38; Wyrwa, Clemens, 933-934.

30 Als Textgrundlage dient die Ausgabe von O. Stählin (Clemens Alexandrinus, Protrepticus und Paedagogus, hrsg. und übers. von Otto StÄHLIN, (GCS 55 [ursprüngl. Bd. 12]), 3., durchges. Aufl. v. Ursula TREU, Berlin 1972). Außerdem wurde auch Clementis Alexandrini Protrepticus, ed. Miroslav Marcovich, (Supplements to Vigiliae Christianae 34), Leiden 1995, herangezogen. Zum Protrepticus vgl. Altaner/Stuiber, Patrologie (1978), 192-193; MÉHAt, s.v. Clemens (TRE), 102; Neymeyr, Lehrer, 50 - 54; WyrWA, s.v. Clemens (LACL), 152; Feulner, Clemens, 29-30; KöNIG, Clemens, 89 - 99; WyrWA, Clemens, 929. Zur Datierung vgl. Feulner, Clemens, 29; HeInE, Ronald E., The Alexandrians. In: Young, Frances M. (Hrsg.), The Cambridge History of Early Christian Literature, Cambridge 2004, 117-130, hier 118; anders Wyrwa, Clemens, 929, u.U. vor 189 v. Chr.

31 StÄhlin, Prot. u. Paed. (BKV), hier v. a. 21-22.

32 Zum genus deliberativum siehe Aristot. rhet. 1,3-8; Cic. inv. 2,157-176; part. 24,83-27,97; de orat. 2,334-340; Quint. inst. 3,4,15; und v.a. 7,1-28; vgl. MARTIN, Rhetorik, 167-176; FuHRMANn, Rhetorik, $79-81$. 
zum Zuge. Es zielte darauf, den Hörern zu einer bestimmten Handlung, einem Verhalten oder Vorgehen ab- oder zuzuraten. ${ }^{33}$

Die Mehrheit der Forschung nimmt an, dass der Protrepticus an Heiden gerichtet ist und diese zur Abwendung von ihrem alten Glauben und zur Hinwendung zum Christentum auffordert. ${ }^{34}$

Dagegen hat H. König gewichtige Gründe angeführt, in den Adressaten Menschen zu sehen, die nicht mehr Heiden im eigentlichen Sinn sind, sondern der christlichen Gemeinde bereits nahestehen. Sie hätten schon eine Anfangsunterweisung erhalten ${ }^{35}$, aber den Schritt zur Anmeldung zur Taufe noch nicht vollzogen und scheuten sich wegen der ablehnenden Reaktion der Umwelt davor. ${ }^{36}$ Diese Gruppe will Clemens davon überzeugen, die Eintragung in die Listen ${ }^{37}$ der Taufbewerber zu wagen. Soweit dürfte H. König Recht gegenüber der bisherigen Forschung zu geben sein. Ihr entgegen $^{38}$ sollte allerdings festgehalten werden, dass Clemens seine Adressaten noch nicht als Christen begreift und sie auch nicht als solche anspricht. ${ }^{39}$ Sie stehen vielmehr am Rand der Gemeinde, gehören aber noch nicht - auch nicht in der Weise der Kate-

33 Siehe z.B. Aristot. rhet. 1,3.

34 Vgl. StÄHLIn, Prot. u. Paed. (BKV), hier v. a. 21; KnaUber, Adolf, Ein frühchristliches Handbuch katechumenaler Glaubensinitiation - Der Paidagogos des Clemens von Alexandrien. In: MThZ 23, (1972), 311-334, hier 316, 319 und 334; MEEs, Christengemeinde, 122; MÉHAT, s.v. Clemens (TRE), 102; Neymeyr, Lehrer, 50-54; CAMPENHAuSEn, Griechische Kirchenväter, 34-35; WyrwA, s.v. Clemens (LACL), 152; Le Boulluec, Schule, 580 - 581; FeulnER, Clemens, 29; pointiert zuletzt OsBorn, Clement, 5 und v. a. 14: ,a handbook for Christians as missionaries, taking the gospel to those who do not believe“; WYRWA, Clemens, 929. JAKAB, Ecclesia alexandrina, 131-133.

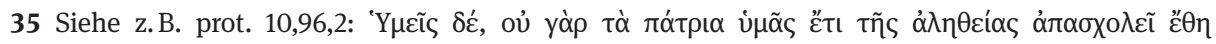

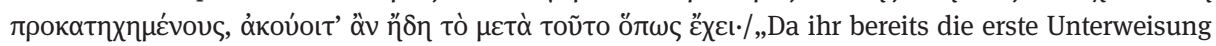
erhalten habt und euch das väterliche Herkommen nicht mehr von der Wahrheit abhält, so könnt ihr bereits hören, wie sich die darauffolgende Lehre verhält." (ÜS: O. Stählin). Auf diesen Text verweist KöNIG, Clemens, 30, Anm. 25, und bespricht ihn ebd., 96-97. Anders NEYMeYr, Lehrer, 51: Der Protrepticus selbst sei diese erste Unterweisung und sollte (ebd., 53) „Heiden für den katechetischen christlichen Unterricht [werben] und vorbereite[n].“

36 KöNIG, Clemens, 30, Anm. 25, und 93-99. Ihr wichtigster Beleg ist prot. 10,96,2.4.

37 Siehe die mit einer „Einschreibeterminologie“ (KöNIG, Clemens, 98) verbundenen bildlichen Aufforderungen in prot. 9,82,5 und 10,108,4.

38 Vgl. z. B. KöNIG, Clemens, 161: „[...] dass diese Schrift hauptsächlich an Christen gerichtet war, die die innere Bekehrung bereits in ersten Schritten vollzogen hatten [...] und die nun vor dem Schritt in die Verbindlichkeit [...] standen.“ Das klingt im Sinne der Alten Kirche eher nach den Katechumenen als nach denen, die den Schritt zur Taufanmeldung noch vor sich her schoben. Vgl. z. B. KRETSCHMAR, s.v. Katechumenat/Katechumenen, 1-2 (unter Verweis auf Tert. paen. 6,15.17); siehe außerdem WyrWA, Lernen, 278-279. H. König ist sich allerdings bewusst, dass es letztlich um das Problem der Definition des Begriffs ,Christ‘ im Sinne der Alten Kirche geht, vgl. ebd., 30, Anm. 25: „Christen im Vollsinn, d.h. Getaufte, sind die Hörer des Protrepticus nicht, aber sie sind es in einem weiteren Sinne [...].“

39 Vgl. nur die dringlichen Mahnungen zur Umkehr und Taufe in 10,93-96, beides eng verbunden mit der Verheißung der Gnade und der Androhung des Gerichts (10,95,1), zwischen denen sich die Adressaten entscheiden sollen. Siehe auch prot. 10,108,3-4; 12,123,2; paed. 1,1,3-4, wo der 入óyos

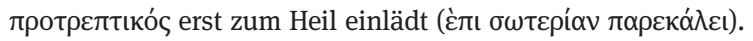


chumenen $^{40}$ - zu ihr. Daher sollte auch nicht davon gesprochen werden, dass sich der Protrepticus an ,Christen“ richtet. Hier hat U. Neymeyr Recht, wenn er im Protrepticus „ein Dokument dieser präkatechumenalen Unterweisung“ sieht, die „ihren Platz vor dem katechetischen Unterricht [hat], der auf den Empfang der Taufe vorbereitet“..41 Nur sieht die Zielgruppe als Heiden im Vollsinn in zu großer Distanz zur Gemeinde.

Für den Zweck dieser Untersuchung ist eine endgültige Entscheidung dieser Frage allerdings nicht nötig. Es genügt festzuhalten, dass der Protrepticus einen für die verbindliche Hinwendung zum Glauben werbenden Charakter hat. Damit ist er ähnlich dem Apologeticum Tertullians - auf eine gewisse Außenwirkung bedacht. Es ist dieser Gesichtspunkt, den es bei der Interpretation unbedingt zu berücksichtigen gilt.

Ebenso von hohem Gewicht für die Interpretation ist die rhetorische Gliederung des Protrepticus. Diese ist sehr klar nachvollziehbar ${ }^{42}: 1$.) eine einleitende narratio $(1,1-10)$ 2.) die probatio $(2,11-10,110)$, unterteilt in a) eine refutatio $(2,11-5,66=$ wovon wird abgeraten) und b) eine confirmatio $(6,67-10,110=$ wozu wird hingeraten) 3.) die peroratio (11,111-12,123), die noch einmal dringlich aufruft, sich dem christlichen Glauben (verbindlich) zuzuwenden.

\section{Paedagogus}

Der Paedagogus ${ }^{43}$, der in die Zeit um 197-200 n.Chr. anzusetzen ist, schließt zeitlich wie thematisch - gemäß dem Programm, das Clemens in paed. 1,1,1-3 entfaltet unmittelbar an den Protrepticus an. Seine Zielsetzung ist, Katechumenen, also Taufbewerber, die bereits in einer engen Anbindung an die christliche Gemeinde leben und sich auf Taufe und Vollmitgliedschaft vorbereiten, in einer dem christlichen Glauben angemessenen Lebensweise zu unterrichten. ${ }^{44}$ Dabei ist der Paedagogus

$40 \mathrm{Zu}$ den altkirchlichen Stufen des Christwerdens vgl. KRETSCHMAR, s.v. Katechumenat/Katechumenen I (TRE); YARnold, s.v. Taufe III (TRE), v.a. 676-677 (zu Clemens); PASQUATo, s.v. Katechese (RAC), v. a. 432-434 (zu Clemens); außerdem Ferguson, Catechesis; und besonders Ferguson, Baptism, v. a. 201-443 (2. und 3. Jhd. n. Chr.) und 309-321 (zu Clemens). Ob Katechese bei Clemens schon terminus technicus für die Taufvorbereitung ist, ist umstritten. Angenommen wird das bei YARNOLD, s.v. Taufe III (TRE), 676 und 679; PASQUATO, s.v. Katechese (RAC), 433; außerdem VAN DEN HoEK, School, 67-71; WyrWA, Lernen, 297-298; NEYMEYR, Lehrer, 52. Eher skeptisch sind KretschmaR, s.v. Katechumenat/Katechumenen I (TRE), 2; Ferguson, Baptism, 315-316; außerdem Scholten, Katechetenschule, 30 -31; KöNIG, Clemens, 40, Anm. 49.

41 Neymeyr, Lehrer, 52-53.

42 Vgl. Rankin, From Clement, 126; im Detail leicht abweichend davon KöNIG, Clemens, 92-93.

43 Der hier verwendete Text ist StÄHLin/Treu, Prot. und Paed. entnommen. Es wurde auch Clementis Alexandrini Paedagogus, ed. Miroslav Marcovich, (Supplements to Vigiliae Christianae 61), Leiden 2002, herangezogen. Zum Paedagogus vgl. Knauber, Handbuch; Altaner/STuiber, Patrologie (1978), 192-193; MÉHAT, s.v. Clemens (TRE), 102; WyrwA, s.v. Clemens (LACL), 152; Feulner, Clemens, 30 - 31; KöNIG, Clemens, 99-105; WyrwA, Clemens, 929 - 930. Zur Datierung vgl. FeUlner, Clemens, 30; HeINE, Alexandrians, 118.

44 Vgl. Knauber, Handbuch, 317; Le Boulluec, Schule, 581; OsBorn, Clement, 14. 
wohl nicht allein für die Katechumenen direkt verfasst worden, sondern wird durchaus auch als „Handbuch“45 konzipiert gewesen sein, das den Katecheten Hilfestellung für ihren Taufunterricht bieten sollte. ${ }^{46}$

Im Mittelpunkt steht dabei nicht eine dogmatisch-inhaltliche, sondern vielmehr eine ganz praktische, alltägliche Situationen ${ }^{47}$ erörternde Unterweisung in Fragen der Lebensgestaltung. Es handelt sich um eine Art ,Knigge' für Taufbewerber und neugetaufte Christen im Alexandria des späten zweiten und frühen dritten Jahrhunderts. Durch diese ethische Belehrung sollen die neuen Christen auf die dann folgende Unterweisung in der eigentlichen Glaubenslehre vorbereitet werden. ${ }^{48}$ Clemens bietet ihnen „eine ethische Ermahnung, das Richtige nicht dem Falschen und das Wichtige nicht dem Unwichtigen zu opfern. “49

Dabei sind die Adressaten schon allein von den behandelten Themen her eindeutig unter den Wohlhabenden und Gebildeten der alexandrinischen Gemeinde zu suchen..$^{50}$ Es dürfte sich also vorwiegend um einen bestimmten, kleineren Teil dieser Gemeinde handeln, den Clemens hier anspricht. Damit ist dieses Werk auch ein wichtiger Beleg, dass das Christentum bereits in den höheren Schichten der alexandrinischen Gesellschaft Eingang gefunden hatte.

Festzuhalten für die Interpretation ist, dass die Schrift - ähnlich Tertullians De idoloatria und De corona - eindeutig in die Gemeinde hinein gerichtet ist, wenn auch primär für den wohlhabenderen Teil, und dass christliche Lebensführung vermittelt werden soll.

Auch hier ist die Gliederung für die Interpretation von Bedeutung und zugleich sehr geradlinig. Mit D. Rankin ist zu gliedern ${ }^{51}$ : narratio $(1,1)$, confirmatio $(1,2-7)$, re-

45 KnAUber, Handbuch, hier v. a. 333. Ihm folgen u. a. NeYmeYr, Lehrer, 57; van Den Hoek, School, 67; LE Boulluec, Schule, 581; KöNIG, Clemens, 103; WyrWA, Lernen, 298 mit Anm. 138.

46 Vgl. z. B. die für diese beiden Gesichtspunkte bahnbrechende Studie von KnAUBER, Katechetenschule, hier v.a. 316-322; außerdem NEYMEYR, Lehrer, 54-58; vAN DEN HoEK, School, 66-67; LE Boulluec, Schule, 581; KöNIG, Clemens, 102-103. Zu Katechumenat und Taufe siehe die S. 396, Anm. 40 genannte Literatur.

47 Es gibt kaum einen Lebensbereich, den er nicht in „lockerer, unpedantischer Weise“ (CAMPENHAUSEN, Griechische Kirchenväter, 35; vgl. auch MüHLENKAMP, Heiden, 151) behandelt. Es geht um Tischmanieren, den Umgang mit Alkohol, die Gestaltung des Ehelebens, Fußbekleidung, das Verhalten in Bädern, Sport etc.

48 So erklärt Clemens selbst den Sinn des Paedagogus in strom. 6,1,3. Vgl. dazu KNAUBER, Handbuch, 317. Diese mehr ethische als dogmatische Ausrichtung der präbaptismalen Unterweisung entspricht im Wesentlichen den Gegebenheiten der Zeit. Vgl. dazu z. B. KNAUBER, Handbuch, 323-326; KRETSCHMAR, s.v. Katechumenat/Katechumenen I (TRE), 2-3; vAN DEN HoEK, School, 70 - 71; Ferguson, Catechesis, 229, 236, 265.

49 Feulner, Clemens, 30.

50 Vgl. WyrWA, s.v. Clemens (LACL), 152; LE BoullueC, Schule, 589 - 590; JAKAB, Ecclesia alexandrina, 123-126; MüHLENKAMP, Heiden, 148-152; WyrWA, Clemens, 930. So auch OsBoRn, Clement, 22, zum Protrepticus.

51 Rankin, From Clement, 126; vgl. zur Gliederung außerdem KöNIG, Clemens, 100. 
futatio (1,8), confirmatio (1,9-2,12 [sic! 2,11; AG] $\left.{ }^{52}\right)$, refutatio (2,13 [sic! 2,12; AG]), confirmationes und refutationes (3,1-11), confirmatio und peroratio $(3,12)$. Inhaltlich legt Clemens im ersten Buch methodische sowie thematische Grundlagen und erläutert die Heilspädagogik des guten Erziehers, des göttlichen Logos (= Christus) ${ }^{53}$. Im zweiten und dritten Buch gibt Clemens thematisch geordnet Ratschläge für das Leben im Alltag „und stellt dar, wie eine christliche Lebenshaltung die konkreten Lebensvollzüge prägen soll. “54 Am Ende steht eine Doxologie, ein langes Gebet zum Logos. ${ }^{55}$

\section{Stromata}

Die Stromata ${ }^{56}$ sind das am schwierigsten einzuordnende Werk des Clemens. U. Neymeyr hat dazu sehr treffend festgehalten:

„[Es] muss aber der Versuch des Clemens, in den Strom. ,verborgen zu sprechen, verhüllte Aussagen zu machen und schweigend zu verdeutlichen ‘ [strom. 1,15,1, AG], angesichts der vielfältigen Ergebnisse der modernen Forschung auch heute noch als gelungen bezeichnet werden. ${ }^{\text {"57 }}$

Von Interesse für die hier behandelte Thematik sind vor allem die Fragen nach Zielsetzung und Adressaten der Schrift, die eng mit derjenigen nach dem Verhältnis der

52 Für die Unterteilung des zweiten Buches in 13 Kapitel könnte er RoBERTs, Alexander; DonaLDSon, James; Coxe, Cleveland (Hrsg.), The Ante-Nicene Fathers: Translations of the Writings of the Fathers Down to A.D. 325, Bd. 2: Tatian, Theophilus of Antioch, Athenagoras of Athens, Clement of Alexandria, Grand Rapids 2001 [reprint 1886], folgen. Diese Übersetzung weist diese Gliederung wegen einer Zweiteilung von Kapitel 10 auf. Es könnte sich aber auch um ein Versehen handeln. In der bei ihm angegebenen (ebd., 147) Ausgabe Clément d'Alexandrie, Le pédagogue, Bd. 2, par Claude MonDÉSERT; Henri-Irénée MARROU, (Sources chrétiennes 108), Paris 1965, findet sich diese Untergliederung ebenso wenig, wie bei StÄhlin/Treu, Prot. und Paed. oder Marcovich, Paedagogus.

$53 \mathrm{Zu}$ Christus als dem göttlichen Logos und seiner Rolle als göttlicher Pädagoge innerhalb der Heilspädagogik Gottes vgl.VöLKeR, Walther, Der wahre Gnostiker nach Clemens Alexandrinus, (TU 57), Berlin 1952, 98-109; MÉHAT, s.v. Clemens (TRE), 106-107; FeulneR, Clemens, 167-174; KöNIG, Clemens, 310 -317; Kovacs, Judith L., Divine Pedagogy and the Gnostic Teacher according to Clement of Alexandria. In: JECS 9 (2001), 3-25; HeInE, Origen, 57-58; WYRWA, Clemens, 950.

54 KöNIG, Clemens, 100.

55 Paed. 3,10,101.

56 Als Textgrundlage wurde Clemens Alexandrinus, Stromata Buch I-VI, griech./dt., hrsg. und übers. von Otto STÄHLIN, (GCS 52 [ursprüngl. Bd. 15]), neu hrsg. von Ludwig FRÜCHTEL, 4. Aufl. mit Nachträgen von Ursula Treu, Berlin 1985; und Clemens Alexandrinus, Stromata Buch VII und VIII, Excerpta ex Theodoto. Eclogae propheticae, Quis dives salvetur, Fragmente, hrsg. und übers. von Otto STÄHLIN, (GCS 17), 2. Aufl. neu hrsg. von Ludwig FRÜCHTEL, Berlin 1970, herangezogen. Zu den Stromata vgl. Altaner/Stuiber, Patrologie (1978), 193-194; MÉHat, s.v. Clemens (TRE), 102; WyrWA, s.v. Clemens (LACL), 152-153; Le Boulluec, Schule, 581-583; Osborn, Clement, 5-18; Feulner, Clemens, 31-33; KöNIG, Clemens, 105-131; Wyrwa, Clemens, 931-933. Buch 1-5 der Stromata sind wohl noch in Alexandria abgefasst worden, Buch 6 und 7 dagegen nach seiner Abreise; vgl. FeULNER, Clemens, 33; HEINE, Alexandrians, 118.

57 NeymeYr, Lehrer, 59. 
drei Hauptschriften untereinander zusammenhängt. Diese Fragen sollen hier nur in aller Kürze skizziert werden.

Der Zusammenhang der Stromata mit den beiden anderen Hauptwerken wird in der Forschung seit langem lebhaft diskutiert. ${ }^{58}$ Entscheidend ist hier zunächst die Stelle paed. 1,1,1,1-3,3, in der Clemens die einzelnen Stufen der göttlichen Unterweisung erläutert:

„1 [1] [...] so hat das ermahnende Wort die Gesinnungen des Menschen als sein Arbeitsfeld zugeteilt erhalten, als ein Führer zur Gottesfurcht [...]. [2] Die Leitung aller Handlungen aber hat das beratende [...] Wort. Es ist aber dies alles nur ein und dasselbe Wort [...].

2 [1] Freilich hat das gleiche Wort auch die Aufgabe zu lehren, aber nicht jetzt; denn das belehrende Wort hat die Aufgabe, bei der Behandlung der Glaubenssätze zu erklären und zu offenbaren; der Erzieher dagegen, der auf das Handeln gerichtet ist, trieb zuerst zur Bildung eines sittlichen Charakters an [...].

3 [3] Da er aber bestrebt ist, uns in heilsamem, stufenweisem Fortschreiten zur Vollkommenheit zu führen, verwendet der in jeder Hinsicht liebreiche Logos die vortreffliche und für eine wirksame Ausbildung zweckmäßige Erziehungsweise, indem er zuerst ermahnt, dann erzieht und zuletzt lehrt.,",

Das göttliche Wort lehrt die Menschen nach Clemens auf dreifache Weise, durch Ermahnung/Ermutigung, Erziehung/Beratung sowie durch Unterweisung/Lehre. ${ }^{60}$ In diesen Stufen erkennt man seit langem auch den literarischen Plan des Clemens, eine Trilogie abzufassen, in der er jeder Erziehungsstufe ein Werk zuordnet. Der Protrepticus stellt die ermahnende Stufe dar, der Paedagogus die erziehende Stufe und, nach traditioneller Auffassung ${ }^{61}$, die Stromata die unterweisende Stufe. Damit würden sich

58 Eine ausführliche Darstellung der Forschungsdiskussion bis in die 80er Jahre hinein bietet Feulner, Clemens, 38-47; vgl. außerdem OsBorn, Clement, 5-15; und ITtER, Esoteric Teaching, 15-32, die auch neuere Literatur berücksichtigen.

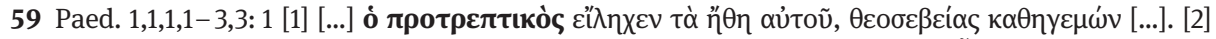

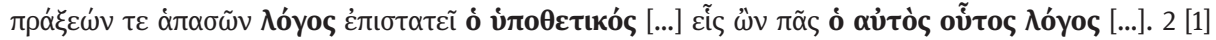

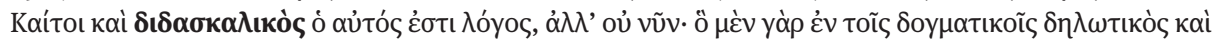

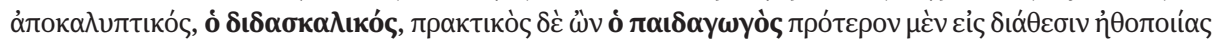

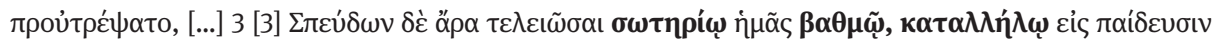

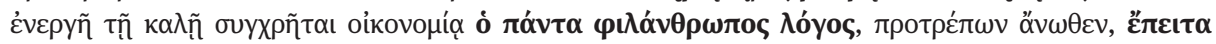

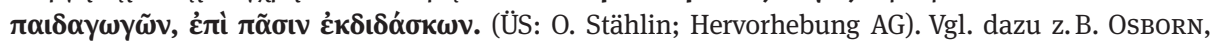
Clement, 5 und 14-15.

60 Kovacs, Pedagogy, 7-24, zeigt, wie der Logos und der ideale Gnostiker in ihrer Pädagogik 1.) sich den Fähigkeiten ihrer Schüler anpassen, 2.) um die Notwendigkeit einer abgestuften Unterweisung wissen, 3.) auf eine ganzheitliche (= intellektuelle, moralische, spirituelle) Formung der Person zielen, und 4.) die Notwendigkeit kennen, bestimmte Inhalte zu verhüllen, um Schüler nicht auf einer zu frühen Stufe mit ihnen zu konfrontieren. Diese Pädagogik der Anpassung an das „Vermögen“ der Adressaten entspricht dem Wirken des Logos „als Erzieher und Lehrer der Menschheit“ (WYRwA, Clemens, 950).

61 Vgl. Feulner, Clemens, 38 mit Anm. 210 (Literatur); OsBorn, Clement, 5. 
die Stromata an getaufte Christen richten, mit dem Ziel, sie tiefer in den Glaubenslehren zu unterrichten. ${ }^{62}$

Seit dem Ende des 19. Jahrhunderts ist diese traditionelle Sicht durch die Kritik E. de Fayes ${ }^{63}$ zunehmend hinterfragt und durch eine Vielzahl von Hypothesen ${ }^{64}$ ersetzt worden. In den letzten Jahren wurde dann wieder deutlicher erkannt, dass Clemens in den Stromata auf jeden Fall eine Form didaskalischer Unterweisung bietet, wenn auch nicht in der erwarteten geradlinig-systematischen Weise. Ob die Stromata nun allerdings der Didaskalos sind oder nur ein Didaskalos, ist dabei weiterhin strittig. ${ }^{65}$

Wie auch immer man sich in dieser Frage entscheidet, aufgrund der Identifikation der Stromata als zumindest einer Form der didaskalischen Unterweisung ist anzunehmen, dass der primäre Adressatenkreis unter getauften Christen zu suchen ist. Unter diesen sind es vor allem solche, die schon mündlich von ihm unterrichtet worden sind und denen die Stromata helfen sollen, sich die Inhalte zu vergegenwärtigen und sie weiter zu durchdenken. ${ }^{66}$ Diese Christen will Clemens auf dem Weg hin zum wahren Gnostiker, und das heißt auch zum Lehrer und Seelenführer ${ }^{67}$, weiterhin begleiten.

Allerdings scheint Clemens auch noch mit einem weiteren Leserkreis zu rechnen und seine Schrift auch mit Blick auf diesen hin zu gestalten. ${ }^{68}$ Es handelt sich dabei um Leser, die seine mündlich vorgetragene Lehre nicht gehört haben, die vielleicht noch nicht einmal Christen sind. ${ }^{69}$ Mit dem Ziel zu vermeiden, dass diese seine Unterweisung missverstehen oder gar missbrauchen, hat er sich dieser verhüllenden Form bedient. ${ }^{70}$ Um aber diese Leser ebenfalls auf ihrem Weg zur (christlichen) Erkenntnis zu unterstützen, durchziehen die Stromata auch protreptische und pädagogische Züge, durch welche die christliche Wahrheit für uneingeweihte Leser in

62 Vgl. die treffende Beschreibung bei NEYMEYR, Lehrer, 59: „In seiner lehrenden, didaskalischen Funktion vermittelt der Logos also dogmatisch-theologische Inhalte, während er sich in seiner erziehenden pädagogischen Funktion mit praktisch-moralischen Fragen beschäftigt. [...] Die Adressaten der

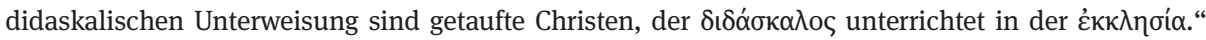
63 Siehe dazu Feulner, Clemens, 39-41; Wyrwa, Clemens, 931.

64 Siehe die S. 399, Anm. 58 genannten Forschungsüberblicke, v. a. FEULnER, Clemens, 41- 47.

65 Deutlich in die erste Richtung neigen LE Boulluec, Schule, 581-583; OsBoRn, Clement, 6-7 und 14. Die zweite Position nehmen beispielsweise NEYMEYR, Lehrer, 58-63; und KöNIG, Clemens, 125-126 und 128-130 ein. WYRWA, Clemens, 931, neigt ebenfalls in erstere Richtung, meint aber, es „bleiben Fragen offen“.

66 Einen guten Überblick über die Bedeutung der platonischen Reflexion zum Wert und Unwert schriftlicher Unterweisung und mündlichen Lehre für das Denken des Clemens vgl. LE Boulluec, Schule, 581-582; sowie OsBorn, Clement, 12-14 und 16-17.

67 Vgl. NeymeYR, Lehrer, 73-79. Zum ,Wahren Gnostiker‘ als einem vollendeten Lehrer vgl. KovACS, Pedagogy.

68 Vgl. KöNIG, Clemens, 122-131; Kovacs, Pedagogy, 23-24.

69 Siehe z. B. strom. 1,1,6,3 und 1,1,14,4.

70 Siehe z. B. strom. 1,1,15,1 (unmittelbar auf 1,1,14,4 folgend). Vgl. NEYMEYR, Lehrer, 79; LE BouLLUEC, Schule, 582; KöNIG, Clemens, 117-119 und 129-131. Das Thema „use of concealment“ in der Pädagogik des Clemens behandelt eingehender Kovacs, Pedagogy, 17-24. 
angemessener Weise vermittelt wird. ${ }^{71}$ Durch seinen teilweise verhüllenden und vielschichtigen Stil kann er sein Werk dieser vielfältigen Leserschaft anpassen und ihnen allen auf ihrer Suche nach Erkenntnis dienen. Der christlichen Leserschaft, der die didaskalischen Züge gelten, steht in dem vielfach nur Angedeuteten und Verborgenen der Weg zur vertieften Erkenntnis des Glaubens offen. Diesen Weg können sie mit dem Wissen um die bereits mündlich erhaltene Unterweisung des Clemens und im existentiellen Nachvollzug des Gelehrten ${ }^{72}$ gehen.

$\mathrm{Zu}$ den Stromata gilt es festzuhalten, dass sie auf jeden Fall zu einem gewichtigen Teil der Unterweisung von Christen dienen, wenn auch nicht ausschließlich. Diese Christen sollen zur reifen Glaubenserkenntnis geführt werden. Damit setzen die Stromata die ersten beiden Schriften des Clemens voraus und führen sie weiter. Sie sind also als ein Werk christlicher Glaubenslehre im weitesten Sinn zu lesen, das neben anderen Themen auch eine Unterweisung in Fragen christlicher Ethik bietet. Damit sind die dort angesprochenen Problemstellungen, beispielsweise $\mathrm{zu}$ Krieg und Gewaltanwendung, für die Erarbeitung der ,christlichen' Position des Clemens von großer Bedeutung. Gleichzeitig stellt allerdings die verhüllende Form der Stromata die Interpretation der konkreten Texte vor nicht geringe Herausforderungen.

\subsection{Textinterpretation}

\subsubsection{Die Haupttexte}

Bei diesen Haupttexten handelt es sich um prot. 10,100,4, paed. 2,11,117,2 und paed. 3,12,91,2, wobei die beiden zuletzt genannten Stellen mit Blick auf ihre Bedeutung für die hier diskutierte Fragestellung in umgekehrter Reihenfolge besprochen werden. Diesen drei Texten aus dem Protrepticus und dem Paedagogus ist gemeinsam, dass das Thema Soldatendienst in der einen oder anderen Weise direkt angesprochen und in zwei Fällen unter einer ethisch relevanten Fragestellung behandelt wird.

Ein Text, der in der Forschung seit A. Bigelmair und A. von Harnack gelegentlich ebenfalls angeführt wird ${ }^{73}$, nämlich paed. 2,12,121, $5^{74}$ soll hier nicht weiter untersucht

71 Vgl. KöNIG, Clemens, 128-131 mit Anm. 300. Bereits ebd.118, schreibt sie sehr treffend: „Er rechnet keineswegs nur mit frommen und ernsthaften Lesern, sondern auch mit unerfahrenen, mit lässigen, mit solchen, denen nichts heilig ist; [...] und vor allem natürlich mit denen, die sich um Erkenntnis bemühen [...]. Sie alle sollen aus seinem Werk Nutzen ziehen können auf die ihnen je eigene Weise: Allen will er alles werden, ,um alle zu gewinnen', wie er Paulus zitierend sagt [strom. 1,15,5; AG]. "Siehe auch Kovacs, Pedagogy, 21-24; OsBoRN, Clement, 24: „Today, his enigmatic Stromateis are seen as an invitation rather than an exclusion.“ Dagegen meint LE Boulluec, Schule, 582, dass die verhüllende Form gewählt wurde, weil sie „die Uneingeweihten fernhält“.

72 Vgl. OsBorn, Clement, 10 - 11; WYRWA, Lernen, 297.

73 Bigelmair, Beteiligung, 181; HARnACK, Militia Christi, 58, Anm. 1; CAdoux, Christian Attitude, 232; ScHöpF, Tötungsrecht, 221. 
werden, da er - gegen die genannten Autoren - nichts zum Thema beiträgt. ${ }^{75}$ Im Zusammenhang geht es um das Tragen von Schmuck, das Clemens kritisiert. Die Erwähnung der Soldaten geschieht hier in derartig beiläufiger Weise und ist für das eigentliche Argument so nebensächlich, dass sich aus diesem Text nichts zur Haltung des Clemens zur Soldatenfrage herauslesen lässt. Auch für die Lebenswelt des Clemens, mit Blick auf die Frage nach der Kenntnis christlicher Soldaten erlaubt dieser Text keine Schlussfolgerungen. Es handelt sich lediglich um eine wahrscheinlich durch das angeführte Dichterzitat aus der Ilias ${ }^{76}$ angeregte Illustration, die vielleicht Rückschlüsse auf die Belesenheit des Clemens und seines Publikums zulässt, nicht aber für die vorliegende Problemstellung.

\subsubsection{Prot. $10,100,4$}

\section{Text}

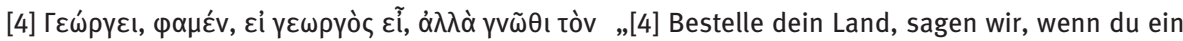

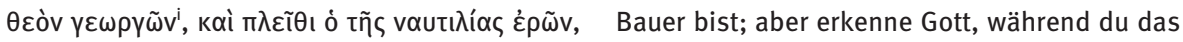

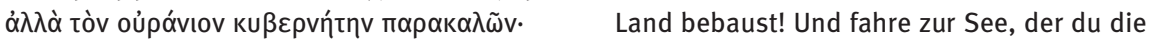

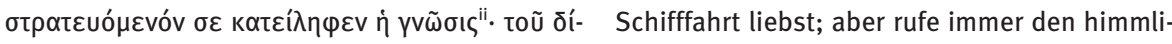

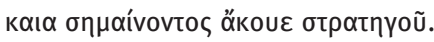
schen Steuermann an! Als Soldaten hat dich die Erkenntnis vorgefunden; höre auf den Feldherrn, der gerechte Signale geben lässt!“

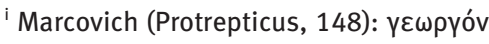
(ÜS: AG nach O. Stählin)

\footnotetext{
ii Marcovich (ebd.): 〈тoũ $\theta \varepsilon$ oũ〉
}

\section{Kontext}

Dieser Text ist Teil der confirmatio ${ }^{77}$ des Protrepticus, er gehört folglich zur positiven Darlegung dessen, wofür Clemens wirbt, zur positiven Darlegung des Christentums also, zu dem die Adressaten sich (verbindlich) hinwenden sollen. Dieser Sachverhalt ist in mehrfacher Hinsicht sehr bedeutsam. Zum einen handelt es sich hier um eine den christlichen Glauben nach außen beziehungsweise zu den Rändern der Gemeinde hin werbend darstellende Schrift. Es geht im Protrepticus, zumal in der confirmatio um

74 ,Jetzt wollen aber auch die Soldaten mit Gold geschmückt sein, da sie nicht einmal jenes Dichterwort gelesen haben: ,Er, der mit goldenem Schmuck in den Kampf zog gleichwie ein Mädchen tö-

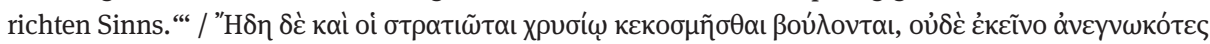

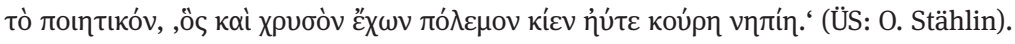

75 So mit Recht SIDER, Killing, 182. Vergleichbares gilt für die von HELGELAND, Christians (ANRW), 745, als Beispiel für die Sorge um militärische Effektivität angeführte Stelle strom. 2,18,83,3-4.

76 Il. 2,872-873.

77 Zur confirmatio im Rahmen der antiken Rhetorik siehe v. a. Cic. inv. 1,34-77; die positive Beweisführung behandelt außerdem ausführlich Quint. inst. 5,1-12; vgl. MARTIN, Rhetorik, 95ff. Cicero schreibt (inv. 1,34): confirmatio est, per quam argumentando nostrae causae fidem et auctoritatem et firmamentum adiungit oratio. / „Die Bekräftigung ist es, mit deren Hilfe die Rede durch Beweisführung unserer Sache Glaubwürdigkeit, Gewicht und Stütze verleiht.“ (ÜS: Th. Nüßlein). 
eine positive Außendarstellung. Bis zu einem gewissen Grad ist also ein Vergleich mit dem Apologeticum Tertullians statthaft. In letzterem hatte er ja den Soldatendienst von Christen sehr positiv dargestellt, ehe er sich dann in den innergemeindlichen Schriften mehr oder weniger scharf in eine kritische Auseinandersetzung damit begeben hat. Es wird interessant sein, zu beobachten, wie sich das Verhältnis von (zumindest teilweise) nach außen gerichteten Schriften einerseits und in die Gemeinde hinein gerichteten Schriften andererseits bei Clemens hinsichtlich der Soldatenfrage darstellen wird. Zum anderen knüpft Clemens hier sehr eng an einen Gedanken des Apostels Paulus aus seinem ersten Brief an die christliche Gemeinde in Korinth ${ }^{78}$ an, was für die Interpretation von entscheidender Bedeutung sein wird.

Zum engeren literarischen Kontext: Clemens hat in prot. 10,93-96 nachdrücklich zu Umkehr und Taufe aufgerufen. Daraufhin hat er erneut die alten Götter und das ihnen zugewandte Leben dem Spott preisgegeben ${ }^{79}$ und stellt dann die entscheidende Frage: „Wie nun mag man fragen, kann ich in den Himmel hinaufkommen?" ${ }^{\text {"80 }}$. Darauf antwortet er in prot. 10,100,1-101,3 und erläutert, wie eine Hinwendung zu Christus, der selbst der Weg ist ${ }^{81}$, und gleichbedeutend damit, wie die Erkenntnis Gottes auszusehen hat.

In diesem Zusammenhang steht dann der hier untersuchte Absatz. Es handelt sich also um einen zutiefst positiven Text, ohne abwehrende oder gar polemische Funktion. Vielmehr soll dem Nichtchristen beziehungsweise dem am Rand der Gemeinde verharrenden Interessierten eine Anweisung zur Konversion gegeben werden, exemplarisch vorgeführt an den drei im Text genannten, sehr konkreten Beispielen, dem Bauern, dem Seemann und dem Soldaten.

\section{Interpretation}

Damit jetzt zur eigentlichen Interpretation: Zuerst gilt es festzuhalten, dass Clemens hier den Soldaten in eine Reihe mit - im christlichen Verständnis - ehrenwerten Berufen stellt. ${ }^{82}$ Das allein ist bereits ein wichtiger Punkt, will man verstehen, wie Clemens den Soldatenberuf beurteilt. Man frage sich nur, ob Clemens hätte schreiben können: ,Wenn du Gladiator oder Prostituierte bist, wenn dich die Erkenntnis Gottes erreicht, bleibe bei deinem Beruf, ehre dabei nur Gott, den großen Gladiatorentrainer oder Bordellbesitzer.' Undenkbar! Daraus folgt, dass der Beruf des Soldaten für Clemens zumindest grundsätzlich ein ehrenwerter Beruf sein muss, den man auch nach

78 1. Kor 7,20; siehe dazu die folgenden Ausführungen.

79 Prot. 10,97-99.

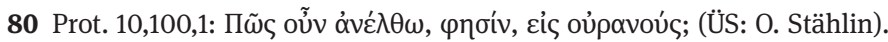

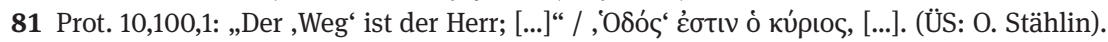

82 So schon ScHöPF, Tötungsrecht, 221. Zu den ,ehrenwerten` Berufen vgl. GRANT, Christen als Bürger, 78-110, hier v. a. 97-101; FiENSY, Living. 
der Konversion als Christ weiterhin ausüben darf; es ist zunächst ein Beruf, wie alle anderen auch. ${ }^{83}$

Der entscheidende Punkt dieses Textes, mit den Worten des Paulus gesprochen, an den sich Clemens hier anlehnt ${ }^{84}$, ist nämlich: „Jeder bleibe in der Berufung, in der er berufen wurde. “85 Es gilt, in seinem alten (ehrenwerten) Beruf oder Stand weiterzuleben, aber jetzt mit einer klaren Neuausrichtung des Lebens, auch des Lebens in diesem Beruf, auf Gott hin. ${ }^{86}$ Darauf weisen jeweils die Mahnungen am Ende eines jeden Satzes hin. Bemerkenswert daran ist außerdem, darauf hat bereits J. Moffat hingewiesen, dass Clemens sich nicht einmal genötigt fühlt, seine Haltung zu begründen, denn „he was stating the normal Christian principle.“87

83 Vgl. HaRnaCK, Militia Christi, 58; Moffat, War, 664; HaRnaCK, Mission und Ausbreitung (1924), 581; SCHÖPF, Tötungsrecht, 220 - 221; KLEIN, Tertullian, 107; HELGELAND, Christians (ANRW), 744 - 745; SCHÄFKE, Widerstand (ANRW), 543; JAKAB, Ecclesia alexandrina, 125-126, sieht in diesem Text einen Beleg für den unrevolutionären Charakter der Lehre des Clemens; BREnNECKE, An fidelis (2007), 200; HUNTER, Research, 90, völlig zu Recht: „explizit approval“. Zu Unrecht allerdings meint er, es sei der einzige Text ist, indem sich Clemens positiv zur Möglichkeit christlichen Heeresdienstes äußert. Bereits BIGELMAIR, Beteiligung, 181, stellte unter Berufung v. a. auf die drei hier untersuchten Haupttexte fest, dass Clemens „einer exclusiven Stellung gegen den Kriegsdienst überhaupt völlig fern[steht.]“ CADoux, Christian Attitude, 232, kommt dem nahe, erklärt aber, dass Clemens nicht mit dem Problem von Christentum und Krieg konfrontiert war, hier also gegen seine eigentliche pazifistische Einstellung (zu Unrecht) den Soldatenberuf zu erlauben scheint. Zur Frage, ob Clemens das Problem der Gewaltanwendung und den Beruf des Soldaten unverbunden nebeneinander stehen lässt, siehe unten S. $250 \mathrm{f}$. SwIFT, War (ANRW), 852, meint dagegen nur, „he comes very close to endorsing the military career in the Protrepticus 10,4.“; vgl. auch Swift, Views, 284. Das dürfte deutlich zu vorsichtig formuliert sein.

Andererseits verneint R. Bainton (BAInTon, Early Church, 199-200 [= Kirche und Krieg, 199-200]; BAINTON, Attitudes, 80), dass Clemens im Soldatenberuf einen normalen Beruf erblickt. Er räumt zwar ein, dass Clemens dem Christen den Verbleib im Heer gestatte, meint aber, dass die Einschränkung des zweiten Satzteils nur Polizeiaufgaben zuließe. Ähnlich KARPP, Stellung, 506, der in Anm. 40, auch auf R. Bainton verweist: Clemens „rechtfertigt das Verbleiben im Kriegerstand“, und zwar gemäß der Logik des Paulus, „,aber er rückt den Kriegsdienst unter das Friedensgebot, das [nach prot. 11,116] dem Christen gilt“. Leider erklärt er nicht, wie man sich das praktisch vorzustellen hat. Der Verweis auf R. Bainton könnte darauf hindeuten, dass er an eine Beschränkung auf Polizeiaufgaben denkt. Vergleichbar ist die Problematik bei Campenhausen, Kriegsdienst, 257.

Ganz anders dagegen HoRnus, Politische Entscheidung, 122-123 mit Anm. 20 und 21: Er ist der Ansicht, „daß dieser Text auf keinen Fall als Zustimmung zum Militärdienst gedeutet werden kann und daß er ohne Zweifel vielmehr als Aufforderung zu verstehen ist, die Armee zu verlassen." Es gehe darum, „,von der Unterwerfung angesichts eines menschlichen Anführers überzugehen zu der Unterordnung gegenüber dem einzig wahren Anführer, nämlich Gott selbst“. Leider erklärt er nicht, wie dazu einerseits die Parallele Konstruktion der drei Satzglieder und andererseits die unmissverständliche Bezugnahme auf das Pauluswort aus 1. Kor 7,20 passen sollen.

84 Vgl. Harnack, Militia Christi, 58; Moffat, War, 664; CAmpenhausen, Kriegsdienst, 257; Karpp, Stellung, 506; RIESNER, Militia Christi, 54.

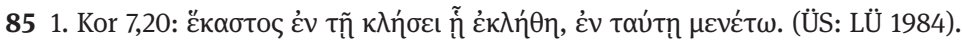

86 Treffend formuliert Helgeland, Christians (ANRW), 745: „Whatever the occupation a man undertakes is not important, but in it he must find himself in relation to God; the military profession did not disturb the Christian's relationship to God, as Clement saw it.“ Ähnlich schon Moffat, War, 664. 87 Moffat, War, 664. Man sollte evtl. einschränkend hinzufügen das galt zumindest in Alexandria. 
Interessant ist die Frage, wer mit dem „Feldherrn, der gerechte Signale geben lässt“"88 gemeint ist. In der Forschung wurden hier bisweilen zwei unterschiedliche Antworten gegeben. Zum einen kann es sich um den irdischen Befehlshaber handeln. ${ }^{89}$ Dann würde Clemens hier eine Einschränkung hinsichtlich der Gehorsamspflicht geben. Als Christ darf man nur dem Feldherrn folgen, der gerechte Befehle gibt, aber, so müsste man dann wohl ergänzen, nicht dem, der Unrecht befiehlt. ${ }^{90} \mathrm{Im}$ Hinblick darauf, dass sich im Werk des Clemens an anderer Stelle möglicherweise auch erste Ansätze zu einer ,Lehre vom gerechten Krieg‘ finden ${ }^{91}$, wäre das eine Option, mit der grundsätzlich zu rechnen ist. Mit Blick auf den unmittelbaren Kontext empfiehlt es sich aber, der zweiten Interpretation den Vorzug zu geben, die auch in der heutigen Forschung mehrheitlich vertreten wird. Bei dem Feldherrn handelt es sich um niemanden anderen als Gott selbst. ${ }^{92}$ Darauf weist die Tatsache hin, dass bei den ersten beiden Beispielen jeweils auf Gott direkt Bezug genommen wird, er wird vom Bauern beim Pflügen erkannt, er ist der „himmlische Steuermann“933, den der Seemann anzurufen hat. Sollte M. Marcovich mit seiner Konjektur Recht haben und der

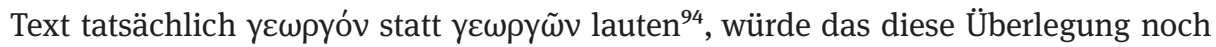
verstärken, würde dann doch Gott selbst Bauer sein beziehungsweise sollte er als Bauer erkannt werden, die Parallele wäre also noch deutlicher. Da diese Konjektur aber auf der parallelen Struktur des Abschnitts beruht, besteht hier die Gefahr des

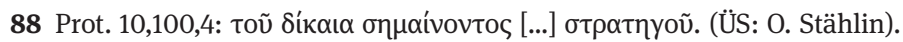

89 Combes, Gustave, La doctrine politique de saint Augustin, Paris 1927, 261; EpPSTEIN, John, The Catholic Tradition of the Law of Nations, komm. Neuaufl., Clark 2008, 40 (= EPPSTEIN, John, The Catholic Tradition of the Law of Nations, Washington DC 1935, 40). Die Angabe zu G. Combes erfolgt nach Bainton, Early Church, 199 (= Kirche und Krieg, 199); und Bainton, Attitudes, 80. Den Arbeiten von R. Bainton, ist auch der Hinweis auf J. Eppstein - in der Auflage von 1935 - entnommen. Für diese Untersuchung wurde die Neuauflage von 2008 herangezogen. Außerdem könnte BIGELMAIR, Beteiligung, 181, in dieser Weise zu verstehen sein, auch wenn das aufgrund seines paraphrasierenden Stils nicht ganz sicher zu entscheiden ist.

90 Eine Parallele dazu findet sich evtl. in strom. 7,7,42,7, wo vom Gehorsam gegen die Vorgesetzten

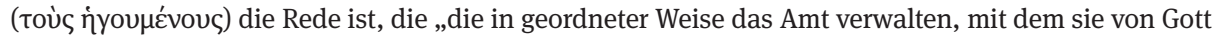

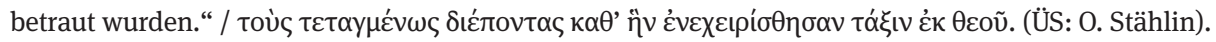
Der dahinterstehende Gedanke scheint zu sein, dass man solchen Amtsträgern oder allgemein solchen Vorgesetzten, die ihr Amt in rechtswidriger Weise verwalten, nicht gehorchen muss. Vgl. ScHöPF, Tötungsrecht, 189, der als Parallele noch auf strom. 1,24,159,5 hinweist; RIESNER, Militia Christi, 56. Mit äußerster Vehemenz widerspricht HoRnus, Politische Entscheidung, 122, Anm. 20, dieser Interpretation von prot. 10,100,4.

91 Siehe unten, S. $238 \mathrm{ff}$.

92 Vgl. Bainton, Early Church, 199-200 (= Kirche und Krieg, 199-200); KLEIN, Tertullian, 107; ScHöPF, Tötungsrecht, 221, erwägt das zumindest und sieht dadurch, falls es zutrifft, „die Möglichkeit ,christlicher Soldaten’ noch stärker zum Ausdruck [kommen]“. Nach CAMPEnHAUSEN, Kriegsdienst, 257, ist der Feldherr Christus. Nicht zu erschließen ist das Verständnis von Cadoux, Christian Attitude, 232; KaRPP, Stellung, 506; Helgeland, Christians (ANRW), 744-745; SwIFT, War (ANRW), 852; RIESNER, Militia Christi, 54; SwIFT, Views, 284.

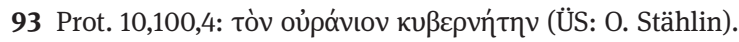

94 Marcovich, Protrepticus, 148. 
Zirkelschlusses und es soll daher die Partizipialform als Lesart für die Interpretation beibehalten werden. Aber auch so ist die Parallelität der drei Sätze eng genug, um gut begründet anzunehmen, dass Clemens mit Blick auf den betreffenden Feldherren Gott meint. Erhärtet wird diese Überlegung, wenn man bedenkt, dass er in paed. 1,8,65,3 den Logos, also Christus, als einen „gewaltige[n] Heerführer“95 bezeichnet. Der Ge-

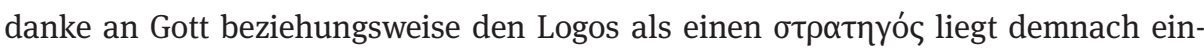
deutig im Horizont des Clemens und kann darum auch hier ohne Bedenken angenommen werden.

\section{Fazit}

Als Fazit lässt sich festhalten: Wird ein Soldat Christ, kann er nach Clemens selbstverständlich in seinem Beruf verbleiben, hat sich aber wie jeder andere berufstätige Christ auch bei der Ausübung dieses Berufs auf Gott hin auszurichten. ${ }^{96}$ Implizit ist dann auch darin eine nicht näher bestimmte Grenze der Gehorsamspflicht enthalten, die nämlich dann greift, wenn Befehle dieser Ausrichtung des Lebens auf Gott hin widersprechen. Wie das aber auszusehen hätte, thematisiert Clemens an dieser Stelle nicht näher, da es für seine rhetorische Zielsetzung auch nicht von Bedeutung ist. Bemerkenswert ist, wie unbefangen er dem bekehrten Soldaten das Verbleiben in seiner Profession gestattet, vor allem wenn man bedenkt, wie schwer sich Tertullian damit getan hat ${ }^{97}$, der sogar in coron. 11, wo er das Verbleiben im Heer zumindest unter bestimmten Umständen gestattet, doch ein sofortiges Ausscheiden aus dem Militärdienst - falls möglich - dringlich nahelegt. ${ }^{98}$

\subsubsection{Paed. 3,12,91,1-3}

\section{Text}

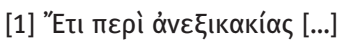

„[1] Ferner über das Ertragen von Unbill [...].

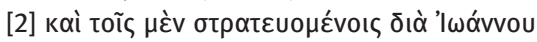
[2] Und den Soldaten befiehlt er durch Johannes,

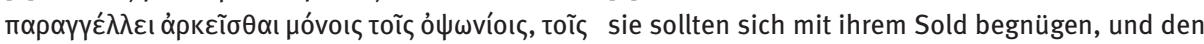

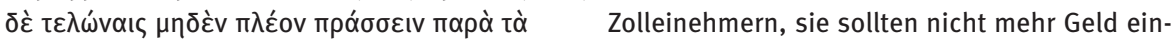
ठı treiben, als ihnen vorgeschrieben ist. Dem Richter

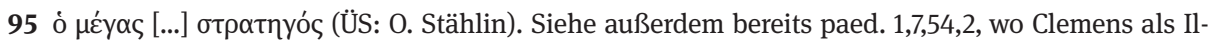
lustration für den göttlichen Erzieher, der seine Kinder fürsorglich zu einer heilsamen Lebensweise

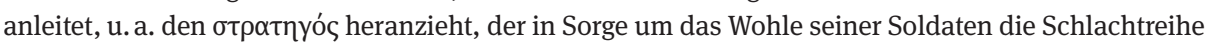
(i் $\varphi \alpha \dot{\lambda} \alpha y \xi)$ ordnet.

96 Siehe oben, S. 210, Anm. 83 für die Positionen der Forschung. Mit Wyrwa, Clemens, 940, kann man festhalten, dass sich für Clemens „das ethische Handeln [...] zugleich als Gehorsam gegenüber dem Willen Gottes [...] erweist“.

97 Vgl. idol. 19 und coron. 11, hier v. a. 11,4.

98 Vgl. SwIFT, War (ANRW), 852, der meint, Clemens sei hier ,at odds with Tertullian“. RIESNER, Militia Christi, 59, hält fest, man könnte fast meinen, hinter den Gegnern Tertullians in idol. 19 Clemens zu hören. 


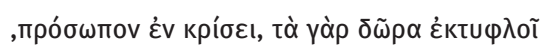

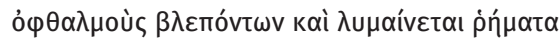

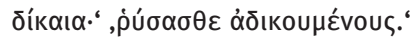

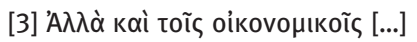

aber sagt er: ,Du sollst beim Gericht nicht die Person ansehen; denn Geschenke blenden die Augen der Sehenden und verderben gerechte (Richter-)Sprüche.' ,Rettet die, denen Unrecht geschieht.'

[3] Aber auch den Hausverwaltern sagt er [...].“ (ÜS: AG nach O. Stählin)

\section{Kontext}

Bei den Texten aus dem Paedagogus sollen die beiden Textstellen in umgekehrter Reihenfolge behandelt werden, da die zweite Stelle inhaltlich eindeutig die gewichtigere ist. Der Text paed. 3,12,91,1-4 ist ein Teil der peroratio ${ }^{99}$, in der Clemens den Regeln der Rhetorik folgend noch einmal zentrale Punkte der vorhergehenden Erörterungen zusammenfasst. Er legt seinen Hörern und Lesern gebündelt sowohl methodische Überlegungen als auch wichtige praktische Lebensregeln vor.

Im unmittelbaren Kontext ${ }^{100}$ erläutert Clemens unter Aufnahme eines Gedankens aus dem 1. Petrusbrief ${ }^{101}$, wie wichtig es ist, sich von dem alten, heidnischen Lebenswandel abzuwenden und das Kreuz zu nehmen ${ }^{102}$, und fährt dann fort:

„Die beste Lebensführung aber ist ein wohlgeordneter Wandel, der in vollkommener Wohlanständigkeit besteht und in einer bestimmten, sicheren Kraft, die die der Reihe nach aufeinander folgenden Pflichten in rühmlicher Weise durch die Tat erfüllt und an sittlicher Haltung nicht zu übertreffen ist. “103

Um seine Hörer zu diesem „wohlgeordneten Lebenswandel“ hinzuführen, ermahnt der Erzieher (Christus) diese, da er deren Rettung wünscht ${ }^{104}$, und er bietet ihnen noch einmal „die Hauptlehren des Heils“105, die seine eigene Denkweise enthüllen und die den Weg zum Heil weisen ${ }^{106}$. Diese Hauptlehren bestehen, wie A. Knauber festhält,

\footnotetext{
99 Zur Funktion der peroratio siehe Aristot. rhet. 3,19; Cic. inv. 1,97-109; part. 15,52-17,60; Quint. inst. 6,1; vgl. MARTIn, Rhetorik, 147-166; FuHRmann, Rhetorik, 94-96: „der Schluss soll das Gesagte zusammenfassen [...]; er soll außerdem mit Hilfe der Amplifikation, der Steigerung, Affekte mobilisieren [...].“ (Ebd., 95).

100 Vgl. dazu auch KNAUBER, Handbuch, 330 - 332.

101 Vgl. 1. Petr 1,17-19 und 4,3.

102 Paed. 3,12,85,2-3.

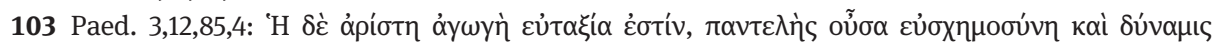

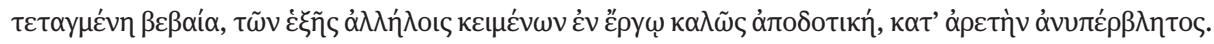
(ÜS: O. Stählin).

104 Paed. 3,12,86,1-2.

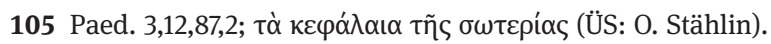

106 Paed. 3,12,87,2.
} 
„in einer knappen, sehr geschickt ausgewählten Sammlung von Merksätzen aus der Heiligen Schrift ausgesprochen moralisch-aszetischen Inhalts. [...] Clemens selbst nennt diese biblischen

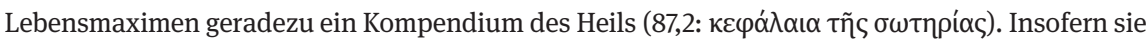
für alle gelten und das Böse sozusagen an der Wurzel anpacken, will er sie als Beispielsammlung hierher setzen.“"107

Diese so treffende Charakterisierung des Abschnitts als Sammlung von Lebensmaximen und allgemeingültigen Regeln ist für das richtige Verständnis der zu behandelnden Textstelle von größter Wichtigkeit.

In diesem Rahmen nennt Clemens dann die goldene Regel ${ }^{108}$ und das Doppelgebot der Liebe ${ }^{109}$ als die äußerste Zusammenfassung dieser Hauptlehren, um daraufhin „die liebevolle Lehre des Erziehers durch die mannigfachen und heilsamen Gebote vor Augen [zu] führen“"110. Dieses Vorhaben führt er in zwei größeren Abschnitten aus: Zuerst, indem er die Gebote des Mose und der Propheten, also des Alten Testaments, vor Augen führt, freilich mit neutestamentlichen Einsprengseln. ${ }^{111}$ In einem zweiten Schritt bietet er dann die Gemeindeermahnung der Apostel in Form einer Sammlung neutestamentlicher Mahnungen und Anweisungen dar. ${ }^{112}$ Damit greift er wieder auf, was er schon in Buch 1 angeführt hatte, nämlich dass der Logos, also Christus, „,in alter Zeit“113 durch Mose und die Propheten Gottes Volk erzogen hatte und das Gesetz, mit Paulus gesprochen, als „Erzieher auf Christus“114 gegeben worden war. ${ }^{115}$ Mit dem Kommen Christi, des Erziehers schlechthin, hat dieser dann selbst die erzieherische Aufgabe übernommen ${ }^{116}$ und spricht durch die Apostel.

Bei der Entfaltung der alttestamentlichen Gebote spricht Clemens daraufhin zahlreiche konkrete Einzelfälle an und bietet Antworten vor allem aus dem Gesetz des Mose und aus den Propheten sowie teilweise aus dem Neuen Testament. Hier nennt er zum Beispiel das Fasten, die Opfer, das Ertragen von Unrecht, das Verhältnis zum Staat, den Eid, das Verhalten Sklaven gegenüber und vieles mehr, was im alltäglichen

107 KnaUber, Handbuch, 331-332. Er bezieht diese Charakterisierung auf den Abschnitt paed. 3,12,87-96 und spricht auch (ebd., 331) von einer „Art ,Christenspiegel““. Vgl. ebenfalls MüHLENKAMP, Heiden, 166.

108 Lk 6,31; Mt 7,12. Clemens bietet die Fassung des Lukas.

109 Mt 22,37.39; Mk 12,30-31; Lk 10,27. Clemens verwendet die Fassung des Matthäusevangeliums.

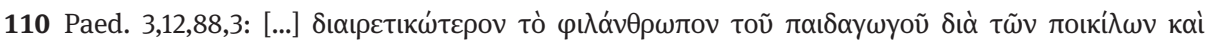

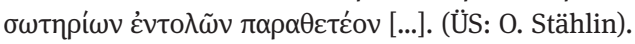

111 Paed. 3,12,89-93.

112 Paed. 3,12,94-96. Hier zeigt sich, dass für Clemens das Alte und das Neue Testament eine Einheit bilden. Wie FeulNER, Clemens, 199 festhält: „Aus beiden Testamenten spricht derselbe Logos-Paidagogos, wenngleich in unterschiedlicher Weise.“

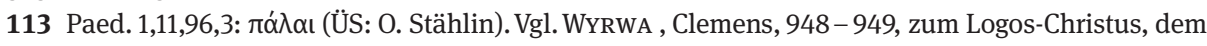
ewigen Sohn Gottes, als dem Offenbarungsmittler des unerkennbaren Gottes der Schöpfung gegenüber.

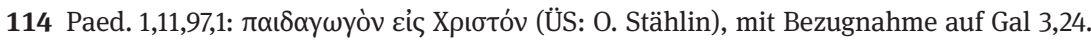

115 Paed. 1,11,96,1-97,3.

116 Paed. 1,11,97,2-3. 
Leben seiner Adressaten eine Rolle gespielt haben dürfte. Gegen Ende beschließt er seine Darstellung, indem er noch einmal auf den hohen Wert der aus der Heiligen Schrift ${ }^{117}$ entnommenen Beispiele für die ethische Unterweisung durch den Erzieher hinweist ${ }^{118}$ :

„Diese wenigen Lehren von vielen entnimmt der Erzieher des Beispiels halber aus den heiligen Schriften selbst und legt sie seinen Kindern vor; durch sie wird das Böse sozusagen mit der Wurzel ausgerissen und das Unrecht beseitigt. “119

Im Zusammenhang dieser , liebevollen` Erziehung zu einem wohlgeordneten, christlichen Lebenswandel, wie sie sich in diesem „Christenspiegel“120 ausdrückt, findet sich dann der hier zu behandelnde Text über die Standespredigt Johannes des Täufers als eines der vielen von Clemens angeführten biblischen Beispiele.

\section{Interpretation}

Der von Clemens zitierte Text stammt aus dem Lukasevangelium, es handelt sich dabei um die sogenannte Standespredigt Johannes des Täufers. ${ }^{121}$ Dieser Text spielte in der innerkirchlichen Diskussion um den Beruf des Soldaten in dieser Zeit allem Anschein nach eine wichtige Rolle, wie aus den zwei Bezugnahmen bei Tertullian ${ }^{122}$ deutlich wird. Darin ermahnte Johannes eine nicht weiter bestimmte Volksmenge, Steuereinnehmer und Soldaten, die $\mathrm{zu}$ ihm gekommen waren, um sich taufen $\mathrm{zu}$ lassen, einen ehrlichen, dem kommenden Reich Gottes entsprechenden Lebensstil zu führen. Er forderte diese Soldaten aber nicht auf, ihren Beruf aufzugeben, er dürfte also ihre Tätigkeit nicht in grundsätzlichem Konflikt mit einer entsprechenden Ethik gesehen haben. Darauf schienen sich die innergemeindlichen Gegner Tertullians berufen zu haben, weswegen dieser in De idololatria versuchte, diesen Text heilsgeschichtlich zu entkräften und seine Gültigkeit post Christum zu bestreiten. ${ }^{123}$ Ganz

117 Vgl. Feulner, Clemens, 199-200: „Die Heilige Schrift ist für Clemens das große Erziehungs- und Lehrbuch des Christentums und besitzt höchste Autorität. Es ist das Erziehungswerk, in dem die Menschen die göttliche Paidagogia nachlesen und meditieren können [...]. [...] Die Heilige Schrift ist für Clemens das sichere und handgreifliche Beweismittel der göttlichen Erziehung. Sie verkündet allen den Logos-Paidagogos und vermittelt den Zöglingen Zugang zu ihrem Erzieher.“ Siehe außerdem MÉHAT, s.v. Clemens (TRE), 105-106; OSBoRN, Clement, 56-80 und hier v.a. 68-75.

118 Vgl. van DEN HoEK, School, 65.

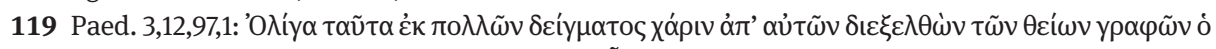

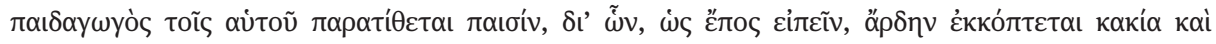

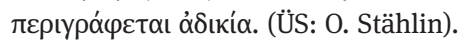

120 KnaUber, Handbuch, 331.

121 Zum Text s. oben S. 131, Anm. 480.

122 Idol. 19,3; coron. 11,4.

123 Siehe oben S. $90 \mathrm{ff}$. In De corona, unter veränderten argumentativen Bedingungen, nutzte er diesen Text dann allerdings auch, um die eventuelle Erlaubtheit des Verbleibens im Heer für bekehrte Soldaten einzuräumen (s. oben S. 131). 
anders dagegen Clemens, der dieses Wort des Johannes nicht nur als eine aktuell gültige ethische Weisung zitiert, sondern es sogar noch als ein Herrenwort, ein Wort des Logos Christus anführt, gesprochen durch Johannes, und ihm damit höchste Autorität und Aktualität zuweist. ${ }^{124}$

Dieser Sachverhalt muss kurz erklärt werden: Clemens ist in Übereinstimmung mit den Zeugnissen des Neuen Testaments ${ }^{125}$ und auch der frühen Kirche ${ }^{126}$ der Überzeugung, dass Christus als der ewige, göttliche Logos präexistent gewesen sei. ${ }^{127}$ Wie R. Feulner festhält, ist dieser Logos für Clemens „der große Mittler zwischen Gott und Welt und Gott und Mensch. [...] Er ist das allmächtige Wort Gottes, das dieser vor aller Zeit ausgesprochen hat und das er den Menschen unaufhörlich zuspricht. “128 Als präexistenter Logos hat er durch die Propheten des Alten Testaments gesprochen wie auch später durch die Apostel des Neuen Testaments. ${ }^{129}$ Johannes der Täufer galt dem Clemens dabei, ebenfalls in Übereinstimmung mit dem Neuen Testament ${ }^{130}$, in heilsgeschichtlicher Hinsicht als der letzte und größte der Propheten des alten Bundes und als direkter Vorläufer und Wegbereiter Christi. So schreibt er in prot. 1,9,1-2:

124 Zum Gewicht dieser Zuschreibung vgl. HARnAck, Militia Christi, 58, wo er schreibt, Clemens habe dem Ausspruch des Täufers „den Wert eines Herrenwortes beigelegt“ und daraus folgerichtig die Konsequenz zieht, „es darf also christliche Soldaten geben, wenn sie sich vor Raub und Erpressung hüten und auf die Stimme des himmlischen Heerführers hören.“; vgl. außerdem MofFAT, War, 665; ScHöpF, Tötungsrecht, 221; HoRnus, Politische Entscheidung, 123; KLEIN, Tertullian, 107; RIESNER, Militia Christi, 54. Einige Autoren wie z.B. BIgelmaIR, Beteiligung, 181; BAINTON, Early Church (= Kirche und Krieg); Bainton, Attitudes, 66-84; Helgeland, Christians (ANRW), 744-746; Shean, Soldiering, 100 -101; SIDER, Killing, 182, übersehen die Bedeutung dessen, dass Clemens das Johanneswort hier als Herrenwort anführt, völlig. Unklar ist, welches Gewicht CADoux, Christian Attitude, 232, und SwIFT, War (ANRW), 852, diesem Sachverhalt geben. Ein vergleichbares Gewicht als Rede des Heiligen Geistes durch Johannes erhält das Wort des Johannes aus Lk 3 auch bei Origenes (hom. in Lc. 23,5), der allerdings die Antwort an die Soldaten übergeht (s. unten S. $319 \mathrm{ff}$.$) .$

125 Vgl. z. B. Joh 1,1-18; 1. Kor 8,6; Phil 2,6-11; Kol 1,15-20.

126 Vgl. z. B. Ign. Magn. 6; Pol. 3; Justin Mart. Dial. 87.

127 Vgl. Feulner, Clemens, 118-120 und 167-169; Vgl. Wyrwa, Clemens, 949-950.

128 FEUlner, Clemens, 168; vgl. Vgl. WyrWA , Clemens, 948-949.

129 Programmatisch: paed.1,11,96-97; strom. 7,16,95,3.Vgl. die folgende, unvollständige (!) Auflistung aus dem Protrepticus und dem ersten Buch des Paedagogus: Der Logos spricht durch Johannes $d$. T. (prot. 1,9,2; 8,79,3; paed. 1,9,80,1); sowie durch Mose (prot. 8,79,1; paed. 1,2,5,1; 1,5,14,3; 1,7,56,1; 1,7,58,1; 1,7,60,1; 1,9,81,2; 1,10,91,4), David (paed. 1,7,61,2; 1,9,80,2; 1,9,86,1.2; 1,9,87,3; 1,10,90,1; 1,10,92,1), Salomo (paed. 1,9,78,4; 1,9,82,1; 1,10,90,1; 1,10,91,3; 1,10,94,3), Psalmisten (paed. 1,7,61,3; 1,8,73,1), Jesaja (prot. 8,78,2; 8,79,3; paed. 1,5,15,3; 1,5,24,1-2; 1,8,73,1; 1,9,76,4; 1,9,77,3; 1,9,78,1.2; 1,9,80,1; 1,9,81,2; 1,10,91,4), Jeremia (prot. 8,78,1; paed. 1,9,77,1.4; 1,9,78,2.3; 1,9,79,1; 1,9,80,2.3; 1,9,81,1; 1,10,91,3; 1,10,92,3; 1,10,93,1), Hesekiel (paed. 1,9,76,2; 1,9,84,2; 1,10,91,2; 1,10,95,1), Hosea (prot. 8,79,2; paed. 1,7,53,3; 1,9,77,2), Amos (paed. 1,8,69,3), den Apostel Paulus (paed. 1,6,49,2).

130 Mt 11,7-15; Lk 7,24-28. 
„Wer ist also Johannes? Um es kurz zu fassen, wollen wir sagen: ,Die mahnende Stimme des Logos, die in der Wüste ruft.' [...] Ein Vorläufer ist Johannes und seine Stimme eine Vorläuferin des Logos, eine einladende Stimme, vorbereitend zum Heil [...].“"131

Und in paed. 1,5,24,4 heißt es von Johannes: „[...] auch Johannes, ,der größte Prophet unter den von Frauen Geborenen' [...]“132.

Für Clemens spricht hier also Christus selbst durch den Mund des Johannes eine ethische Weisung aus, die selbstverständlich auch in seiner, des Clemens eigener Zeit, nach wie vor Gültigkeit besaß. Durch dieses Herrenwort wird (zumindest teilweise) aufgezeigt, welches Verhalten bei Soldaten, die im Sinne von prot. 10,100,4 zum Glauben gefunden haben, der geforderten ethischen Orientierung an dem „Feldherrn,

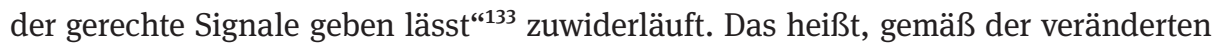
rhetorisch-argumentativen Zielsetzung beantwortet Clemens auf der fortgeschrittenen Stufe der Erziehung zum Heil, die der Paedagogus im Vergleich zum Protrepticus darstellt, die in letzterem implizit aufgeworfene und offen gelassene Frage. Orientierung an Christus bedeutet für christliche Soldaten, sich mit dem eignen Sold zu begnügen und nicht die Zivilbevölkerung erpresserisch auszubeuten. ${ }^{134} \mathrm{Um}$ eine erschöpfende Antwort dürfte es sich dabei nicht gehandelt haben, wie auch der Vergleich mit den Texten zeigen wird, die unter Umständen erste Ansätze zu einer ,Lehre vom gerechten Krieg enthalten'. ${ }^{135}$ Es gibt noch mehr, was Soldaten im Allgemeinen und christlichen Soldaten im Besonderen verboten ist. Aber eine erste Antwort ist hiermit eben doch gegeben. Und der unmittelbare Zusammenhang, in dem es konkret um aktuelle Lebensvollzüge bei den Adressaten geht, die im Licht der elementaren Lebensregeln des göttlichen Erziehers behandelt werden, zeigt das Folgende: Clemens rechnet nicht nur mit der Existenz christlicher Soldaten, sondern regelt deren Verhalten wie das anderer Personen und Gruppen auch, nämlich durch ein Wort des göttlichen Logos. ${ }^{136}$

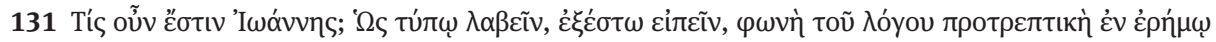

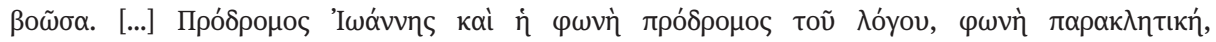

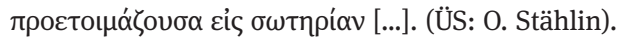

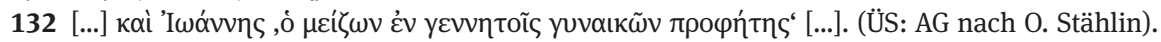

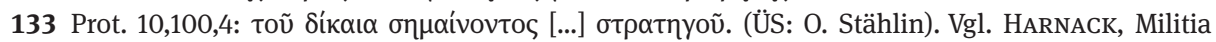
Christi, 58: „Das Wort des Johannis des Täufers an die Soldaten hat er wiederholt und ihm den Wert eines Herrnworts beigelegt; es darf also christliche Soldaten geben, wenn sie sich vor Raub und Erpressung hüten und auf die Stimme des himmlischen Heerführers hören. “ Außerdem RIESNER, Militia Christi, 54, der festhält, dass sich hier „Aufschluss über die Grenzen des christlichen Gehorsams im Militärdienst“ gewinnen lässt.

134 Für die mannigfachen Möglichkeiten, welche die Soldaten dieser Zeit hatten und auch ausübten, um Geld- und Sachwerte aus der Zivilbevölkerung zu erpressen, vgl. MacMulLEN, Soldier, 50 -51; 84-92; FunRmann, Policing, 186-190, 228-237.

135 Siehe unten S. $238 \mathrm{ff}$.

136 Mit BREnNECKe, An fidelis (2007), 200, ist dieser Text ein Beleg dafür, dass Clemens von christlichen Soldaten als einem Normalfall wusste und er zeigt zusammen mit dem zuvor besprochenen und dem unmittelbar folgenden Text außerdem, dass zu seiner Zeit „bei im Osten stationierten Einheiten 


\section{Fazit}

Als Fazit lässt sich festhalten: Erneut zeigt Clemens, dass er nicht nur mit christlichen Soldaten rechnet, sondern auch dass er deren Beruf als mit dem christlichen Bekenntnis vereinbar betrachtet. ${ }^{137}$ Auch das Verhalten des christlichen Soldaten, der hier um seiner selbst willen Thema ist, soll durch „die liebevolle Lehre des Erziehers durch die mannigfachen und heilsamen Gebote“138 geregelt werden, damit dieser zu dem zuvor geforderten „wohlgeordnete[n] Wandel, der in vollkommener Wohlanständigkeit besteht“"139, gelangt. Dabei ist der Kontrast zu Tertullian beachtlich: Während sich dieser in seinen jeweils nach außen und nach innen gerichteten Schriften sehr unterschiedlich zur Soldatenfrage äußert, bietet Clemens ein sehr viel einheitlicheres Bild. Dieser in die Gemeinde hinein gerichtete Text steht in vollkommener Übereinstimmung mit dem ersten Text aus dem mehr auf Außenwirkung bedachten Protrepticus und setzt diesen in gewisser Weise sogar fort. Ein vergleichbares Ergebnis wird auch der folgende Abschnitt aus dem Paedagogus bieten.

\subsubsection{Paed. $2,11,117,1-3$ \\ Text}

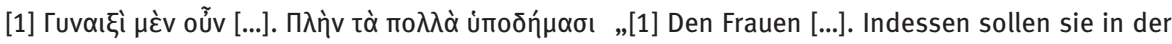

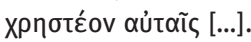

Regel Schuhe tragen [...]

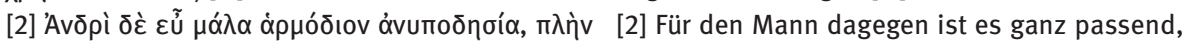

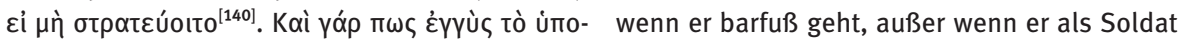

mit größeren christlichen Truppenteilen zu rechnen“ ist. Anders RiESNER, Militia Christi, 53-54, der meint, dass es sich nur um einen seltenen Fall im Umfeld des Clemens gehandelt habe, dass dieser aber immerhin christliche Soldaten gekannt habe, was die genannten Texte zeigen würden. Und HeLGELAND, Christians (ANRW), 745, stellt - zu Unrecht - sogar fest: „Possibly he was not aware of any such Christians, although we cannot say for certain.“ Die Einschätzungen von R. Riesner und J. Helgeland übersehen die eminent lebenspraktische Ausrichtung des gesamten Abschnitts, in dem Clemens durch die angebotenen biblischen Lebensregeln seinen Adressaten helfen will, ihren Alltag im Sinne einer christlichen, dem Logos gemäßen Lebensführung zu meistern. Siehe dazu auch unten S. $250 \mathrm{f}$. Hat man den literarischen bzw. rhetorischen Kontext (peroratio) im Blick, ist unverständlich wie SIDER, Killing, 182, der diese Stelle unter die „ambiguous texts“ (ebd., 181) einordnet, behaupten kann „Nothing in this text says anything about whether Clement thinks it is permissible for a Christian to be a soldier.“ Noch wird es dem Text gerecht, wenn er (ebd., 185, Anm. 155) meint, der Text „may suggest“, dass Clemens Christen im Heer kannte.

137 So verstehen auch Bigelmair, Beteiligung, 181; HARNACK, Militia Christi, 58 mit Anm. 1; RIESNER, Militia Christi, 54; BREnNECKe, An fidelis (2007), 200 diese Stelle. Nahe kommen dem zumindest Cadoux, Christian Attitude, 232; und Swift, War (ANRW), 852, siehe dazu S. 210, Anm. 83, und unten S. 250 f. HoRnus, Politische Entscheidung, 123, deutet zwar an, dass dieser Text seinem Verständnis des Clemens entgegenstehen könnte, lässt ihn dann aber fast völlig unkommentiert stehen.

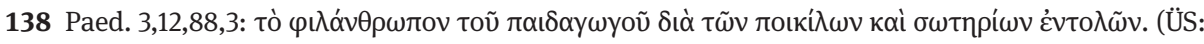
O. Stählin).

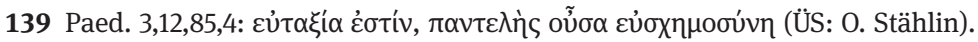

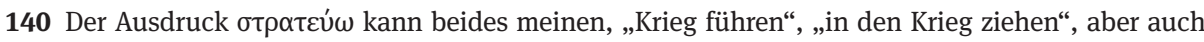
„als Soldat dienen“, „Soldat sein“. Vgl. LIDdell, Henry G.; ScotT, Robert; Jones, Henry S., A Greek- 


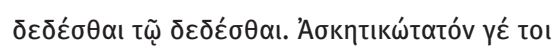

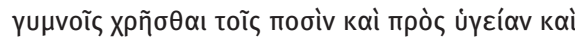

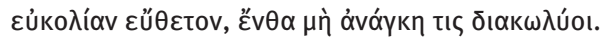

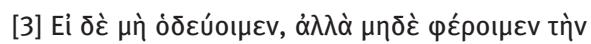

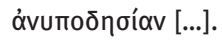

dient; denn das Beschuhtsein ist auch wohl nahe verwandt mit dem Gefesseltsein. Es ist aber auch eine gute Übung, barfuß zu gehen; und es fördert die Gesundheit und die körperliche Frische, wenn nicht ein dringender Grund davon abhält.

[3] Wenn wir aber keinen größeren Marsch machen, aber doch das Barfuß gehen nicht vertragen [...].“

(ÜS: AG nach O. Stählin)

\section{Kontext}

Dieser Abschnitt aus dem zweiten Buch des Paedagogus ist ein Teil der confirmatio. Hier zeigt sich exemplarisch, wie Clemens alltägliche Fragen wie die nach Bekleidung, Schmuck und Fußbekleidung aufgreift und versucht, Ratschläge für einen dem christlichem Glauben angemessenen, unprätentiösen Umgang damit zu geben.

Der Text entstammt dem kurzen Kapitel über Fußbekleidung ${ }^{141}$, welches zwischen das Kapitel über die richtige Art, sich zu kleiden ${ }^{142}$, und dasjenige über den richtigen Umgang mit Schmuck ${ }^{143}$ eingeschoben ist. Dort kritisiert Clemens zuerst, dass Frauen genauso wie edler Kleidung auch schmuckvollen Schuhen über das angemessene Maß hinaus zusprechen. ${ }^{144}$ Dagegen wendet er ein, dass Schuhe nur zum Bedecken des Fußes und zum Schutz der Fußsohle vor Verletzungen da seien. ${ }^{145}$ Frauen solle man daher schlichte weiße Schuhe erlauben und bei Wanderungen Stiefel für sie zulassen, da es sich nicht schicke, wenn sie ihren Fuß nackt zeigten, und sie sich außerdem verletzen könnten. ${ }^{146}$ Darauf folgt der hier zu besprechende Text, in dem er Männern vorschreibt, barfuß zu gehen, ,außer wenn er als Soldat dient“"147 Daraufhin erörtert er die Vorzüge des Barfußgehens, erlaubt aber Sandalen oder leichte Schuhe

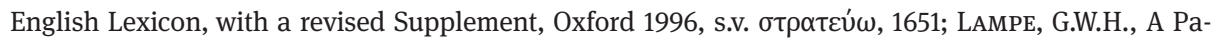

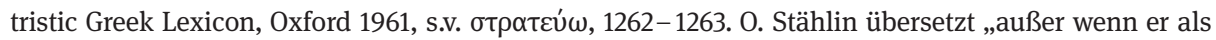
Krieger im Felde ist“ (Des Clemens von Alexandreia Der Erzieher Buch II-III, Welcher Reiche wird gerettet werden?, aus dem Griech. übers. von Otto STÄHLIN, (BKV 2. Reihe, Bd. 8), München 1934, 122). Hier wird der allgemeineren Übersetzung im Sinne von „Soldat sein“ der Vorzug gegeben. Diese Übersetzung kann das ,in den Krieg ziehen“ einschließen, macht aber zugleich eine verfrühte Festlegung unnötig, wie Clemens über die reine Ausübung des Soldatenberufs hinaus zu einer möglichen Kriegsteilnahme steht.

141 Paed. 2,11,116-117.

142 Paed. 2,10,103-115.

143 Paed. 2,12,118-129.

144 Paed. 2,11,116,1-2.

145 Paed. 2,11,116,2.

146 Paed. 2,11,117,1.

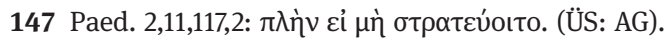


für diejenigen, die das Barfußgehen nicht vertragen. Zum Abschluss führt er Johannes den Täufer als Vorbild und Zeugen für einfache Fußbekleidung an. ${ }^{148}$

\section{Interpretation}

Für die Interpretation dieser Stelle ist es wichtig festzuhalten, dass Clemens den Beruf des Soldaten nur beiläufig ins Spiel bringt. Anders als in paed. 3,12,91,4 wird er nicht um seiner selbst willen thematisiert, sondern er wird nur im Vorübergehen als eine mögliche Ausnahme von der Empfehlung des Barfußgehens erwähnt. Im Unterschied zu paed. 2,12,121,5 ist diese Beiläufigkeit aber nicht von der Art, dass sie keine weiteren Rückschlüsse auf die Haltung des Clemens zur vorliegenden Fragestellung erlauben würde. Denn anders als dort handelt es sich nicht nur um ein literarisch inspiriertes Beispiel, sondern er spricht den Soldatenberuf in einer Weise an, die zeigt, dass er ein Beispiel aus der Lebenswelt seiner Hörer und Leser bieten möchte, das ihnen vertraut ist und das mit Blick auf die ethische Fragestellung einen Praxisbezug aufweist. Der Dienst als Soldat kommt hier als eine mögliche Ausnahme vom Gebot des Barfußgehens in den Blick, eine Ausnahme, die im Umfeld des Clemens eine realistische Option dargestellt haben dürfte.

Diese Annahme lässt sich noch weiter absichern. Dazu muss die für heutige Ohren etwas merkwürdige Aussage des Clemens, dass das Tragen von Schuhen dem Gefesseltsein gleichkommt, näher betrachtet werden. Diese Aussage ist vor einem zweifachen Hintergrund zu verstehen. Zum einen handelt es sich um ein einfaches Wortspiel im Griechischen: Schuhe zu tragen bezeichnet Clemens in gängiger Weise als ن் $\delta \varepsilon \delta \varepsilon ́ \sigma \theta \alpha l^{149}$, etwas untergebunden, etwas an die Füße gebunden zu haben. Sandalen, die gängige Fußbekleidung der Zeit, wurden nämlich an den Fuß gebunden. Für das Gefesseltsein verwendet er den Ausdruck $\delta \varepsilon \delta \varepsilon \dot{\varepsilon} \sigma \theta \alpha$, die Perfektform von $\delta \varepsilon^{\prime} \omega^{150}$, fesseln. Zum anderen knüpft Clemens hier eng an den Stoiker Musonius Rufus an ${ }^{151}$, der im Rahmen einer Vorlesung zur angemessenen Art, sich zu kleiden, zur Einfachheit aufruft und Luxuskritik übt ${ }^{152}$ :

148 Paed. 2,11,117,4.

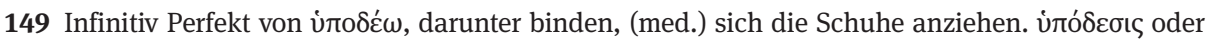

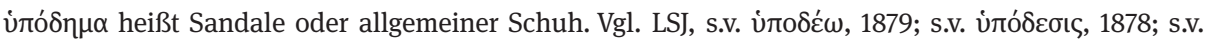

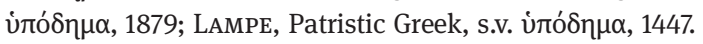

150 Vgl. LSJ, s.v. $\delta \dot{c} \omega$ A, 383.

151 Vgl. BERnHARDT, Rainer, Luxuskritik und Aufwandsbeschränkungen in der griechischen Welt, (Historia Einzelschriften 168), Stuttgart 2003, 207 und 209.

152 Vgl. Reydams-Schils, C. Musonius Rufus und Lukios, 162: „Die letzten längeren Vorlesungen, die von Musonius erhalten sind, behandeln materielle Angelegenheiten wie Ernährung, Kleidung, Hausrat oder die äußere Erscheinung. [...] Im Grundsatz vertritt er die Tugend der Mäßigung und die Vorstellung vom einfachen Leben, in materieller Hinsicht die Beschränkung auf das Allernötigste.“ Außerdem Dillon, Musonius Rufus, 21: „Clothing and shelter. Both of these are for the protection of the body, nor for display, and they ought to provide moderate covering, not expensive and superfluous (D19). The best clothes are those that are most useful to the body, not those that cause foolish people to turn and 
„Und besser als Sandalen an den Füßen zu haben ist es, barfuß zu gehen, für den, der es vertragen kann. Ist doch, scheint es, das ,Untergebundensein` ähnlich dem Gebundensein, denn die ,Ungebundenheit' gewährt den Füßen eine gewisse Freiheit und leichte Beweglichkeit, wenn sie darin geübt sind. Daher sieht man auch bei den Tagesläufern, dass sie unterwegs keine Sandalen an den Füßen haben wie auch die Läufer bei den Wettspielen, die nicht die Schnelligkeit einhalten könnten, wenn sie mit Sandalen laufen müssten.“ (R. Nickel)“153

Da Clemens ebenfalls immer wieder Wert auf eine einfache, nicht dem Prunk und Luxus verschriebene Lebensweise legt, findet er hier einen passenden Bezugspunkt. Nun wählt Clemens aber andere Beispiele als Musonius. Dessen Beispiele für die

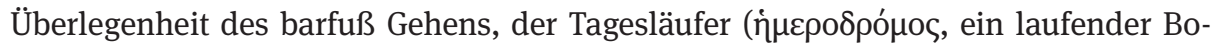
$t^{154}$ ) und der Athlet, sind aus seiner alltäglichen Lebenswelt gegriffen. Clemens wählt seine Beispiele nicht, um das barfuß Gehen zu illustrieren, sondern mögliche Ausnahmen davon. ${ }^{155}$ Dennoch sind sein exempla ebenso alltagsnah wie die des Musonius. Sowohl der Anblick eines Soldaten wie auch die Notwendigkeit, einen längeren Fußmarsch zu unternehmen, entstammen dem alltäglichen Leben.

Diese sehr unbefangene und beiläufige Erwähnung des Heeresdienstes zeigt also, dass Clemens die Möglichkeit, dass einer seiner Adressaten als Soldat Schuhe oder Stiefel tragen könnte, nicht als Problem empfunden haben dürfte. ${ }^{156}$ Schließlich wäre es sinnlos und würde auch dem ganzen Textzusammenhang nicht entsprechen, ein völlig unrealistisches Beispiel anzuführen, das in der Lebenswirklichkeit der Adressaten des Clemens überhaupt keine Rolle spielte. Und noch weniger Sinn würde es machen, als Ausnahme einen Fall einzuführen, der in den Augen des Clemens von vornherein entfällt, da er für Christen problematisch beziehungsweise gar nicht erlaubt ist, und den problematischen Charakter des Falls dann nicht einmal zu er-

stare. Clothing should make the body better and stronger, not weaker and worse. [...]“ Beide bieten außerdem einen sehr guten Überblick über sein Leben und Denken.

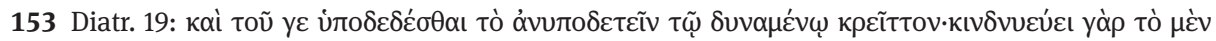

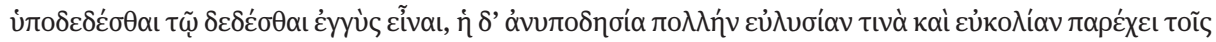

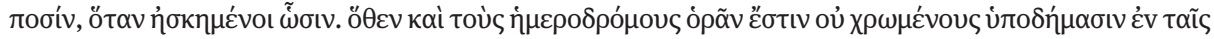

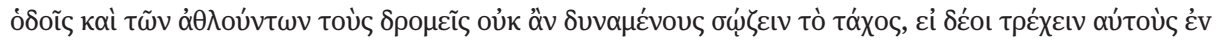
ن்

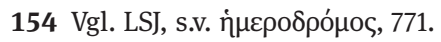

155 Das zeigt zugleich, dass Clemens nicht einfach nur einen Topos philosophischer Luxuskritik unbesehen übernimmt, sondern ihn inhaltlich für die Bedürfnisse seines Publikums kontextualisiert. Im Gegensatz zu der Ausnahme für Soldaten, die Clemens macht, steht eine Anekdote bei Plutarch (Plut. Phoc. 4,2), der athenische Stratege Phokion habe auf dem Land und auf Feldzügen, außer bei sehr großer Kälte, weder Schuhe noch Mantel gebraucht (vgl. Bernhardt, Luxuskritik, 290).

156 Vgl. Helgeland, Christians (ANRW), 745. Selbst HoRnus, Politische Entscheidung, 123 räumt ein, dass Clemens hier „den Militärdienst als neutrale Gegebenheit, die zum täglichen Leben gehört“ versteht. Auf eine weitere Erklärung des Textes oder eine Einordnung in sein Gesamtverständnis des Clemens verzichtet er dann allerdings. Anders wieder SIDER, Killing, 182: „[...] nothing in the text says that Christians may legitimately be in the military. At the most, it shows that he knew of Christians in the military." Auch hier wird das Gewicht des rhetorischen Kontexts für die Deutung der Stelle nicht erkannt. 
wähnen. Es sei hier noch einmal an das fiktive Beispiel mit dem Gladiator oder der Prostituierten aus dem Abschnitt zu prot. 10,100,4 erinnert. ${ }^{157}$

\section{Fazit}

Auch hier ist in keiner Weise erkennbar, dass Clemens ein schwerwiegendes Problem mit der Existenz christlicher Soldaten hatte. Im Gegenteil, auch dieser Text aus der ethischen Unterweisung der Taufbewerber zeigt, dass Clemens diese Möglichkeit sehr „unbefangen“158 als eine legitime Möglichkeit anerkennt. ${ }^{159}$ Nur so ist seine Verwendung gerade dieses Beispiels in einem solchen Zusammenhang zu erklären.

\subsubsection{Weitere Texte in Auswahl}

Nachdem die drei für die vorliegende Fragestellung wichtigsten Texte aus dem Werk des Clemens, in denen er den Soldatenberuf direkt anspricht und zugleich mit einer positiven Wertung versieht, besprochen wurden, gilt es nun, sich mit einer weiteren Gruppe von Texten zu befassen. Diese Texte werden oftmals angeführt, um zu zeigen, dass Clemens trotz der gerade besprochenen Passagen doch letztlich dem Pazifismus zugewandt war. ${ }^{160}$ Dabei wurden für diesen Abschnitt vor allem diejenigen Texte ausgewählt, auf die wichtige Teile der Forschung Bezug nehmen, um die pazifistische Grundhaltung des Clemens zu erweisen, oder solche Texte, welche die hier vertretene Gesamtinterpretation in Frage stellen können. Vollständigkeit ist dabei nicht angestrebt, es wurde aber mittels einer Durchsicht des Werkes des Clemens darauf geachtet, die wichtigsten und aussagekräftigsten Texte einzubeziehen.

Bei der Untersuchung dieser weiteren Texte ist es methodisch geboten zu versuchen, sie im Licht der drei schon besprochenen Haupttexte zu lesen. Diese Haupttexte

157 Siehe oben S. 209.

158 HARNACK, Militia Christi, 58.

159 In diesem Sinn interpretieren diese Stelle auch BigElmAIR, Beteiligung, 181; HARNACK, Militia Christi, 58 mit Anm. 1; CADOux, Christian Attitude, 232, allerdings mit einer gewissen Reserve (s. dazu oben S. 210, Anm. 83, und S. 250 f.); SchöpF, Tötungsrecht, 221; HelgEland, Christians (ANRW), 745, der sie allerdings fälschlicherweise als II 118[sic!],2 angibt; RIESNER, Militia Christi, 54, dem dieselbe Fehlzuweisung zu II 118[sic!],2 unterläuft; BRENNECKE, An fidelis (2007), 200.

160 So z.B. bereits CAdoux, Christian Attitude, 51, 64, 71-72 und 78; außerdem mit Nachdruck BAInTON, Early Church, 196 und 197 (= Kirche und Krieg, 195-196 und 197), wo er seinen Clemens einschließenden Überblick mit den Worten schließt: „Thus all of the outstanding writers of the East and the West repudiated participation in warfare for Christians.“ Ebenso BaInTon, Attitudes, 73. Außerdem sieht neuerdings SHEAN, Soldiering, 100 -101, in einigen der hier genannten Texte „pacifist sentiments“ (ebd., 101), wenn er auch die Annahme eines frühchristlichen ,Pazifismus“ im modernen Sinn für die Kirchenväter zurückweist (ebd., 71-72) und die Haltung des Clemens „ambivalent“ (ebd., 100) findet. Schon SwIFT, War (ANRW), 851-852; und SwIFT, Views, 284, fand die Haltung des Clemens schwer zu greifen und widersprüchlich. 
zeigen nämlich in großer inhaltlicher Deutlichkeit die Haltung des Clemens zum Soldatenberuf. Erst von dem dort gewonnenen ,festen Grund‘ aus kann dann nach dem Sinn der weiteren Texte und ihrer Relevanz für die Soldatenproblematik gefragt werden. ${ }^{161}$ Da diese Passagen oftmals nur als Belegstellen kurz zitiert, aber selten in ihrem Kontext untersucht werden ${ }^{162}$, soll auch hier Wert auf eine kontextuelle Einbettung der Texte gelegt werden. Nach der Einzelinterpretation soll dann eine Zusammenschau versucht werden, um zu klären, ob sich eine kohärente Position des Clemens aus den unterschiedlichen Texten gewinnen lässt.

\subsubsection{Strom. 4,8,59,1-61,3}

\section{Text}

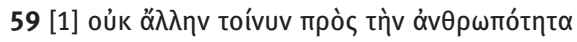

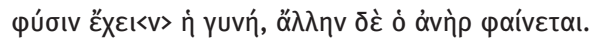

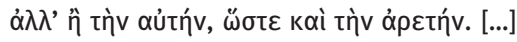

„59 [1] Es ist aber offenbar nicht so, dass hinsichtlich des Menschseins die Frau eine andere Natur hätte als der Mann; vielmehr haben beide die gleiche Natur, also auch die gleiche Tugend. [...]

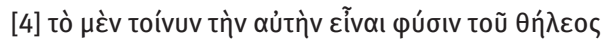

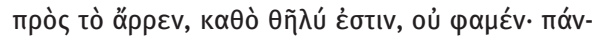

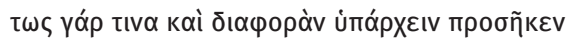

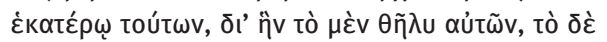

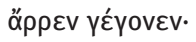

\section{[...]}

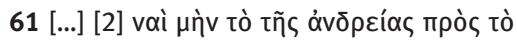

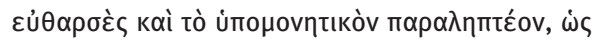

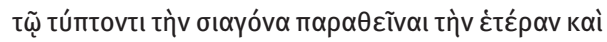

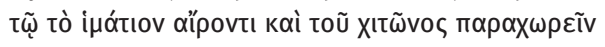

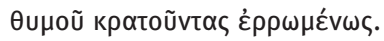

[4] Damit behaupten wir nun nicht, dass ein weibliches Wesen die gleiche Natur wie das männliche habe, insoweit es weiblich ist. Denn es geziemt sich durchaus, dass beide ein unterscheidendes Merkmal an sich tragen, dessentwegen das eine weiblich, das andere männlich geworden ist.

[...]

61 [...] [2] Indessen müssen wir auch Mannhaftigkeit bewähren, wenn es gilt, die Gemütsruhe zu wahren und die Fähigkeit zum Ertragen zu zeigen, so dass wir dem, der uns auf den Backen schlägt, auch den anderen hinhalten und dem, der uns den Mantel nimmt, auch den Rock überlassen, indem wir die Neigung zum Zorn kraftvoll beherrschen.

161 Dass das umgekehrte Vorgehen zu einer verzerrten Interpretation der ,Soldatentexte' führen kann, zeigt exemplarisch CADoux, Christian Attitude, 232, der ihm dann bei der Diskussion der ,Soldatentexte“ Inkonsequenz mit Blick auf seinen „clear grasp of Christian principles in the abstract“ (ebd., 232) vorwirft; außerdem BaINTON, Early Church, 199-200 (= Kirche und Krieg, 199), der die Annahme, prot. 10,100,4 zeige, dass für Clemens der Soldatenberuf ein Beruf wie jeder andere auch sei, für „mit den oben angeführten Zitaten des Clemens, die die Verurteilung des Kriegswesens erkennen lassen, kaum vereinbar[]" hält. Am Extremsten fällt diese, auf einem falschen methodischen Vorgehen beruhende, Fehlinterpretation bei HoRnus, Politische Entscheidung, 122-123, ins Gewicht, wo dieser die drei Haupttexte prot. 10,100,4; paed. 2,11,117,2; 3,12,91,2 ganz im Licht des zuvor von ihm konstruierten Pazifisten Clemens liest und dabei noch einmal weit über J. Cadoux und R. Bainton hinausgeht.

162 Vgl. z.B. Cadoux, Christian Attitude, 51 und 64; Campenhausen, Kriegsdienst, 257; Hornus, Politische Entscheidung, 89, 102, 110, 153; Bainton, Early Church, 196 (= Kirche und Krieg, 195-196); SwIFT, War (ANRW), 851-852; SwIFT, Views, 284; SHEAN, Soldiering 100-101. 


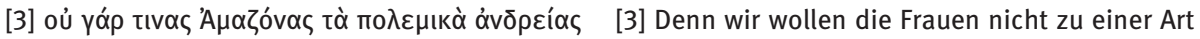

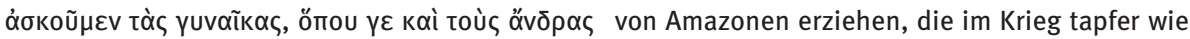

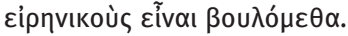

Männer kämpften, da wir doch sogar bei den Männern wünschen, dass sie friedfertig sind.“ (ÜS: 0. Stählin)

\section{Kontext}

Dieser Text entstammt dem vierten Buch der Stromata, in dem sich Clemens vor allem mit dem Martyrium, aber auch mit dem Streben nach Vollkommenheit, Askese und Apathie befasst. ${ }^{163}$ In dem hier behandelten Zusammenhang wird besonders strom. 4,8,61,3 angeführt, um die grundsätzlich pazifistische Einstellung des Clemens zu erweisen. ${ }^{164}$ Da diese Stelle für sich genommen nicht einfach zu verstehen ist, wurde ein größeres Stück des Textzusammenhangs in Auszügen mit angeführt, um beim Nachvollzug der Interpretation zu helfen.

Im unmittelbaren Kontext stehen Erörterungen zum Ertragen von Bedrängnissen und zur Bewährung darin, die der wahre Gnostiker aus Liebe zu Gott sucht (strom. 4,7,55). ${ }^{165}$ Clemens ruft ihn zur Gelassenheit auf, angefüllt mit dem Frieden Christi, und verweist ihn auf die Beispiele der „Gerechten der alten Zeit“ als Vorbilder an „Gelassenheit der Seele und [...] Gemütsruhe“166. Daraufhin folgen zahlreiche exempla aus der antiken Geschichte und Literatur. ${ }^{167}$ Clemens weist dann darauf hin, dass auch die Kirche voll von Leuten sei, die in dieser Grundhaltung lebten, und zwar, so betont er, Männer und Frauen ${ }^{168}$,

„[d]enn wer sein Leben nach unseren Grundsätzen führt, der kann auch ohne wissenschaftliche Bildung nach Weisheit streben (philosophieren), mag er ein Barbar sein oder ein Grieche, ein Sklave, ein Greis oder ein Kind oder eine Frau.“169

Das liegt daran, dass für alle innerhalb einer Gattung, die eine gemeinsame Natur teilen, auch dieselbe Tugend beziehungsweise Sittsamkeit zur Verfügung steht. ${ }^{170} \mathrm{Um}$ die Gültigkeit dieses Satzes auch für die Menschheit, genauer gesagt, für Männer und

163 Strom. 4,1,1,1. Vgl. Chadwick, Henry, Clement of Alexandria. In: Armstrong, Arthur H. (Hrsg.), The Cambridge History of Later Greek and Early Medieval Philosophy, Cambridge 1967, 178.

164 So z. B. Cadoux, Christian Attitude, 106; HoRnus, Politische Entscheidung, 153; BaInTon, Early Church, 196 (= Kirche und Krieg, 195); BAInTon, Attitudes, 72. Sider, Killing, 179, zählt diesen Text zu den „implied prohibition[s] of Christian participation in the military“ (ebd., 178).

165 Zum Verhältnis des wahren Gnostikers zum Martyrium vgl. VöLKER, Gnostiker, 559-579.

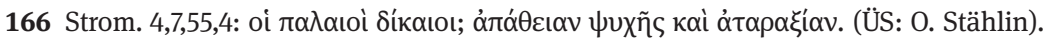

167 Strom. 4,8,56,1-58,1.

168 Strom. 4,8,58,2-4.

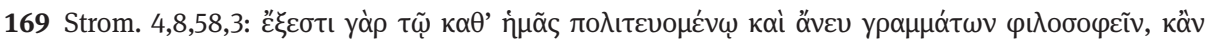

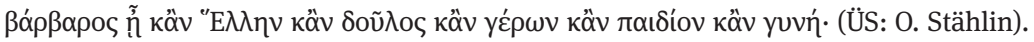

170 Strom. 4,8,58,4. 
Frauen, zu erweisen, diskutiert Clemens im folgenden Abschnitt in einer Art Exkurs die identische Natur von Mann und Frau sowie die daraus abzuleitenden identischen ethischen Forderungen an beide. ${ }^{171}$ Gleichzeitig räumt er darin aber ein, dass es zwischen Mann und Frau auch Unterschiede gibt, den Unterschied zwischen Männlichkeit und Weiblichkeit nämlich. Das belegt er dadurch, dass er auf die allein weibliche Fähigkeit zur Schwangerschaft und zum Gebären von Kindern hinweist. Diese Unterschiede seien aber nicht in dem beiden gemeinsamen Menschsein zu verorten, sondern nur im eben verschiedenen Mann- und Frausein, das sich dann auch - unter Verweis auf mehrere Paulusstellen ${ }^{172}$ - in verschiedenen Aufgabenbereichen im alltäglichen Leben ausdrückt. Der Frau wird dabei das Kindergebären und der Haushalt zugewiesen. Innerhalb dieser Aufgabenbereiche sind aber beide wieder als Menschen zu derselben Tugend und ethischen Lebensweise verpflichtet, beide sollen ihre „Lüste“ ${ }^{\text {“173 }}$ bekämpfen. ${ }^{174}$ Im Anschluss daran folgt die hier zu interpretierende Mahnung an die Männer, Unrecht hinzunehmen und ihren Zorn zu beherrschen, sowie der Satz über die Amazonen. Diesem folgt dann noch der Hinweis, dass Clemens aber von Frauen bei den Sauromaten, Saken und anderen Völkern weiß, die kämpfen und andere männliche Beschäftigungen ausüben. ${ }^{175}$ Diese dienen ihm als Beispiel dafür, dass Frauen nicht weniger für gewisse Tätigkeiten geeignet sind als Männer. ${ }^{176}$ Er empfiehlt schließlich auch den Frauen - im christlichen Sinne - Philosophie zu treiben, trotz ihrer Unterlegenheit unter den Mann. ${ }^{177}$ Damit schließt er

171 Strom. 4,8,59,1-62,4. Vgl. OsBorn, Clement, 229. Für die Haltung des Clemens zur Erkenntnis- und Bildungsfähigkeit von Frauen sowie seine Vorstellungen über die Geschlechterrollen, die deutliche Anklänge an stoische Positionen aufweisen, vgl. kurz Clemens Alexandrinus, Les stromates, Bd. 4, Introd., texte critique et notes, par Annewies VAN DEN HoEK, trad. de Claude MondÉSERT, (Sources chrétiennes 463), Paris 2001, 154, Anm. 1; außerdem Kinder, Donald, Clement of Alexandria - Conflicting Views of Women. In: Second Century 7/4, (1989/1990), 213-220; einige wichtige Korrekturen zu D. Kinder bietet KöNIG, Hildegard, Beobachtungen zur sittlichen Autonomie der Frauen bei Clemens von Alexandrien. In: Müller, Ludwig G. (Hrsg.), Frauen in der Kirche - Eigensein und Mitverantwortung, Würzburg 1999, 166-187.

172 1.Kor 11; Gal 5.

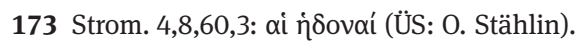

174 Strom. 4,8,59,3-61,1.

175 Strom. 4,8,62,1-3.

176 Siehe v. a. seinen Gebrauch der Hundemetapher in strom. 4,8,62,3. Vgl. vAN DEN HoEk/MondÉSERT, Les stromates 4, 158, Anm. 1: „Clément donne les Amazones et les Sarmates comme exemples d'indépendance et d'égalité. Ces femmes légendaires ont ce rôle depuis le temps de Platon; Platon les cite pour illustrer l'avantage pour l'État de l'éducation égale des filles et des garcons, cf. PLATON, Lois 804d-806c [...]." Siehe auch ebd., 159, Anm. 3 und 4. Gegen A. van den Hoek scheinen die Amazonen anders als die Frauen der Sauromaten und Saken keinen positiven Vergleichspunkt darzustellen, sondern einen negativen, von dem Clemens die Christinnen abheben will. Der Vergleich mit den Amazonen gehört also noch zum vorherigen Abschnitt, während der Vergleich mit den Sauromatinnen und Sakinnen einen neuen Aspekt des Gedankengangs eröffnet.

177 Strom. 4,8,62,4. 
den Kreis und kehrt zur Bedeutung der Tugend für die ganze Menschheit, für Mann und Frau, zurück. ${ }^{178}$

\section{Interpretation}

Es war nötig, den Kontext dieser Stelle so ausführlich aufzuzeigen, damit deutlich wird, in was für eine komplexe Argumentation sie eingeflochten ist. Dementsprechend schwierig ist die Interpretation. R. Bainton ${ }^{179}$ meint, dass Clemens hier auf einen Einwand gegen seine Behauptung gleicher ethischer Normen für alle reagiert, der besagt, dass Frauen ja anders als Männer nicht zum Krieg ausgebildet würden. Als Antwort habe dieser daraufhin auch den Männern „die militärische Betätigung“180 verboten. Zumindest die Erwägung, dass Clemens hier auf einen (möglichen) Einwand eingeht, kann einige Plausibilität beanspruchen. Klar scheint auch zu sein, dass er kämpfende Frauen kritisch sieht, trotz des positiv verwendeten Beispiels der Sakinnen und Sauromatinnen. Ob man aber wirklich sagen kann, dass Clemens hier Männern die „militärische Betätigung untersagt“181 ist mehr als fraglich, und das umso mehr, als die bisher besprochenen, wesentlich eindeutigeren Texte genau in die gegenteilige Richtung weisen.

Der Text muss vielmehr im Zusammenhang des ganzen Kapitels über das Martyrium im allgemeinen und das Ertragen von Bedrängnissen durch den wahren, philosophisch geschulten Gnostiker ${ }^{182}$ in Gelassenheit (Apathie ${ }^{183}$ ) und Gemütsruhe (Ataraxie) im Besonderen gelesen werden. In diesem Rahmen wünscht sich Clemens von Christen, Männern wie Frauen, dass sie die ihnen auferlegten Bedrängnisse gelassen hinnehmen und ertragen. Für die Männer macht er das in strom. 4,8,61,2 unter Aufnahme neutestamentlicher Jesusüberlieferung ${ }^{184}$ sehr deutlich. Im folgenden Satz zeigt er, dass den Frauen gemäß seiner These von der gemeinsam gültigen Tugend in ihrer geschlechtlichen Unterschiedlichkeit der gleiche ethische Standard gesetzt ist. Sie sollen keine kämpfenden Amazonen werden, so wie Clemens sich auch von den Männern ein friedfertiges und gelassenes Verhalten wünscht. Die Erwähnung der Amazonen bietet Clemens dann aber die Möglichkeit, zu anderen kämpfenden Frauen überzuleiten und darauf aufbauend die zumindest annähernde Gleichwertigkeit der Frau mit Blick auf die philosophische Betätigung zu behaupten.

178 Strom. 4,8,63,1.

179 Bainton, Early Church, 196 (= Kirche und Krieg, 195); siehe auch Bainton, Attitudes, 72.

180 Bainton, Early Church, 196 (= Kirche und Krieg, 195).

181 Bainton, Early Church, 196 (= Kirche und Krieg, 195).

182 Zum wahren Gnostiker des Clemens vgl. VöLKER, Gnostiker, hier v. a. 507-609; außerdem die knappen Überblicke bei MÉHat, s.v. Clemens (TRE), 110; NEYMEYR, Lehrer, 73-79; KöNIG, Clemens, 155-160; WyrWa, Clemens, 941-942.

183 Vgl. dazu VöLKER, Gnostiker,183-188 und 524-540.

184 Lk 6,29 par. Mt 5,39-40. 


\section{Fazit}

Es geht im Zusammenhang um das Recht auf philosophische Betätigung für Männer und Frauen sowie die daraus folgende richtige Haltung den Bedrängnissen und dem Martyrium gegenüber, nicht aber um die Frage, ob es erlaubt ist, Militärdienst zu leisten. Und selbst wenn man die Mahnung aus strom. 4,8,61,3 weiter fassen und ein Stück vom unmittelbaren Kontext abheben möchte, so wird man mit R. Riesner sagen müssen, dass es dem alexandrinischen Kirchenschriftsteller „nur um die allgemeine Friedfertigkeit [ging], die natürlich auch Clemens von den Christen erwartete und sich für alle Menschen wünschte“185. Pazifismus oder eine generelle Ablehnung des Soldatendienstes für Christen wird man angesichts des unmittelbaren Textzusammenhangs einerseits und angesichts der sehr eindeutigen Zeugnisse der ersten drei untersuchten Passagen andererseits, die davor bewahren, diese Stelle zu überinterpretieren, hier nicht finden können.

\subsubsection{Paed. 1,12,98,4-99,1}

\section{Text}

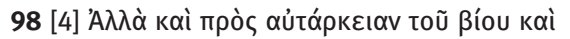

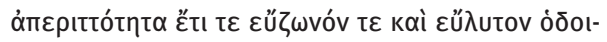

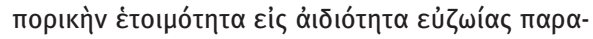

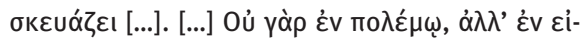

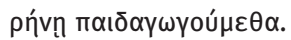

„98 [4] Er bereitet uns aber auch für Genügsamkeit und Anspruchslosigkeit in unserem Leben vor und ferner noch für eine durch nichts beschwerte oder gehemmte Bereitschaft zur Wanderung nach einem ewigen heiligen Leben. [...] Denn nicht im Kriege, sondern im Frieden findet unsere Erziehung statt.

99 [1] Ein Krieg hat allerdings große Zurüstung nötig, und ein üppiges Leben erfordert großen Aufwand; aber Friede und Liebe, zwei einfache und anspruchslose Geschwister, brauchen keine Waffen, keine verschwenderische Zurüstung; der Logos ist ihre Nahrung, der Logos, dem das Amt zugefallen ist, uns zurechtzuweisen und zu züchtigen, von dem wir Einfachheit und Anspruchslosigkeit und überhaupt Freiheitsliebe und Menschenliebe und Liebe zum Edlen erlernen [...].“ (ÜS: O. Stählin)

\section{Kontext}

Der nächste Text findet sich im ersten Buch des Paedagogus, in dem Clemens das erzieherische Wirken des Logos am Menschen beschreibt, um darauf sein eigenes erzieherisches Wirken in den beiden folgenden Bücher zu gründen. Der hier behandelte Abschnitt steht am Ende des ersten Buches, wo Clemens noch einmal wichtige

185 Riesner, Militia Christi, 54. 
Überlegungen zusammenfasst. In der Literatur wird gelegentlich auf diesen Text verwiesen, um die pazifistische Grundhaltung des Clemens zu belegen. ${ }^{186}$

Im unmittelbaren Kontext spricht Clemens davon, dass Jesus den Menschen „das wahre Leben vorzeichnet“"187 und uns erzieht. Er macht das durch die Gabe der Gebote, aber noch viel mehr, indem er selbst in der Inkarnation Mensch und damit zur wahren Erfüllung der Gottesebenbildlichkeit des Menschen im vollsten Sinn wird. ${ }^{188}$ An diesem menschgewordenen Logos haben sich die Menschen auf ihrem Weg zum Heil zu orientieren und sollen „das wahrhaft heilbringende Leben unseres Heilandes in unserem Leben treu nachbilden“"189. Das Vorbild aber, das er gibt, ist das eines einfachen, bedürfnislosen Lebens, das auch den Weg des Menschen zum Heil ausmachen soll. E. Osborn bringt diesen Zusammenhang sehr gut auf den Punkt:

„Man's upward path is guided by the example of the life of the lord; he follows the footsteps of God, who shows in human form the soundness, simplicity and sufficiency of a pilgrim who discards all baggage on the way to life eternal. Alone, uncluttered by servants, the follower of Christ chooses a simple life, taking a day at a time (paed. 1.12.98.3, 4).“190

\section{Interpretation}

Für die Interpretation des Abschnitts ist dieser Kontext von großer Bedeutung. Clemens stellt dem Leser hier das Ideal eines einfachen und anspruchslosen Lebens in der Nachfolge Christi vor Augen. Dieses Leben kontrastiert er mit dem Leben im Krieg, das voller Bedürfnisse und Notwendigkeiten ist und daher auch sehr aufwendig. Die Erziehung des Christen zum Heil, so stellt er fest, findet nicht im beziehungsweise gemäß dem Krieg, sondern im beziehungsweise gemäß dem Frieden statt. Sie ist also nicht an einem aufwendigen Leben orientiert, wie es für den Krieg typisch ist, sondern an dem einfachen, bedürfnislosen Leben des Wanderers, der sein Ziel fest vor Augen hat. Dabei ist dieser Weg geprägt von Frieden und Liebe, die selbst anspruchslos und einfach sind.

Zunächst ist also festzuhalten, dass Clemens hier das Thema Krieg nicht um seiner selbst willen thematisiert, sondern nur als Vergleichspunkt für seine Ermahnung benutzt. Weiterhin ist das tertium comparationis nicht die Frage der Gewaltausübung (oder des Götzendienstes), sondern der Aufwand des Krieges, der dem den Christen empfohlenen einfachen Lebensstil widerspricht. Damit lässt sich keine

186 So z.B. Cadoux, Christian Attitude, 51 und 64; Bainton, Early Church, 196 (= Kirche und Krieg, 195-196); BAINTON, Attitudes, 72; HoRnus, Politische Entscheidung, 89; vorsichtiger sind hier SwIFT, War (ANRW), 851-852; SwIFT, Views, 284; SHEAN, Soldiering, 101. SIDER, Killing, 179, zählt diesen Text ebenfalls zu den „implied prohibition[s] of Christian participation in the military“ (ebd., 178).

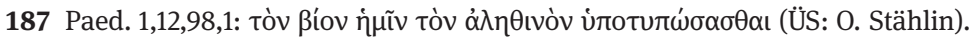

188 Paed. 1,12,98,1-3.

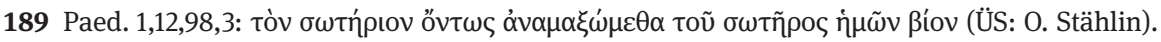

190 OsBorn, Clement, 40. 
grundsätzliche Ablehnung des Soldatenberufs für Christen begründen; darum geht es Clemens aber auch nicht. ${ }^{191}$

Andererseits lässt der Hinweis auf den Gegensatz von Krieg einerseits und Liebe und Frieden andererseits durchaus auf eine kritische Sicht des Krieges schließen, wie sie sich auch in anderen Passagen seines Werkes ${ }^{192}$ feststellen lässt. Denn, dass Clemens den Frieden und die Liebe dem Krieg vorzieht ${ }^{193}$, wie viele andere Schriftsteller der Antike auch - christliche wie heidnische -, steht außer Frage. Charakteristisch für seine Haltung ist hier ein paraphrasierendes Platozitat aus strom. 2,5,23,4:

„Das Beste ist aber weder der Krieg noch der politische Kampf; denn man muss wünschen, dass man davor bewahrt bleibt, ihrer zu bedürfen; dagegen ist Friede untereinander und zugleich freundliche Gesinnung das Beste.“194

Und es spricht für sich, dass Clemens, wenn er Christen in prot. 10,108,4-5 als solche, die sich „in (die Bürgerlisten) Gottes eintragen“ ${ }^{195}$, unter Gottes „Gesetze“196 stellt und in diese Gesetze auch das Mordverbot des alttestamentlichen Dekalogs ${ }^{197}$ und das Gebot „zum Verzicht auf persönliche Gegengewalt“"198 aus der Bergpredigtt ${ }^{199}$ einbezieht. $^{200}$

191 Anders dagegen HoRnus, Politische Entscheidung, 153, der diesen Text in seinem Kapitel über „de[n] christliche[n] Antimilitarismus als offizielle[n] Standpunkt der Kirche“ (ebd., 152-179) anführt. Der Abschnitt zeige, dass Clemens sogar „die Vorbereitungen jeglicher Art, die für einen Krieg notwendig sind und zum Frieden und zur Liebe im Gegensatz stehen" verwirft.

192 Siehe z. B. prot. 3,42,1, wo Krieg auf den Menschenhass der Dämonen, d.h. der heidnischen Götter zurückgeführt wird; paed. 3,2,13,4-5, wo Krieg am Beispiel des trojanischen Krieges als Folge

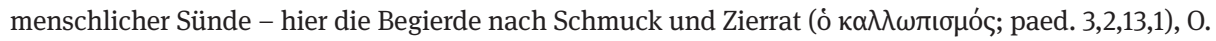
Stählin übersetzt „Putzsucht“ (STÄHLIN, Paed. II-III (BKV), 146) - und als Unrecht beschrieben wird; strom. 5,14,126,5, wo Krieg mit den Worten des Orpheus (Orpheus Frg. 245,11-12 [Kern] ) als ein Übel (Tò какóv) beschrieben wird; außerdem strom. 7,4,23,4-5. Vgl. dazu ScHöPf, Tötungsrecht, 219. Dass eine solche kritische Sicht des Krieges kein Alleinstellungsmerkmal christlicher Autoren ist, sondern sich auch bei heidnischen Schriftstellern findet, darauf wurde bereits hingewiesen. Siehe oben S. $142 \mathrm{ff}$. 193 Vgl. Bainton, Early Church, 196 (= Kirche und Krieg, 196); Bainton, Attitudes, 72; Riesner, Militia Christi, 62.

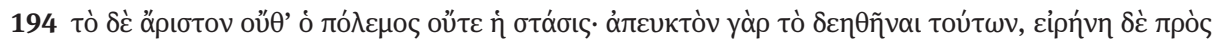

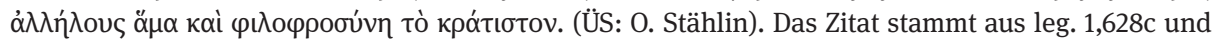

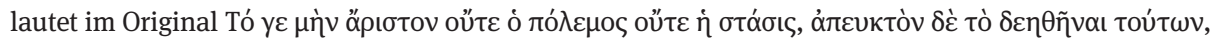

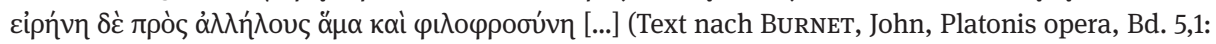
Tetralogias I-II continens: Euthyphro, Apologia, Crito Phaedo, Cratylus, Theaetetus, Sophista, Politicus, Oxford 1907 [Nachdr. 1973]). Der Hinweis darauf stammt aus ScHöpF, Tötungsrecht, 219-220.

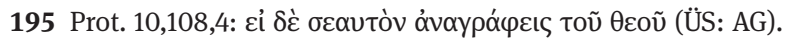

196 Prot. 10,108,4: oi vó $\mu$ ot (ÜS: AG).

197 Ex 20,13.

198 Riesner, Militia Christi, 62.

199 Lk 6,29; siehe auch Mt 5,39.

200 Prot. 10,108,5: „Wie lauten aber seine Gesetze? ,Du sollst nicht morden, du sollst nicht ehebrechen, du sollst nicht Knaben schänden, du sollst nicht stehlen, du sollst kein falsches Zeugnis geben, du sollst den Herrn deinen Gott lieben!‘ Es gibt aber auch Ergänzungen zu diesen Geboten, weise 


\section{Fazit}

Aber auch aus dieser Unterstellung unter Gottes Gesetz lässt sich kein doktrinärer Pazifismus ableiten und noch weniger eine Ablehnung des Heeresdienstes. Mit Blick auf den Gesamtbefund der untersuchten Texte wird man vielmehr B. Schöpf Recht geben müssen, der feststellt, dass Mord und Krieg für Clemens gerade nicht identisch sind. ${ }^{201}$ Daher lassen sich diese Texte nicht direkt auf die hier behandelte Frage nach Heeres- und Kriegsdienst anwenden. Und aus paed. 1,12,98,4-99,1 selbst lässt sich nicht mehr als eine (deutliche) Bevorzugung des Friedens gegenüber dem Krieg entnehmen.

\subsubsection{Prot. 11,116,2-4 Text}

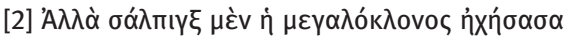

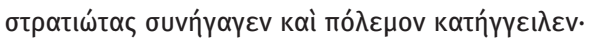

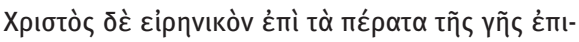

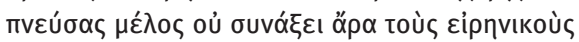

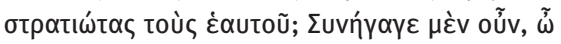

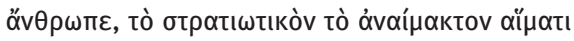

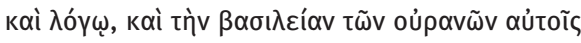

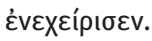

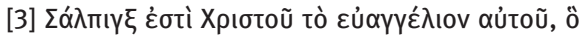

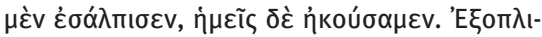

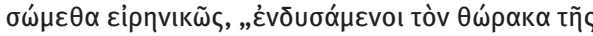

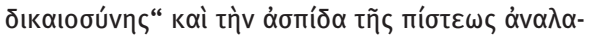

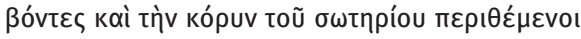

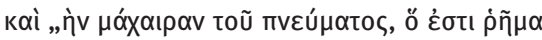

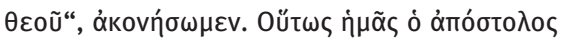

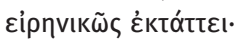

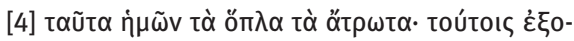

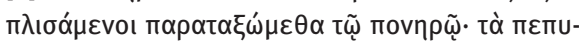

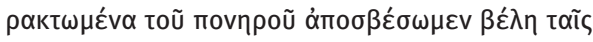

„[2] Aber wenn die laut schmetternde Trompete durch ihren Schall Krieger zusammenruft und Krieg verkündigt, sollte da Christus, wenn er sein Friedenslied, bis an die Enden der Erde' erschallen lässt, nicht seine friedfertigen Krieger versammeln? In der Tat, o Mensch, hat er sein Heer, das kein Blut vergießt, mit seinem Blut und Wort versammelt und ihnen das Königreich der Himmel anvertraut.

[3] Die Trompete Christi ist sein Evangelium; er hat die Trompete ertönen lassen, wir haben es gehört. Nun wollen wir uns mit den Waffen des Friedens rüsten, indem wir „den Panzer der Gerechtigkeit“ anlegen und den Schild des Glaubens ergreifen und den Helm des Heiles aufsetzen; und wir wollen „das Schwert des Geistes, welches das Wort Gottes ist", schärfen. So reiht uns der Apostel in das Friedensheer ein.

[4] Dies sind unsere unverwundbaren Waffen; mit diesen ausgerüstet, wollen wir uns zum Kampf gegen den Bösen aufstellen; die glühenden Geschosse des Bösen wollen wir mit unseren nassen

Gesetze und heilige Lehren, die in den Menschenherzen selbst eingeschrieben sind: ,Du sollst deinen Nächsten lieben wie dich selbst‘, und ,dem, der dich auf die Wange schlägt, biete auch die andere‘, und

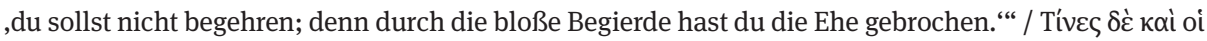

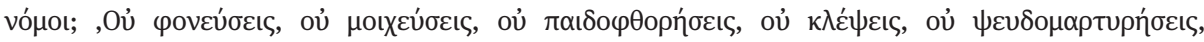

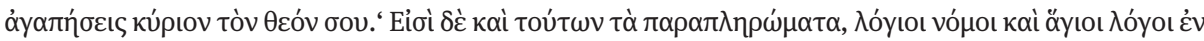

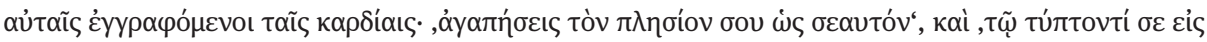

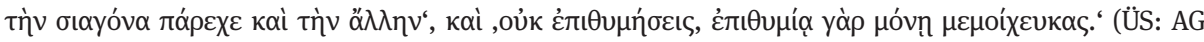
nach O. Stählin).Vgl. Hornus, Politische Entscheidung, 102; BAInTon, Early Church, 207 (= Kirche und Krieg, 209-210); RiESner, Militia Christi, 62. Siehe auch die Bezugnahmen des Clemens auf Mt 5,44-45 und Lk 6,27-31 in strom. 2,1,2,2; 4,14,95,1.

201 Scнöpf, Tötungsrecht, 221. Siehe das Zitat S. 246, Anm. 283. 


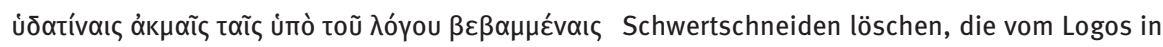
$[\ldots]$. Wasser getaucht sind [...].“

(ÜS: O. Stählin)

\section{Kontext}

Auch dieser Text aus der peroratio des Protrepticus wird mitunter angeführt, um den Pazifismus des Clemens zu erweisen. ${ }^{202}$ Clemens greift hier ein Thema aus der einleitenden narratio wieder auf, das des göttlichen Logos, also Christi, als des „einzigartigen Sänger[s] und Lehrer[s] der neuen Welt“203.

Im unmittelbaren Zusammenhang, der peroratio, erinnert Clemens an die Wohltaten Gottes von Anbeginn der Schöpfung ${ }^{204}$, ruft angesichts dieser erwiesenen Wohltaten zur Umkehr zu diesem Gott, die durch Christus ermöglicht wurde, und zur Annahme seiner Gesetze auf ${ }^{205}$. Gott will die Menschen retten und hat daher den Logos, Christus, gesandt, der die Wahrheit enthüllt, zur Umkehr ruft und Gerechtigkeit predigt. ${ }^{206}$ Dadurch sammelt er die Menschen, die zu ihm gehören.

\section{Interpretation}

Hier setzt der zu untersuchende Text ein. Im Unterschied zu den Göttern und Dämonen, gegen die Clemens ausführlich polemisiert hat ${ }^{207}$ und die für Gewalt und Bosheit verantwortlich sind ${ }^{208}$, sammelt der Logos durch die Verkündigung des Evangeliums, seines „Friedensliedes“209, sein Heer des Friedens. Dieses ist in Aufnahme eines Textes aus dem Epheserbrief ${ }^{210}$ ausgerüstet mit geistlichen Waffen des Friedens, die zum Kampf gegen eben diese Dämonen befähigen.

202 Bainton, Early Church, 196 (= Kirche und Krieg, 196); Bainton, Attitudes, 72; ShEAN, Soldiering, 101. Laut KARPP, Stellung, 507-508 mit Anm. 40, stellt dieser Text den Kriegsdienst des Christen unter das Friedensgebot. Ähnlich SIDER, Killing, 178-179, er gehöre zu den „implied prohibition[s] of Christian participation in the military" (ebd., 178).

203 Feulner, Clemens, 29.

204 Prot. 11,111-112.

205 Prot. 11,113-115.

206 Prot. 11,116,1.

207 Prot. 2,11-5,66; 10,89-92.

208 Prot. 3,42,1-9. Siehe dazu ausführlicher unten S. $236 \mathrm{ff}$.

209 Prot. 11,116,2: घipnvıкós (ÜS: O. Stählin).

210 Eph 6,11-17: „11 Zieht an die Waffenrüstung Gottes, damit ihr bestehen könnt gegen die listigen Anschläge des Teufels. 12 Denn wir haben nicht mit Fleisch und Blut zu kämpfen, sondern mit Mächtigen und Gewaltigen, nämlich mit den Herren der Welt, die in dieser Finsternis herrschen, mit den bösen Geistern unter dem Himmel. 13 Deshalb ergreift die Waffenrüstung Gottes, damit ihr an dem bösen Tag Widerstand leisten und alles überwinden und das Feld behalten könnt. 14 So steht nun fest, umgürtet an euren Lenden mit Wahrheit und angetan mit dem Panzer der Gerechtigkeit 15 und an den Beinen gestiefelt, bereit einzutreten für das Evangelium des Friedens. 16 Vor allen Dingen aber ergreift den Schild des Glaubens, mit dem ihr auslöschen könnt alle feurigen Pfeile des Bösen, 17 und nehmt 
Der vorliegende Abschnitt handelt zuerst von der Verkündigung des Evangeliums, durch die der göttliche Logos Menschen zu ihrer Errettung zusammenruft. Der Gegensatz, der hier aufgebaut wird, ist nicht der zwischen dem Friedensheer Christi einerseits und dem weltlichen Heer des römischen Kaisers andererseits, wie das bei Tertullian mehrmals sehr deutlich anklingt ${ }^{211}$. Vielmehr wird die Sammlung der Menschen zum Heil - in Zuspitzung des in prot. 11,113-115 ausgeführten - ihrem Leben unter der Herrschaft der heidnischen Götter und Dämonen, das zuvor kapitelweise in den dunkelsten Farben dargestellt wurde, entgegengestellt. Der Kontrast zwischen diesem Text und beispielsweise prot. 3,42,1-9 $9^{212}$ könnte stärker nicht sein! Menschen, die durch die Verkündigung des Evangeliums zum christlichen Glauben finden, werden in das Friedensheer Christi eingereiht. Damit werden sie der friedlosen Herrschaft der Dämonen entrissen. Dieser Kampf, durch den Menschen den Dämonen entrissen werden, ist aber ein geistlicher Kampf, der mit geistlichen Waffen ${ }^{213}$ und daher ohne Blutvergießen geschlagen wird. Gegründet wird dieser Kampf im Getauftsein des Christen, der Ansatz der Ethik ist also ähnlich wie bei Tertullian bei der Taufe zu suchen. ${ }^{214}$ Dies ist der Gegensatz, den Clemens aufstellt.

Indirekt wird daran aber auch deutlich, was in 3,42 expliziter ausgesagt wird: Gott steht tatsächlich auf der Seite des Friedens, Krieg und Gewalt kommen nicht von Gott, sondern - per implicationem - von den Dämonen. Daher werden auch die Verkündigung des Evangeliums und die daraus folgende Verbreitung des christlichen Glaubens den Frieden in der Welt fördern. ${ }^{215}$ Denn wo das Evangelium, das „Friedenslied“"216 Christi gehört und angenommen wird, werden die Dämonen beziehungsweise

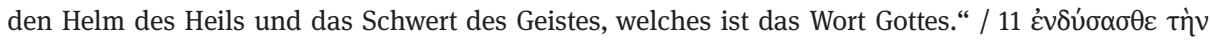

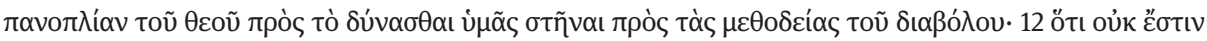

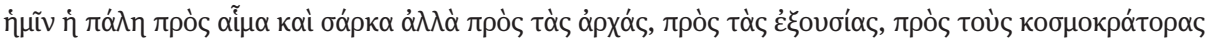

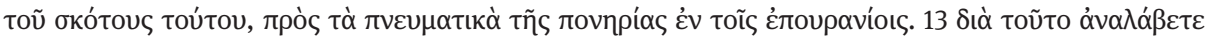

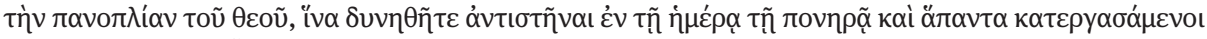

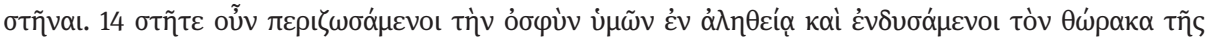

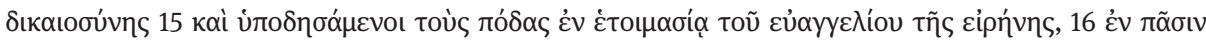

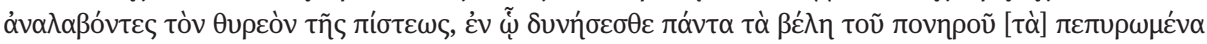

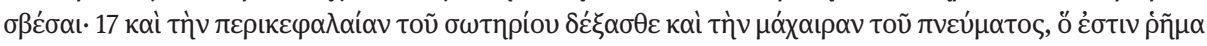

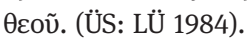

211 Vgl. Tert. idol. 19,2, wo er das sacramentum divinum dem sacramentum humanum, das signum Christi und das signum diaboli sowie das castra lucis dem castra tenebrarum gegenüberstellt; außerdem coron. 11,3. Siehe dazu oben S. $82 \mathrm{ff}$. und $127 \mathrm{ff}$.

212 Siehe dazu ausführlicher unten S. $236 \mathrm{ff}$.

213 Prot. 11,116,3-4. Zum Gedanken eines geistlichen Kampfes vgl. auch strom. 2,20,110,2-3. Auf diese Parallele macht auch HoRnus, Politische Entscheidung, 72-73, aufmerksam.

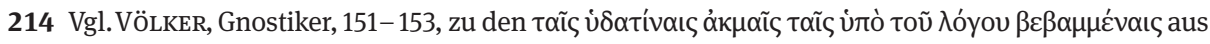
$11,116,4$.

215 RIESNER, Militia Christi, 62, sieht in dieser Förderung des Friedens durch die Verkündigung des Evangeliums zu Recht im Sinne des Clemens eine Aufgabe der Christen.

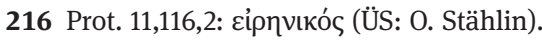


„der Böse“`217, die Streit und Krieg verursachen, in diesem geistlichen Kampf zurückgedrängt.

\section{Fazit}

Hier ist also durchaus eine indirekte, dabei aber keineswegs undeutliche Kritik an Krieg und Gewalt herauszuhören, die an anderer Stelle ${ }^{218}$ auch noch direkter wird. Diese Kritik am Krieg ist aber, auch darauf wurde bereits mehrfach hingewiesen, keinesfalls mit Pazifismus gleichzusetzen. Einen konkreten Beitrag zur Soldatenfrage leistet dieser Text angesichts der völlig anderen argumentativen Zielsetzung außerdem auch nicht.

\subsubsection{Paed. 2,4,42,1-3}

\section{Text}

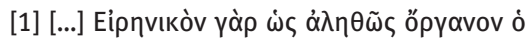
„[1] [...] Denn ein Friedensinstrument ist in Wahr-

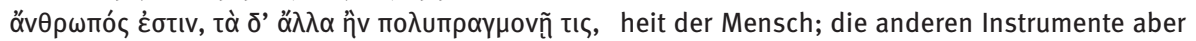

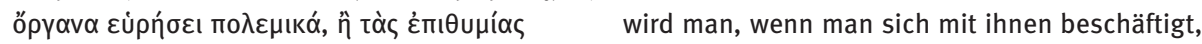

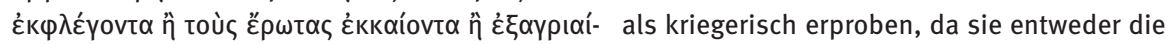
vovta toùs $\theta$ unoús. Begierden entflammen oder die Liebesleidenschaften entfachen oder den Zorn auflodern lassen.

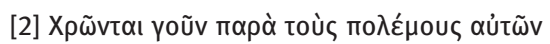
[2] So verwenden bei ihren Kriegen die Tyrrhener

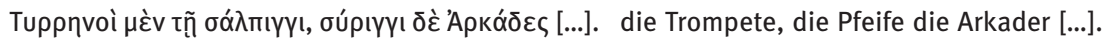

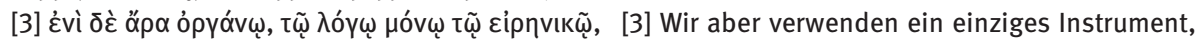

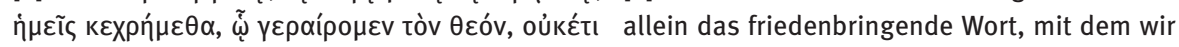

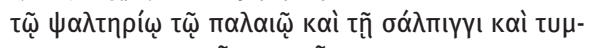

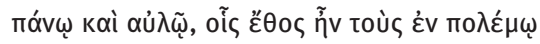
Gott preisen, nicht mehr wie ehedem die Harfe

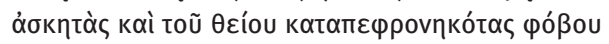
und die Posaune und die Pauke und die Flöte, die

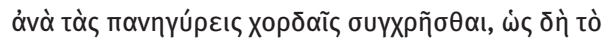

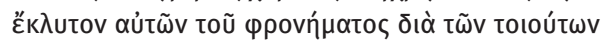

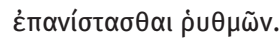
jene im Kriege geübten und die Furcht Gottes verachtenden Männer bei ihren Festversammlungen zu verwenden pflegten, auf dass ihr gesunkener Mut durch solcherlei Rhythmen wieder gehoben werde."

(ÜS: 0. Stählin)

\section{Kontext}

Dieser Text aus der confirmatio des Paedagogus ist ein weiteres Beispiel dafür, wie Clemens in einer „lockere[n], unpedantische[n] Weise“219 alltägliche Themen aus dem Leben seiner wohlhabenden Leserschaft abhandelt und dabei quasi im Vorbeigehen weitere Themen streift. Hier geht es um das dem Christen angemessene Verhalten bei

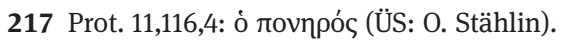

218 Siehe oben S. 229, Anm. 192.

219 Campenhausen, Griechische Kirchenväter, 35. 
Gastmählern. Auch dieser Text wird in der Forschung gelegentlich genannt, um die vorgeblich pazifistische Haltung des Clemens zu belegen. ${ }^{220}$

In paed. 2,4,40 - 44 wendet sich Clemens der Frage zu, wie man sich bei Gastmählern zu verhalten hat und welche Art der Unterhaltung dabei statthaft ist. ${ }^{221}$ Damit dürfte er vor allem bei den ersten Punkten primär die Veranstalter eines solchen Gastmahls ansprechen, die einen Einfluss auf die Ausrichtung der Veranstaltung haben. Wie man sich als Gast zu verhalten hat, wurde von ihm ja schon mehrfach thematisiert und wird auch in späteren Passagen dieses Kapitels nochmals angesprochen werden.

Clemens lehnt das Abhalten eines Umzugs und nächtlicher Feiern ab, diese hätten bei einem „vernünftigen Gastmahl“222 nichts zu suchen. Auch die dabei benutzten Flöten, Saiteninstrumente und andere Musikinstrumente müsse man von einem „nüchternen Gastmahl fernhalten“223. Denn man müsse sich vor allem unanständigem Sehen und Hören in Acht nehmen und dabei besonders vor Musik, die zu einem solchen Verhalten verführt. ${ }^{224}$ Es soll also bei den Gastmählern weder Musik noch Tanz geben, damit sich die Teilnehmer nicht zu unanständigem Verhalten hinreißen lassen.

Als Gegensatz zu einem solchen fragwürdigen Gastmahl erläutert Clemens daraufhin, wie eine angemessene Feier auszusehen hat, nämlich eine „Feierlichkeit zur Verehrung Gottes“225, die der Geist Gottes in einem Psalm erläutert. Dann erklärt er mit Zitaten aus dem alttestamentlichen Psalm 150, dass man Gott mit einer Posaune

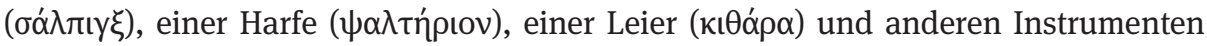
loben soll, allegorisiert im Folgenden diese aber Instrumente, so dass aus ihnen menschliche Körperteile werden, aus der Harfe die menschliche Zunge, aus der Leier der menschliche Mund usw., die dann das Gotteslob erklingen lassen. Mit anderen Worten, Gesang zur Ehre Gottes ohne Begleitung von Instrumenten ist gestattet. ${ }^{226}$ Diese Beschränkung auf den Gesang zum Lobe Gottes wiederholt er noch einmal mit anderen Beispielen und Erläuterungen in den folgenden Absätzen. ${ }^{227}$

220 So z.B. CADOux, Christian Attitude, 51 und 64; HoRnus, Politische Entscheidung, 89; BAINTON, Early Church, 196 (= Kirche und Krieg, 196). SIDER, Killing, 178-179, zählt diesen Text ebenfalls zu den „implied prohibition[s] of Christian participation in the military“ (ebd., 178).

221 Vgl. MüHLENKAmp, Heiden, 161.

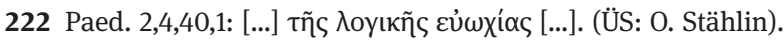

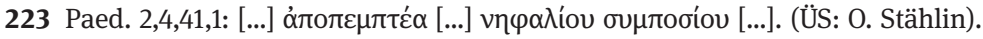

224 Paed. 2,4,41,3.

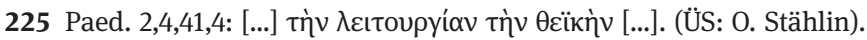

226 Vgl. MÜHLENKAMP, Heiden, 161.

227 Paed. 2,4,42-44. 


\section{Interpretation}

Unmittelbar nach der Erklärung, dass die erlaubten Instrumente Teile des Menschen sind, der zum Gotteslob aufgerufen ist, setzt dann der zu interpretierende Text ein. „Denn ein Friedensinstrument ist in Wahrheit der Mensch [...]“228. Dieses Friedensinstrument allein erregt im Gegensatz $\mathrm{zu}$ all den anderen Instrumenten nicht Leidenschaften, Begierden und Zorn. Die anderen sind nämlich „kriegerische Instrumente“229, für die er dann einige Beispiele anführt. Christen aber verwendeten als Instrument - bei ihren Gastmählern, so muss man ergänzen - ,allein das friedenbringende Wort“ ${ }^{\text {230, }}$, mit dem sie Gott loben, und nicht mehr die Instrumente kriegstüchtiger, aber Gott verachtender Männer.

Der Kontext allein macht bereits deutlich, dass Clemens bei diesen Worten keineswegs daran denkt, sich zur Erlaubtheit des Krieges oder gar des Soldatenberufs zu äußern. ${ }^{231}$ Die Gegenüberstellung zwischen dem Friedensinstrument der Christen und den kriegerischen Instrumenten der Heiden dient rhetorisch einem ganz anderen Zweck. Es geht darum, den Verzicht auf musikalische Begleitung der Feste einsichtig zu machen. Neben dem Zorn, den die Instrumente der Anderen auslösen, sowie neben deren kriegerischem Charakter stehen außerdem auch Begierde ( $\dot{\pi} \pi \theta u \mu i ́ \alpha)$ und leidenschaftliche Liebe ("

Clemens ruft einmal mehr zu einem Lebensstil auf, der einfach, anständig und nicht ausschweifend ist, das heißt letztlich, zu einem Lebensstil, der Gott zugewandt ist. Dieser Lebensstil soll sich auch in der Art Feste zu feiern ausdrücken. Dazu im Gegensatz stehen die Leidenschaft und der Krieg sowie die zu diesen gehörenden Instrumente.

An diesem Punkt setzt dann auch hier wieder eine indirekte Kritik am Krieg ein. Krieg und kriegerische Musik erregen die Leidenschaften und vertragen sich schlecht mit dem einfachen, auf Gott ausgerichteten Lebensstil.

\section{Fazit}

Hier zeigt sich erneut, dass Gott beziehungsweise sein Logos auf der Seite des Friedens stehen und sich auch das grundsätzliche Verhalten der Christen in der Gesellschaft daran orientiert beziehungsweise orientieren soll. Aber Pazifismus ist das nicht. Für die Klärung der Soldatenfrage allerdings dürfte auch diese indirekte Kritik nicht allzu

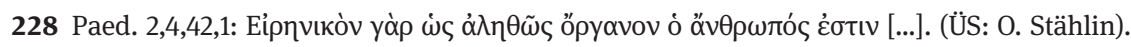

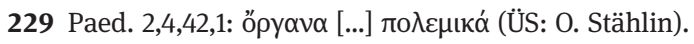

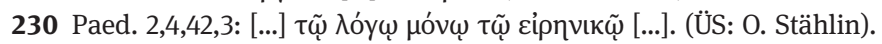

231 Auch hier ist v.a. HoRnus, Politische Entscheidung, 153, wieder anderer Meinung. Auch dieser Text (siehe oben S. 229, Anm. 191) zeigt s.E., dass Clemens sogar „die Vorbereitungen jeglicher Art, die für einen Krieg notwendig sind und zum Frieden und zur Liebe im Gegensatz stehen [verwirft]. Hierbei geht er so weit, daß er sich gegen die Art von Musik wendet, die ,den Kundigen des Krieges und Verächtern der Gottesfurcht‘ eigen ist.“ 
weit reichen. Wie dieser Text im Licht der grundsätzlichen Bejahung des Soldatenberufs für Christen zu verstehen ist, muss sich erst noch erweisen.

\subsubsection{Prot. $3,42,1$ \\ Text}

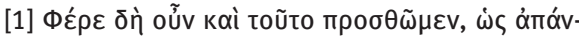

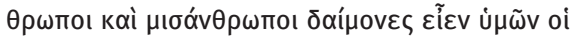

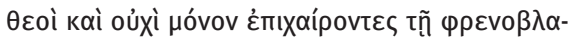

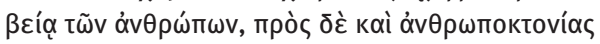

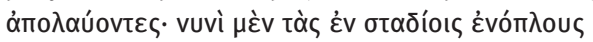

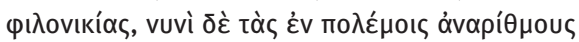

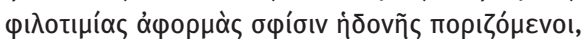

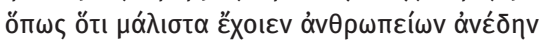

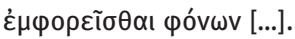

„[1] Nun wollen wir auch dies noch hinzufügen, wie unmenschlich und mit Hass gegen die Menschen erfüllte Dämonen eure Götter sind und wie sie sich nicht nur an der Verblendung der Menschen freuen, sondern sich auch am Menschenmord ergötzen: Bald machen sie sich die Waffenkämpfe in den Stadien, bald die unzähligen Kämpfe von Ruhmbegierde erfüllter Männer in den Kriegen zur Quelle ihres Vergnügens, damit sie wenn möglich bis zum Übermaß ihre Freude am Hinmorden von Menschen sättigen könnten [...].“ (ÜS: O. Stählin)

\section{Kontext}

Dieser Text aus der refutatio des Protrepticus wurde bereits berührt und gehört sicherlich zu den schärfsten und kritischen Passagen über Gewalt und Krieg im Werk des Clemens. Dementsprechend wird gerade dieser Text in der Forschung häufig herangezogen, um eine zumindest kritische, wenn nicht sogar ablehnende Haltung dem Krieg gegenüber zu begründen. ${ }^{232}$ Hier wird sich erweisen müssen, wie viel er zur Haltung des Clemens zur Soldatenfrage beitragen kann.

Die Passage ist ein Teil der refutatio ${ }^{233}$, in der es darum geht, den Gegner und die von ihm vorgebrachten Argumente zu widerlegen. Clemens stellt hier ausführlich dar, wie schlecht und unsinnig der Glaube an die Götter ist. Er entfaltet eine ausführliche Polemik gegen den heidnischen Götterglauben ${ }^{234}$, an deren Ende er meint gezeigt zu haben, dass diese Götter überhaupt keine echten Götter sind. Daraufhin fragt er, ob es vielleicht Dämonen seien, wenn es schon keine Götter sind, und lässt eine ebenso scharfe Polemik gegen die Dämonen folgen. ${ }^{235}$ In prot. 3,42,1-9 beginnt er dann damit,

232 Vgl. Schöpf, Tötungsrecht, 219; SwIFT, War (ANRW), 851; SwIFT, Views, 284; SHEAN, Soldiering, 101.

233 Zur refutatio siehe Cic. inv. 1,78-96, der hier allerdings den Begriff reprehensio verwendet; part. 12,44; Quint. inst. 5,12,1-23; vgl. MARTIN, Rhetorik, 95-97 und 124-133; FuHRMANN, Rhetorik, 87. Pointiert beschreibt Cicero (inv. 1,78) ihre Funktion: Reprehensio est, per quam argumentando adversariorum confirmatio diluitur aut infirmatur aut elevatur. / „Die Widerlegung ist das, wodurch mittels einer Beweisführung die Bekräftigung der Gegner unhaltbar gemacht, entkräftet oder abgeschwächt wird.“ (ÜS: Th. Nüßlein).

234 Prot. 2,26-39.

235 Prot. 2,40-3,45. 
die Unmenschlichkeit und den Hass der Dämonen gegen die Menschen aufzuzeigen und Beispiel um Beispiel für diesen Hass anzuführen.

\section{Interpretation}

Sein erstes Beispiel ist, dass die Dämonen Menschen zu Kämpfen und zum Krieg aufstacheln, um sich an der daraus folgenden Gewalt und dem daraus hervorgehenden Töten zu weiden. Dabei stehen die Gladiatorenkämpfe in der Arena und kriegerische Auseinandersetzungen Seite an Seite.

Auch wenn das eigentliche Thema des Abschnitts die Bosheit der als Dämonen entlarvten Götter ist, wird dadurch doch zugleich deutlich, dass für Clemens Kriege dämonischen Ursprungs sind und damit widergöttlich. Hier ist die Kritik am Krieg tatsächlich direkt, explizit und scharf. Dasselbe, nämlich dass sie widergöttlich sind, gilt auch für die weiteren Beispiele dämonischer Bösartigkeit wie Menschenopfer und Morde. ${ }^{236}$

Hier ist tatsächlich der erste Text, der die Frage nach der Vereinbarkeit von christlichem Bekenntnis und Soldatenstand in aller Schärfe aufbrechen lassen kann. Wenn Kriege nämlich dämonisch und widergöttlich sind, wie kann ein Christ, der doch sein Leben an Gott auszurichten hat, daran teilnehmen? Interessant ist dabei

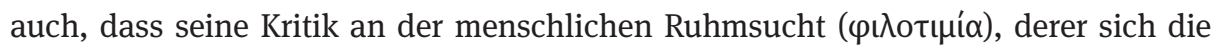
Dämonen bedienen, um Menschen zum Krieg anzustacheln, an Tertullians Kritik an der corona triumphalis ${ }^{237}$ denken lässt.

Auf der anderen Seite hat sich bereits gezeigt, dass die Polemik gegen Krieg und Gewalt kein Alleinstellungsmerkmal christlicher Autoren ist. Auch bei heidnischen Autoren dieser Zeit finden sich ähnlich scharfe Texte, ohne dass diese Autoren deshalb eine mögliche Beteiligung am Krieg grundsätzlich ablehnen würden. ${ }^{238}$ Gerade die zum Teil bittere Kritik an Kriegen, die aus Ruhmsucht und Gier geführt werden, verbindet den Text des Clemens mit einer reichen Tradition heidnischen Denkens. ${ }^{239}$ Er bedient sich hier eines bekannten Topos aus der Literatur seiner Zeit. Für Autoren wie Cicero gilt aber, dass Kritik an menschlicher Ruhmsucht und an Kriegen, die aus diesen Gründen geführt werden, keineswegs zur Ablehnung gerechtfertigter Kriege führt.

\section{Fazit}

Es ist zumindest $\mathrm{zu}$ fragen, ob Clemens mit seiner Kritik an der menschlichen Ruhmsucht und den um ihretwillen geführten Kriegen jede Form von Krieg katego-

236 Prot. 3,42,2-9.

237 Coron. 12,4; siehe oben S. $139 \mathrm{ff}$.

238 Siehe oben S. 142ff., wo u. a. die scharfe Kritik am Krieg bei Sen. epist. 95,30 - 31 angeführt ist. 239 Vgl. den Überblick bei Dawson, Origins, 133-135, der exemplarisch Cic. off. 1,8,26 und 1,22,74 anführt und auf weitere Texte verweist. Außerdem Sснӧрғ, Tötungsrecht, 198-202. 
risch ablehnt. Krieg mag für Clemens, wie für Cicero oder Senaca auch, ein Übel sein, die Frage ist aber, ob er in jedem Fall ein Unrecht ist. ${ }^{240}$ Auch ist zu bedenken, dass das eigentliche argumentative Ziel des Clemens nicht die Kritik am Krieg ist, sondern die Kritik an den Göttern der Heiden. Dazu greift er an dieser Stelle zu einem Topos, den er als bekannt und zumindest weitgehend akzeptiert voraussetzen kann, nämlich die (negativ gesehene) Verbindung von Ruhmsucht und Krieg und ihre Instrumentalisierung durch die Götter. Dennoch bleibt eine kritische Sichtweise des Krieges bestehen: Krieg - zumindest der aus Ruhmsucht geführte Krieg - ist für Clemens „ein großes Übel“241, nicht zuletzt weil die Dämonen als treibende Kräfte dahinter stehen.

\subsubsection{Die Kriege des Alten Testaments und mögliche Ansätze zu einer ,Lehre vom gerechten Krieg' \\ Einführung}

Die Frage, ob jede Art von Krieg für Clemens Unrecht und daher abzulehnen ist, führt $\mathrm{zu}$ einigen weiteren Texten, die zumindest kurz angesprochen werden müssen. ${ }^{242}$ Dabei handelt es sich zum einen um Texte, in denen sich Clemens den militärischen Leistungen des alttestamentlichen Gottesvolkes zuwendet, und zum anderen um Texte, die möglicherweise erste Ansätze zu einer (christlichen) ,Lehre vom gerechten Krieg' - hier v. a. unter dem Aspekt des ius in bello bzw. der iura belli, aber auch dem der iustae belli causae - erkennen lassen. Eine solche Lehre wurde von christlicher Seite ausführlich erst etwa zwei Jahrhunderte später von Augustinus unter Aufnahme der ciceronischen Idee eines bellum iustum ${ }^{243}$ mehr oder weniger systematisch formuliert. ${ }^{244}$ Da diese Überlegungen oft anhand von alttestamentlichen Texten angestellt werden, sollen diese ebenfalls im vorliegenden Abschnitt behandelt werden.

240 Vgl. ScHöpf, Tötungsrecht, 219-220.

241 ScнöpF, Tötungsrecht, 219.

242 Vgl. SwIFT, War (ANRW), 852, der die Spannung zwischen den kriegskritischen Texten bei Clemens und den hier zu besprechenden Stellen deutlich wahrnimmt.

243 Siehe z.B. Cic. off. 3,34-35; rep. 3,34-35 (Ziegler) / 3,24-26 (Powell). Vgl. dazu z. B. DAwson, Origins, 123-130; Noethlichs, s.v. Krieg (RAC), 42-43. Zum bellum iustum im Denken der Römer vgl. ALBERT, Sigrid, Bellum Iustum - Die Theorie des ,gerechten Krieges“ und ihre praktische Bedeutung für auswärtige Auseinandersetzungen Roms in republikanischer Zeit, (FAS 10), Kallmünz 1980, hier v. a. 12-36; Botermann, Helga, Ciceros Gedanken zum „gerechten Krieg“ in de officcis 1,34-40. In: AKG 69/1 (1987), 1-29; Keller, Voraussetzungen, 24-32; und Keller, Andrea, Cicero - Just War in Classical Antiquity. In: Justenhoven/Barbieri (Hrsg.), Just War, 9-29. Zu Ciceros Vorstellungen über die iura belli vgl. Botermann, Ciceros Gedanken, 10-15; Keller, Just War, 13-15 und 19. Zu den iustae belli causae vgl. z. B. ALBERT, Bellum Iustum, 17-18.

244 Siehe z. B. Civ. Dei 3,10; 4,15; 15,4; 19,7.12. Siehe dazu auch oben, S. 147 f. mit Belegen und Literatur. 


\section{Die Kriege des Alten Testaments}

Für dieses Thema sei exemplarisch auf strom. 1,24,158,1-26,170,4 hingewiesen ${ }^{245}$, wo am Beginn der Passage ein Lob des Mose ,als Prophet, als Gesetzgeber, als Schlachtordner, als Heerführer, als Staatsmann und als Philosoph“246 angeführt wird, von dem die Griechen ihr Handwerk in all diesen Gebieten erlernt hätten. ${ }^{247}$ In strom. 1,24,160,1-163,2 folgt dann eine ausführliche Diskussion der Qualitäten eines guten Heerführers. Mose dient dabei als Beispiel dieses guten Heerführers schlechthin, das von den Griechen - unter anderem von den berühmten Feldherren Miltiades, bei seinem Sieg über die Perser bei Marathon ${ }^{248}$, und Thrasybulos, der die Tyrannenherrschaft der Dreißig in Athen beendete ${ }^{249}$, - nachgeahmt wurde..$^{250}$

Dieser ungezwungene Umgang mit den militärischen Leistungen des alttestamentlichen Gottesvolkes steht in einem signifikanten Gegensatz zur diesbezüglichen

245 Man könnte hier auch auf strom. 2,18,82,1-3 hinweisen, wo Clemens das alttestamentliche Gebot aus den Kriegsgesetzen in Dtn 20 aufgreift, das besagt, dass ein Mann, der gerade ein Haus gebaut, einen Weinberg angelegt oder eine Frau geheiratet hat, vom Kriegsdienst befreit ist (Dtn 20,5-7).

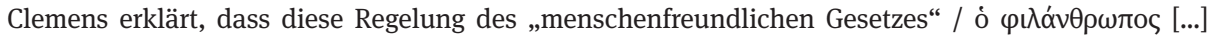

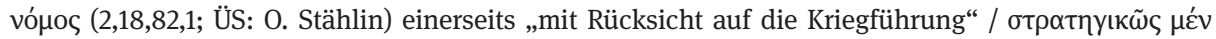
(2,18,82,2; ÜS: O. Stählin) getroffen wurde, andererseits aber auch aus „,freundlicher Rücksicht auf die Menschen“ / $\varphi \iota \lambda \alpha v \theta \rho \omega ́ \pi \omega \varsigma$ $\delta \varepsilon ́$ (2,18,82,3; ÜS: O. Stählin). Hier wird ebenfalls ein alttestamentliches Kriegsgesetz als vorbildliche ethische wie militärische Regelung verstanden. Clemens ist es nicht im Geringsten unangenehm, diese Anordnung auch mit militärischer Notwendigkeit bzw. Klugheit zu begründen. Vgl. dazu CAdoux, Christian Attitude, 232-233: „He quotes the Mosaic regulations in regard to the exemption of certain classes of men from military service [...] without any intimation that they would not be applicable to Christians.“ Wie dagegen Hornus, Politische Entscheidung, 123, diesen Text unkommentiert als Unterstützung für seine Position anführen kann ist mehr als unklar.

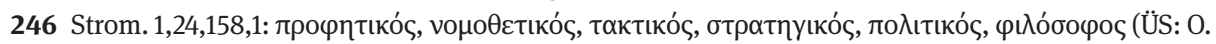
Stählin).

247 Vgl. Cadoux, Christian Attitude, 174 und 205-206; KaRpp, Stellung, 506-507; Schöpf, Tötungsrecht, 220; SwIFT, War (ANRW), 852; HELgELAND, Christians (ANRW), 745; RiesNER, Militia Christi, 55. HoRnus, Politische Entscheidung, 40, sieht hier dagegen nur einen Beleg für eine positive Einstellung dem ,Staat' gegenüber.

248 Clemens bezieht sich hier auf Ereignisse, die in Hdt. 6,107.109-115; Nep. Milt. 5,1-5, überliefert sind. Zu Miltiades vgl. KinZL, Konrad, s.v. Miltiades [2]. In: DNP 8, (2000), 192-193.

249 Hier verarbeitet Clemens Geschehnisse, die bei Xen. hell. 2,4,5-7; Nep. Thras. 2,1-5; Diod. 14,33 berichtet sind. Zu Thrasybulos vgl. SchmiTz, Winfried, s.v. Thrasybulos [3]. In: DNP 12/1, (2002), 493-494.

250 Im Kern geht es Clemens in dem langen Abschnitt über Mose (strom. 1,22,150,1-29,182,3) darum zu zeigen, dass die Weisheit der Juden - und damit die daraus hervorgegangene Weisheit der Christen älter ist als diejenige der griechischen Philosophie. Aus dem höheren Alter folgt im Denken der Zeit zugleich auch eine höhere Autorität und inhaltliche Überlegenheit. Dabei kann sich Clemens auf ältere jüdische Apologeten stützen, v.a. auf den großen Alexandriner Philo. Für den ,Altersbeweis‘ als apologetisches Argument vgl. Fiedrowicz, Apologie, 212-219. Zu Clemens und Philo, besonders zu hier genannten Stelle, vgl.van den Hoek, Annewies, Clement of Alexandria and His Use of Philo in the Stromateis - An Early Christian Reshaping of a Jewish Model, (Supplements to Vigiliae Christianae 3), Leiden 1988, hier v. a. 48 - 68; RuniA, David T., Philo in Early Christian Literature - A Survey, (Compendia rerum Iudaicarum ad Novum Testamentum 3), Assen 1993, 132-156, hier v.a. 139. 
Haltung des Tertullian und vor allem des Origenes. ${ }^{251}$ Ersterer gibt sich in idol. 19,2 größte Mühe, die Berufung seiner Gegner auf exempla aus dem Alten Testament zu entwerten. ${ }^{252}$ Letzterer bemüht sich sehr, die entsprechenden Geschichten, die ihm sehr unangenehm sind, zu allegorisieren oder sie ebenfalls heilsgeschichtlich $\mathrm{zu}$ entschärfen. ${ }^{253}$ Gerade der Kontrast zu dem Mit-Alexandriner Origenes ist mehr als auffällig. Dass Clemens hier den Mose in dieser Ungezwungenheit als Feldherren rühmen kann, ohne das Problem einer Beteiligung am Krieg auch nur anzusprechen, deutet stark darauf hin, dass er bei aller Kritik am Krieg diesen doch nicht kategorisch ablehnt - auch nicht für Christen, denen Mose doch noch mehr ein Vorbild ist als den Griechen. ${ }^{254}$

\section{Ansätze zu einer ,Lehre vom gerechten Krieg“}

Bei einigen Texten, vor allem solchen Texten, in denen Clemens auf die kriegerischen Verwicklungen des alttestamentlichen Gottesvolkes zu sprechen kommt, geht er sogar noch einen Schritt weiter. Hier stellt er Überlegungen an, die das Verhalten der Israeliten in bestimmten Situationen als gemäß dem Kriegsrecht (ius in bello bzw. iura belli) beziehungsweise grundsätzlich als gerecht und die Kriegsgründe als gerechtfertigt (iustae belli causae) erweisen sollen. Da diese Texte sehr verstreut stehen und nirgends systematisiert werden, kann nicht im eigentlichen Sinn von einer ,Lehre vom gerechten Krieg' gesprochen werden. Dennoch sagen dieses Texte etwas über seine mögliche Haltung zur Kriegführung aus und lassen sich möglicherweise zumindest als erste Ansätze zur Herausbildung einer solchen ,Lehre` deuten. ${ }^{255}$

So argumentiert er in strom. 1,23,157,2-4, dass die Mitnahme der erbeuteten Schätze der Ägypter im Rahmen des Auszugs aus Ägypten ${ }^{256}$ kein Akt der Habgier (

$251 \mathrm{Zu}$ beiden vgl. kurz die gute Diskussion bei BaInTon, Early Church, 121 (= Kirche und Krieg, 215 - 216), der aber über Clemens an dieser Stelle kein Wort verliert. Außerdem KARPP, Stellung, 507, zu Origenes, der den Gegensatz zu Clemens ausdrücklich herausstellt.

252 Siehe oben S. $90 \mathrm{ff}$.

253 Zum Umgang des Origenes mit diesen Texten siehe unten S. $327 \mathrm{ff}$. Damit soll nicht abgestritten werden, dass Clemens diesen Geschichten ebenfalls eine ,geistliche‘ Bedeutung beimisst.

254 Wie HoRnus, Politische Entscheidung, 57, mit Recht festhält, schreibt Clemens betont „unser

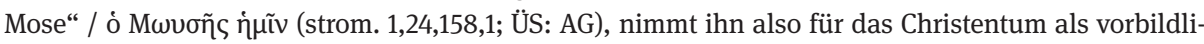
chen Propheten, Gesetzgeber, Schlachtordner, Heerführer, Staatsmann und Philosophen in Anspruch. Für SHEAN, Soldiering, 100 - 101, ist das dagegen einer der Gründe, warum er die Haltung des Clemens für „ambivalent“ (100) hält.

255 Vgl. zu den folgenden Überlegungen v.a. ScHöPf, Tötungsrecht, 219-220; und RIESNER, Militia Christi, 55-56.

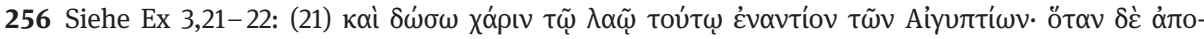

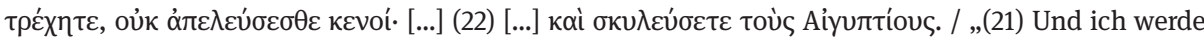
diesem Volk Ansehen vor den Ägyptern zuteilwerden lassen. Wenn ihr fortgeht, sollt ihr nicht leer ausgehen; [...] (22) [...]und ihr sollt die Ägypter ausplündern.“ (ÜS: LXX Deutsch); außerdem Ex 11,2; $12,35-36$. 


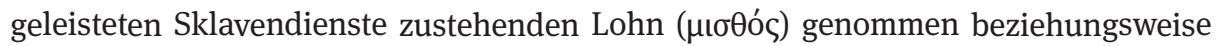

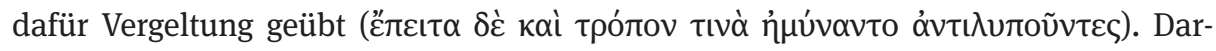
aufhin stellt er noch einmal ausführlicher die zwei Möglichkeiten zur Auswahl, wie man diese Ereignisse verstehen könnte. Die zweite Möglichkeit sei, es als ein Ge-

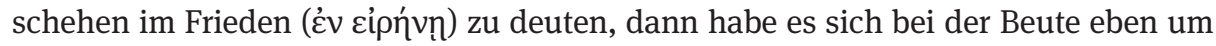
den gerechten Lohn gehandelt, der ihnen verweigert worden sei. Die erste Möglichkeit sei aber, anzunehmen, es habe sich um ein Geschehen im Krieg ( $\dot{\varepsilon} \nu \pi \circ \lambda \varepsilon \dot{\varepsilon} \mu)$ gehandelt. Dann „konnten sie sich nach dem Gesetz der Sieger für berechtigt halten, den Besitz der Feinde, als die Stärkeren den der Unterlegenen, mit sich fortzunehmen (und zum Krieg hatten sie einen gerechten Anlass [...]).“257. Es hätte sich dann also um

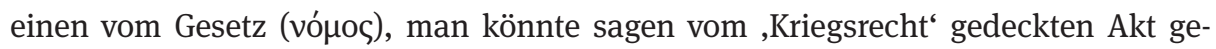
handelt, und das umso mehr, als der Anlass zu diesem Krieg, die Gewinnung der

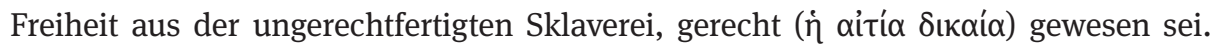
Clemens geht also davon aus, dass es einen gerechten Krieg im Sinne der iustae belli causae geben könnte, der dann seinerseits durch gewisse Regeln und Gesetze (iura belli) geordnet ist. ${ }^{258}$

In eine vergleichbare Richtung weist strom. 6,14,112,2, wo der Kampf gegen die Lust (†் dem Kampf der „Frontkämpfer“260 in einem Krieg um die Freiheit verglichen wird. Die Art des Vergleichs legt nahe, dass es sich in beiden Fällen um gerechtfertigte und damit gerechte Kämpfe im Sinne der iustae belli causae handelt. Es ist von daher bis zu einem gewissen Grad plausibel, diesen Text im Zusammenhang mit strom. 1,23,157,4 zu lesen und darin eine Bestätigung dafür zu sehen, dass Clemens einen Krieg um die Freiheit als einen gerechten Krieg betrachtet. ${ }^{261}$ Die Kürze der Bezugnahme und ihr gleichnishafter Charakter erlauben aber an dieser Stelle kein hohes Maß an Gewissheit über die Richtigkeit dieser Interpretation. Aus diesem Grund sollte man diesem Text kein allzu großes argumentatives Gewicht aufbürden.

In strom. 2,18,88,1-89,2 folgt ein weiterer Abschnitt, der in diesem Zusammenhang von Interesse ist. Clemens nimmt hier Regelungen aus den Kapiteln 20 und 21 des alttestamentlichen Buches Deuteronomium auf, die Verordnungen zur Kriegsführung für das alttestamentliche Bundesvolk (wieder im Sinne der iura belli) enthalten. ${ }^{262}$ Dabei wird von ihm im Rahmen der Behauptung, dass das Gebot Gottes eine

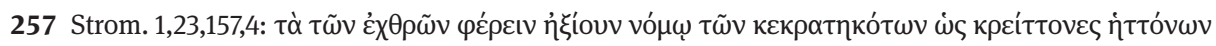

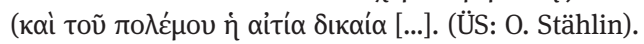

258 Vgl. ScHöPf, Tötungsrecht, 220.

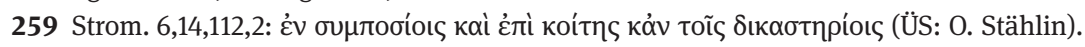

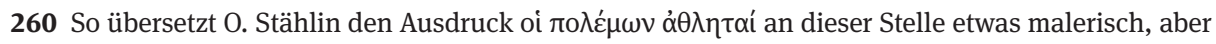
treffend (STÄHLIN, Strom. IV-VI (BKV), 313).

261 So Schöpf, Tötungsrecht, 220; RIESnER, Militia Christi, 55. Selbst Cadoux, Christian Attitude, 205-206; meint mit Blick auf diesen Text: „Some of his military illustrations are more than mere illustrations [...].“

262 Vgl. zur Stelle aus dem Deuteronomium RAD, Gerhard von, Das fünfte Buch Mose, (ATD 8), Göttingen 1964, 93-99; McConville, J. Gordon, Deuteronomy, (AOTC 5), Leicester 2002, 315-333. 
„Quelle des Lebens“263 sei, unter anderem die angemessene Weise, einen Krieg zu beginnen, sowie die korrekte Behandlung weiblicher Kriegsgefangener ${ }^{264}$ geregelt. Für ersteres bezieht er sich in strom. 2,18,88,3 auf Dtn 20,10, wo die folgende Regelung $\mathrm{zu}$ finden ist: Vor Beginn eines Krieges soll man den Feinden zuerst einen Boten schicken und ihnen Frieden bieten. Erst wenn diese den angebotenen Frieden ablehnen, dürfe man sie bekriegen. ${ }^{265}$ Für den zweiten Punkt greift Clemens in strom. 2,18,88,4 auf Dtn 21,10 - 14 zurück, wo die Vergewaltigung weiblicher Kriegsgefangener $^{266}$ verboten ist. Stattdessen sollen die gefangenen Frauen, für den Fall, dass ein

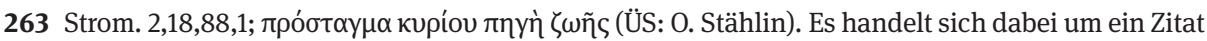

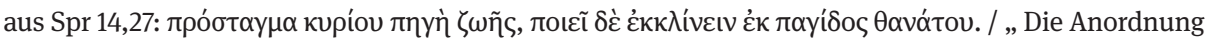
des Herrn ist eine Quelle des Lebens, sie lässt ausweichen vor der Falle des Todes.“ (ÜS: LXX Deutsch). 264 Zur Möglichkeit weiblicher Kriegsgefangener innerhalb der Vorstellungen des Buches Deuteronomium siehe Dtn 20,14.

265 In Dtn 20,10 heißt es allerdings nach der LXX (Text nach Septuaginta - Id est Vetus Testamentum graece iuxta LXX interpretes, edidit Alfred RAHLFS; Robert HANHART, 2. Aufl., Stuttgart 2006): 'Eàv $\delta \dot{\varepsilon}$

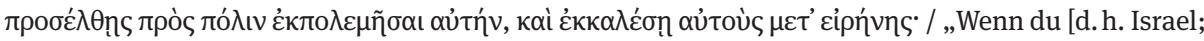
AG] dich aber einer Stadt näherst, um sie zu bekriegen, dann sollst du sie mit einem Friedensangebot herauslocken.“ (ÜS: LXX Deutsch). Auch der Masoretische Text, wie er u. a. der LÜ 1984 zugrunde liegt, liest gleichlautend: „Wenn du vor eine Stadt ziehst, um gegen sie zu kämpfen, sollst du ihr zuerst

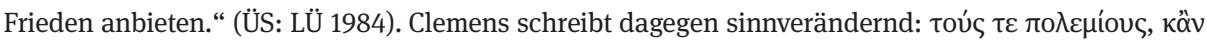

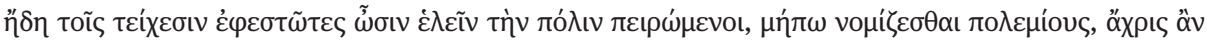

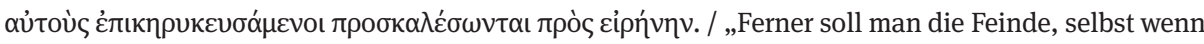
sie schon an den Mauern stehen und die Stadt zu erobern versuchen, noch nicht für Feinde halten, bevor man nicht Herolde an sie abgesandt und sie zum Frieden aufgefordert hat.“ (ÜS: O. Stählin). Die Fassung des Clemens könnte durch eine (missverstandene?) Übernahme aus Philo von Alexandria zu erklären sein, der diese alttestamentliche Verordnung in De virtutibus 109 ebenfalls frei paraphrasiert. Zwischen den beiden Paraphrasen gibt es zahlreiche sprachliche Parallelen, die eine solche Übernahme nahelegen. Zum Verhältnis zwischen Clemens und Philo vgl. kurz van DEN HoEK, How Alexandrian, hier v. a. 185-190; dies., Annewies, Techniques of Quotation in Clement of Alexandria - A View of Ancient Literary Working Methods. In: VigChr 50/3 (1996), 223-243, hier 231-237, mit weiterer Literatur. Ausführlich behandelt wird die Frage nach dem Verhältnis der beiden großen Alexandriner bei vaN DEN HoEK, Clement; und außerdem bei Runia, Philo, 132-156.

266 Strom. 2,18,88,4: „Weiter verbietet das Gesetz auch, einer Kriegsgefangenen Schande anzutun

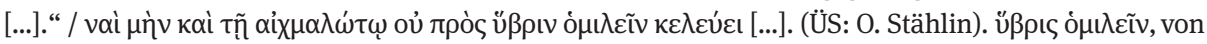
O. Stählin als „Schande antun“ übersetzt, nimmt hier die auch anderweitig gut belegte Bedeutung von „vergewaltigen“ an; vgl. LSJ, s.v. ǔßpıৎ A II.2, 1841. Vgl. dazu von RAD, 5. Mose, 98: „Auch diese Bestimmung ist von einem humanen Motiv getragen. Auch eine Kriegsgefangene darf nicht missbraucht werden; das Verhältnis zu ihr muß ein legales werden. Wird es gelöst, so darf die Frau in ihrem sozialen Stand, den sie inzwischen erhalten hat, nicht beeinträchtigt werden [...].“ McConville, Deuteronomy, 329 hält ebenfalls fest, dass „,...] the main concern of the law is that the captive should be treated with

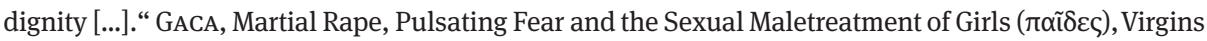

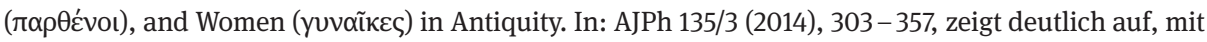
welcher Brutalität durch die Antike hindurch „populace-ravaging warfare against underage girls, virgin-aged girls, and women“ (ebd., 303) betrieben wurde. Wie sie weiter festhält (ebd., 306), „martial heterosexual rape was [...] a top-down part of the orders given and was integral to ravaging warfare, not a ,boys will be boys' accompaniment to war. Ancient historians, further, recognize that martial sexual aggression against girls and women was integral to warfare [...]. 
Israelit Gefallen an einer von ihnen gefunden hat, nach einer Trauerzeit von 30 Tagen in ordentlicher Weise geehelicht werden. Auch hier wie in der im Folgenden zu behandelnden Stelle strom. 2,18,95,1 greift Clemens in positiver Weise alttestamentliche Regelungen zur Begrenzung des Krieges und seiner Schrecken auf. Es handelt sich dabei um Regelungen, die er auch in seiner Zeit als gut und normativ ansieht und in denen er eine Verbindung von „Menschlichkeit mit Enthaltsamkeit“267 entdeckt, die ihm Zeichen der Güte Gottes sind. Dabei setzt er selbstverständlich voraus, dass diese Verordnungen auch für das Volk Gottes seiner eigenen Zeit noch immer Quelle des Lebens, und das heißt auch, noch immer in gewisser Weise gültige Norm sind. Selbst J. Cadoux, der sich um eine pazifistische Interpretation der vorkonstantinischen Zeit und damit auch des Clemens bemüht, meint zu der erstgenannten Stelle: „He [d.h. Clemens; AG] quotes the Mosaic regulations [...] without any intimation that they would not be applicable to Christians.“268

Als letztes ist noch auf strom. 2,18,95,1 hinzuweisen. Es handelt sich um ein aus Dtn 20,19-20269 entnommenes Verbot der Verheerung des Landes und vor allem des Fällens von Bäumen mit essbaren Früchten bei der Belagerung einer Stadt. Dabei handelt es sich um eine Diskussion, die auch in der Literatur der griechischen und der römischen Welt geführt wird. So galt es zwar allgemein als erlaubt, die jährliche Getreideernte zu verwüsten, ob man aber auch früchtetragende Bäume zerstören durfte, die nicht innerhalb eines Jahres nachwuchsen, war umstritten. ${ }^{270}$ Nach Clemens ist es ein Zeichen der Güte Gottes, dass er in seinem Gesetz eine solche Regelung erlässt, die der Kriegführung Grenzen setzt. ${ }^{271}$ Wie B. Schöpf zu den beiden zuletzt angeführten

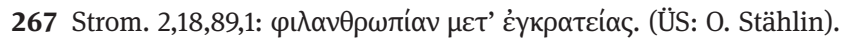

268 Cadoux, Christian Attitude, 232-233. Das Zitat bezieht sich auf diesen Text und auf strom. 2,18,82,1-3, eine Passage, die bereits oben S. 239, Anm. 245 kurz angesprochen wurde. Dagegen behandelt HoRnus, Politische Entscheidung, 110 mit Anm. 102, diese Texte ausschließlich unter dem Aspekt der darin gebotenen Nächstenliebe und Wertschätzung des menschlichen Lebens. Die Implikationen für die Einschätzung des Krieges durch Clemens scheint er vollkommen zu übersehen. Zumindest kommt er mit keinem Wort darauf zu sprechen.

269 Clemens bezieht sich bei der Begründung dieses Verbots explizit auf „das gütige Gotteswort“, das

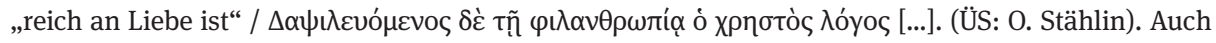
frühjüdische Autoren wie Philo von Alexandria (spec. leg. 4,226-229) und Flavius Josephus (ant. 4,8,42/299) nehmen auf diesen Text aus dem Alten Testament Bezug.

270 Siehe z. B. Pol. 23,15. Vgl. Grant, War, 179-180. Siehe auch von Rad, 5. Mose, 95; McConville, Deuteronomy, 321-322.

271 Der gesamte Abschnitt, in dem sich der besprochene Text findet, steht unter der Frage aus strom. 2,18,91,1: „Ist nunmehr wohl klar geworden, dass das Gesetz, das auf Christus hin erzieht, freundlich und gut und dass ein und derselbe Gott gut und zugleich auch gerecht ist, Gott, der von Anfang bis zum Ende jegliche Art (der Erziehung) den Umständen entsprechend zur Herbeiführung des Heils ver-

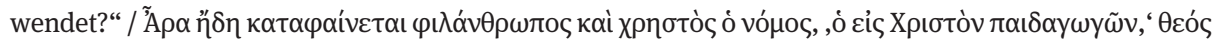

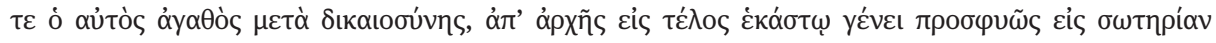

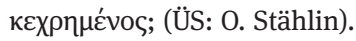


Texten zusammenfassend mit Recht festhält: „Es handelt sich hier zwar um alttestamentliche Vorschriften, aber um solche, die Klemens innerlich bejaht.“272

\subsection{Zusammenfassende Überlegungen zur Haltung des Clemens}

\subsubsection{Zu den ,Soldatentexten'}

Wenn es im Folgenden darum geht, die bisherigen Ergebnisse zusammenzufassen und die Frage nach der Haltung des Clemens zur Soldatenfrage zu stellen, so ist zuerst festzuhalten, dass den Texten Priorität zu geben ist, die sich explizit mit dem Soldatenberuf befassen. Diese Texte sind sehr direkt, eindeutig und zeigen, dass Clemens keine Schwierigkeiten mit der Vorstellung hatte, dass Christen im Heer dienen. ${ }^{273}$ Das gilt, wie prot. 10,100,4 gezeigt hat, auf jeden Fall für Soldaten, die erst während ihres Dienstes zum Christentum fanden. Nach Clemens können sie selbstverständlich in ihrem Beruf verbleiben, haben sich aber - wie alle anderen Christen auch - bei der Ausübung ihres Berufs auf Gott hin auszurichten und sich an dessen Willen zu orientieren. Diese Haltung findet sich übereinstimmend sowohl im nach außen gerichteten, für den christlichen Glauben werbenden Protrepticus als auch im Paedagogus, der in die Gemeinde hinein gerichtet ist und angemessene christliche Lebensführung lehren soll. Die Übereinstimmung zwischen den beiden unterschiedlich ausgerichteten Schriften ist ein sehr überzeugender Hinweis auf das Vorhandensein einer stimmigen Position bei Clemens und steht in einem deutlichen Gegensatz zum spannungsvollen Verhältnis der nach außen und nach innen gerichteten Schriften bei Tertullian.

Schwieriger zu beantworten als die Frage nach Konvertiten im Heeresdienst ist die, was Clemens über Christen gedacht haben mag, die sich als Getaufte freiwillig zum Heeresdienst melden wollten oder gemeldet haben. ${ }^{274}$ Leider findet sich diese Unterscheidung anders als bei Tertullian nirgends im Werk des Clemens. Zieht man einen Text wie paed. 3,12,91,1-4 aus der peroratio des Paedagogus heran, wo Clemens in den Worten A. Knaubers einen „Christenspiegel“275 mit den „Hauptlehren des

272 Schöpf, Tötungsrecht, 220. Dagegen hält BAInTon, Early Church, 211 (= Kirche und Krieg, 214), diese Texte für einen Ausdruck der Anerkennung von „different ethical levels“.

273 Dagegen folgert HoRnus, Politische Entscheidung, 123-124, aus prot. 10,100,4, paed. 2,11,117,2; 3,12,91,2; und stromt. 2,18,82,1-3, „daß Clemens den Militärdienst als eine Tatsache in dieser Welt hinnimmt, ihn jedoch nicht als Entscheidung eines Christen billigt.“ Es wurde bereits bei der Interpretation der jeweiligen Texte darauf hingewiesen, dass sich diese Interpretation nur schwer halten lässt.

274 Den ersten sicheren Beleg für als Christen geborene Soldaten dürfte wie bereits erwähnt Cypr. epist. 39,3 bieten, für Tert. idol. 19,1 und coron. 11,4 besteht zumindest die Möglichkeit, dass sie diesen Fall voraussetzen. Siehe dazu oben S. $77 \mathrm{f}$.

275 Knauber, Handbuch, 331. 
Heils“276 bietet, so scheint es wahrscheinlicher, dass er wohl auch damit zumindest grundsätzlich einverstanden gewesen wäre. ${ }^{277}$ Auch paed. 2,11,117,1-3 dürfte durch die Beiläufigkeit, mit der das Thema für Katechumenen und neugetaufte Christen angesprochen wird, in diese Richtung weisen. Gerade der betont ethische Charakter des Paedagogus, der ja gerade zu einem dem göttlichen Logos gemäßen Lebensstil anleiten will ${ }^{278}$, lässt es unwahrscheinlich erscheinen, dass Clemens, hätte er den Soldatenberuf wirklich für unvereinbar oder auch nur eingeschränkt vereinbar mit dem christlichen Glauben gehalten, dieses an den betreffenden Stellen nicht festgehalten hätte. ${ }^{279}$ Auf der anderen Seite lässt sich zumindest fragen, ob Clemens auch seinem idealen Christen, dem (wahren) Gnostiker, einen solchen Schritt gestattet hätte. Clemens unterscheidet ja durchaus verschiedene Stufen des Christseins und es ist dieser Gnostiker, der am intensivsten nach Ähnlichkeit mit Gott streben soll und dem die eindringlichsten Mahnungen zu einem Leben in Frieden, Liebe, Apathie und Ataraxie gelten. ${ }^{280}$ Ein Maß an Sicherheit, das der positiven Antwort auf die Frage nach im Heer zum Christentum konvertierten Soldaten entspricht, kann für die Beantwortung der Frage nach Christen, die sich dem Heeresdienst zuwandten, nicht gewonnen werden. Hier setzen die vorliegenden Texte engere Grenzen, die es zu respektieren gilt.

Es ist außerdem wichtig festzuhalten, dass Clemens den christlichen Soldaten Grenzen auferlegt. Er bindet sie nämlich an Christus, den „Feldherrn, der gerechte Signale geben lässt" ${ }^{\text {281 }}$, und fordert somit die bereits angesprochene Ausrichtung des Lebens und des Dienstes am Willen Gottes. ${ }^{282}$ Wie das in einem Fall konkret aussehen kann, zeigt der Abschnitt paed. 3,12,91,2. Dort schreibt er christlichen Soldaten vor, sich mit ihrem Lohn zu begnügen und Menschen nicht auszubeuten, indem er ihnen

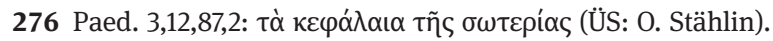

277 Vgl. auch HELGELAND, Christians (ANRW), 744: „Clement never gave the slightest indication that enlistment would be a problem nor did the nature of military life, religious or moral concern him. On the contrary [...].“

278 Vgl.Wyrwa, Clemens, 940: „Das Kriterium ethischen Handelns ist Clemens zufolge der Logos [...]. [...] Aber Clemens versteht unter diesem Logos fast stets zugleich den personal qualifizierten LogosChristus, welcher Urheber jeglicher Gestalt des göttlichen Gesetzes ist, so dass das ethische Handeln sich zugleich als Gehorsam gegenüber dem Willen Gottes [...] erweist.“

279 So auch dezidiert Helgeland, Christians (ANRW), 745.

280 Siehe z. B. strom. 2,11,50,2; 2,19,97,1-2; 3,10,69,3; 4,7,54,1; 4,7,55,1-4; 4,15,97,1-5; 4,16,100,6. Vgl. dazu VöLKER, Gnostiker, hier v. a. 220-230, 254-300 und 449-609. W. Völker schreibt treffend über die Tugendvorstellung des Clemens (ebd., 288): „Es gibt daher keinen plötzlichen Aufstieg zur Vollkommenheit, sondern nur ein langsames fortschreiten, das sich Schritt für Schritt erkämpfen muß.“ Siehe außerdem kurz MÉHAT, s.v. Clemens (TRE), 110; NeymEYR, Lehrer, 73-79; KöNIG, Clemens, 155-160; außerdem WYrwA, Clemens, 941-942, zur zweistufigen Ethik des Clemens (einfacher Gläubiger - vollkommener Gnostiker) und zur Vervollkommnung des Gnostikers als einem lebenslangen Prozess.

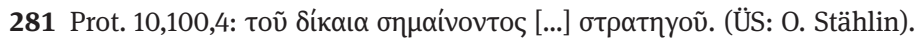

282 Es sei auch noch einmal an den Grundsatz von strom. 7,7,42,7 erinnert, der hier auch eine Rolle spielen könnte. Siehe dazu oben S. 211, Anm. 90. 
mit den Worten des Johannes des Täufers ein Gebot des göttlichen Logos vor Augen führt.

\subsubsection{Zu den ,Kriegstexten“}

Die Texte, die sich auf die eine oder andere Weise mit dem Thema Krieg befassen - die kritischen wie die positiven - sind den zuerst genannten Texten im Blick auf die hier behandelte Fragestellung unterzuordnen. Sie helfen aber dabei auszuloten, welche Aufgaben in den Augen des Clemens für christliche Soldaten vorstellbar waren beziehungsweise wo eventuell die Grenzen der affirmativen ,Soldatentexte' liegen. Sie können aber auch die Frage aufwerfen, ob sich für Clemens eigentlich ein stimmiges Gesamtbild zeichnen lässt.

So ist zu fragen, ob er überhaupt einen Zusammenhang zwischen seiner Haltung zum Krieg und der Frage nach der Erlaubtheit des Soldatenberufs herstellt. ${ }^{283}$ Ist es für Clemens vorstellbar, dass Christen sich an kriegerischen Handlungen beteiligen? Bezieht man diese Texte in die Überlegungen mit ein, so kann man festhalten, dass bei aller Bejahung der Möglichkeit des Soldatendienstes für Christen - Krieg für Clemens sicherlich ein großes Übel ist. Krieg ist, zumindest in bestimmten Fällen, von Dämonen angestiftet, er verursacht Leiden unter den Menschen und er soll durch die Verkündigung des Evangeliums überwunden werden. ${ }^{284}$

Aber Krieg gilt dennoch, wie B. Schöpf festhält, „nicht in jedem Fall als Unrecht“285. Unter gewissen Umständen scheint Clemens Krieg für gerechtfertigt (im Sinne der iustae belli causae) und in gewissen Grenzen für rechtmäßig (im Sinne der iura belli) zu halten. ${ }^{286}$ Diese Grenzen loten die Texte aus den Stromata, in denen einige erste Grundzüge einer ,Lehre vom gerechten Krieg‘ erkennbar sind, zumindest ansatzweise aus. Es gibt für Clemens aus dem Alten Testament entnommene Regeln, welche die Kriegsführung begrenzen und damit auch den Handlungsspielraum und die Gehorsamspflicht christlicher Soldaten. „Krieg ist“, mit B. Schöpf, „für Klemens von Alexandrien keineswegs ein Zustand völliger Gesetzlosigkeit, wo alle Gräuel erlaubt wären [...].“287 Ist Krieg dementsprechend eine unter bestimmten Umständen

283 Vgl. Helgeland, Christians (ANRW), 764, mit Blick auf Kirchenväter allgemein; Swift, War (ANRW), 852; und SwIFT, Views, 284, zu Clemens im Besonderen. Beide verneinen, dass dieser Zusammenhang bereits im Blick war. Konkret zu Clemens siehe auch unten S. 250 f. Dagegen scheint SсHӧрF, Tötungsrecht, 221, davon auszugehen, dass Clemens sich über diesen Zusammenhang Gedanken gemacht haben muss und kann festhalten: „Wenn Krieg und Mord identisch wären, Soldaten und Mörder, könnte Clemens offenbar nicht so reden.“

284 So hält auch RiESnER, Militia Christi, 62 fest, dass Clemens Krieg keinesfalls verklärt. Ähnlich äußerten sich auch schon Moffat, War, 621, Anm. *; und Campenhausen, Kriegsdienst, 257.

285 SchöPf, Tötungsrecht, 219.

286 Trifft diese Interpretation zu, gäbe es an dieser Stelle eine enge inhaltliche Berührung zwischen Clemens und Augustinus. Siehe zu letzterem oben S. $147 \mathrm{f}$.

287 SchöPF, Tötungsrecht, 220. 
ethisch legitime Option, so kann auch der Soldatenberuf dem Christen nicht grundsätzlich verboten sein. Mit B. Schöpf kann man zusammenfassend festhalten:

„Klemens von Alexandrien sieht also im Krieg ein gewaltiges physisches Übel, rechnet aber trotzdem auch mit der Möglichkeit gerechter Kriege. Unter dieser Voraussetzung kann er den Soldatenstand nicht grundsätzlich ablehnen. Von den christlichen Soldaten verlangt er mit keinem Wort, daß sie ihren Dienst verlassen; daraus kann man schließen, daß er nicht jede Tötung in der Schlacht als Sünde betrachtet." ${ }^{\text {288 }}$

Somit bestätigen die Texte, die sich in der einen oder anderen Weise mit dem Thema Krieg befassen, im Wesentlichen die Ergebnisse der Interpretation der ,Soldatentexte‘. Es lässt sich also ein in Grundzügen kohärentes Bild von der Position des Clemens entwerfen, wenn sich auch nicht alle Details mit gleicher Sicherheit klären lassen.

\subsubsection{Kritische Anfragen an die Forschung}

Die in diesem Kapitel vertretene Position steht in explizitem Widerspruch zu Teilen der modernen Forschung. Daher muss an dieser Stelle auf die entsprechenden Autoren und ihre Positionen kurz eingegangen werden.

1. R. Bainton ${ }^{289}$ meint im Anschluss an Überlegungen von J. Cadoux ${ }^{290}$, dass Clemens nur den ,Polizeidienst“ (beispielsweise als Mitglied einer Einheit der vigiles oder als ein beneficiarius, hier denkt er wahrscheinlich an den beneficiarius

288 SснӧрF, Tötungsrecht, 221; siehe auch das Zitat zur Frage von Mord und Krieg oben Anm. 283. Ähnlich auch SwIFT, War (ANRW), 852: „Thus, although it is accurate to say that in Clement's mind the issue of war and pacifism as such was never joined, he did not consider as sinful every act of homicide including that on the battlefield [...]“. Dagegen meint er in einem späteren Aufsatz (SwIFT, Views, 284), dass ,the moral issue of Christian participation in violent action seems not to have been seriously joined in his mind." Dass Clemens die Tötung eines Menschen unter bestimmten Umständen für legitim hält, zeigt auch seine Haltung zur Todestrafe, die er bejaht und in ihrer Rechtmäßigkeit zu begründen versucht. Vgl. dazu SснӧPF, Tötungsrecht, 156-158.

289 Bainton, Early Church, 199-200 (= Kirche und Krieg, 200): „He is saying that if a soldier is converted while in the army he may remain, but he becomes subject to a divine commander. While there is no express statement that police functions only are permissible, such an in terpretation harmonizes this passage with those from Clement in which warfare is condemned." Ebenso BaINTon, Attitudes, 79-81, wo er ausführlichere Überlegungen zur Polizeithese anstellt - zu Clemens v. a. 81. Ohne direkten Bezug auf Clemens verteidigt J. Yoder die These, Christen im Heer hätten nur Polizei- und Verwaltungstätigkeiten übernommen, erneut vehement; vgl. Yoder, Pacifism, 50; YodER, War, 99-100; „During the epoch which understood itself as pax Romana, even battle-ready units seldom saw battle. Most of the time, what most of the people under military authority did was what we would call peacetime civil bureaucracy. “ Dagegen vgl. besonders die treffende Kritik von HELGELAND, Christians (ANRW), 793-795; und von SHEAN, Soldiering, 76.

290 CAdoux, Christian Attitude, 15-16, der dort allerdings allgemeine Überlegungen zu frühchristlichen Schriftstellern insgesamt anstellt. 
consularis $^{291}$ ) zulassen will, obwohl er eingesteht, dass Clemens das nirgendwo explizit schreibt. Mit dieser These will vor allem R. Bainton das Problem lösen, dass seiner Meinung nach Clemens in seiner Haltung „less precise“292 sei. So gestatte er zwar, dass während ihres Militärdienstes zum Christentum konvertierte Soldaten im Heer verbleiben ${ }^{293}$, andererseits vertrete er aber mit Blick auf Krieg und Gewalt eine pazifistische Position ${ }^{294}$.

Da sich die von ihm angenommene pazifistische Haltung als nicht den Texten entsprechend erwiesen hat und somit zu verwerfen ist, stellt sich das Problem nicht, das zu dieser Lösung zwang. Außerdem würde diese ,Lösung“ die Schwierigkeit mit der Gewaltanwendung nicht aus der Welt schaffen. Gerade im ,Polizeidienst‘ eingesetzte Soldaten hatten in Friedenszeiten unter Umständen öfter Gewalt anzuwenden und ihr Schwert zu ziehen, als ihre Kameraden in den Legionslagern. ${ }^{295}$ So fasst R. Alston einen Überblick über die Verwendung des ägyptischen Heeres im Inneren zusammen:

„Indeed for the average Roman soldier fighting street battles against mobs, even lightly armed robbers, or fighting guerrilla wars against rebels might have been considerably more dangerous than fighting set-piece battles.“296

Und J. Helgeland hält nach seinem kritischen Überblick über die ,Polizeithese‘ abschließend fest:

„The distinction between civil and military preservation of order is largely a modern, not a Roman one. Acting in various capacities, the soldiers did most of the policing of the empire. Capturing terrorists, investigating criminal activity, finding missing persons, questioning suspects (torture), raiding houses in search of weapons unlawfully possessed, collecting tariffs and tolls, and spying, were the duties which concerned many Roman soldiers acting as police.“297

291 Siehe oben S. 169f. mit Anm. 679, für eine kurze Auseinandersetzung mit der mittlerweile überholten These, dass eine Hauptaufgabe der beneficiarii consularis die Übernahme von Polizeiaufgaben gewesen sei. Dieser These folgt auch R. Bainton.

292 Bainton, Early Church, 196 (= Kirche und Krieg, 195); vgl. auch Bainton, Attitudes, 72.

293 Bainton, Early Church, 199-200 (= Kirche und Krieg, 199-200); Bainton, Attitudes, 80.

294 Bainton, Early Church, 196, (= Kirche und Krieg, 195-196), wo er die Haltung des Clemens zu den „condemnations more or less explicit of military service“ rechnet.

295 Darauf macht bereits HELGELAND, Christians (ANRW), 795 aufmerksam, der auf den instruktiven Anhang zum Thema „Brigandage“ bei MacMulLEN, Ramsay, Enemies of the Roman Order - Treason, Unrest, and Alienation in the Empire, Pb. der Ausg. Cambridge MA 1966, London, New York 1992, 255-68, verweist. Ebenso Riesner, Militia Christi, 55. Vgl. zur Frage von Polizeidienst und Gewaltanwendung auch den kurzen Überblick bei Davies, Roy W., Police Work in Roman Times. In: History Today 18, (1968), 700 - 707; ausführlicher MACMulLEN, Soldier, 50 - 55; und v. a. FuHRMAnN, Policing, hier v. a. 123-145, 186-190, mit umfassender Diskussion der Quellen und der Literatur.

296 ALSTon, Richard, Soldier and Society in Roman Egypt, London 1998, 78.

297 Helgeland, Christians (ANRW), 795. 
Beachtet werden sollte auch, dass Tertullian in coron. 11,2 gerade die Ausübung polizeilicher Tätigkeiten - „Fesseln, Kerkerstrafen, Folter und Todesurteile vollziehen“ ${ }^{298}$ - als unvereinbar mit dem christlichen Bekenntnis betrachtet. ${ }^{299}$ Es scheint fast, als ob der Karthager hier einen schärferen Blick für die Realitäten des ,Polizeidienstes' hatte als mancher moderne Interpret.

R. Bainton übersieht weiterhin, dass Posten wie der eines beneficiarius consularis, selbst wenn dieser Polizeiaufgaben eingeschlossen haben sollte, nur eine Durchgangsstation in der militärischen Karriere eines Soldaten waren. So war die Beförderung zum beneficiarius consularis spätesten ab dem 3. Jhd. n. Chr. ein wichtiger Posten auf dem Weg vom einfachen Soldaten bis hin zum Zenturio oder zum Alendekurio, unter Umständen sogar zur militia equestris. ${ }^{300}$ Diese Beförderung setzte ihrerseits andere, auch genuin militärische Tätigkeiten voraus. Das bedeutet, dass auch ein solcher Posten keine Gewähr für eine ,friedfertige، Dienstzeit bot. Ähnliches gilt auch für die anderen von R. Bainton genannten

298 Coron. 11,2: vincula et carcerem et tormenta et supplicia administrabit (ÜS: P. Guyot/R. Klein). 299 Siehe dazu oben, S. $120 \mathrm{ff}$.

300 Zur militärischen Laufbahn der beneficiarii vgl. DomASzEwsKi/DoBson, Rangordnung, 24 und 33; OTт, Beneficiarier, 30 -32. Auf diesen Sachverhalt machen bereits Helgeland, Christians (ANRW), 794, Anm. 331, unter Verweis auf CIL III 9908 und VIII 17626 (= CBFIR 753); und das Standardwerk von Domaszewski/Dobson, Rangordnung, 32-35, aufmerksam. In CIL III 9908 ist der Rang des beneficiarius allerdings nicht erhalten, er beruht auf einer Rekonstruktion von A. von Domaszewski (s. ebd., 213; außerdem BREEZE, Organisation, 263; BREEZE, Career Structure (ANRW), 443 mit Anm. 38). Daher ist eine Berufung auf diese Inschrift problematisch. Zu den Laubahnen der beneficiarii vgl. DomasZEWSKI/Dobson, Rangordnung, 32-34, für die beneficiarii der Statthalter (beneficiarii consularis, beneficiarii procuratoris etc.), und ebd., 38-41, für diejenigen der Legionsoffiziere, mit zahlreichen Belegen; außerdem Отт, Beneficiarier, 30 - 32 und 57-59, sowie den Katalog mit Belegen ebd., 167-173 (geordnet nach dem Vorkommen im CBFIR [= SCHALlMAYER, Egon; Eibl, Kordula; OTT, Joachim (Hrsg.), Der römische Weihebezirk von Osterburken I - Corpus der griechischen und lateinischen Beneficiarier-Inschriften des Römischen Reiches 40, Stuttgart 1990]). DomaszewsKi/Dobson, Rangordnung, 32-35, verweist auf CIL III 3306; III 10060; VIII 17626 (= CBFIR 753); XIII 6429a als Belege dafür, dass beneficiarii consularis seit Septimius Severus sogar direkt zum Zenturionat befördert werden konnten. Allerdings macht BREEzE, Organisation, 272, Anm. 38, auf z.T. gewichtige Unsicherheiten bei der Lesung und Rekonstruktion der betreffenden Inschriften durch A. von Domaszewski aufmerksam. Einen guten Überblick über die Rangstruktur und die Beförderungsmöglichkeiten in den Legionen, der über A. von Domaszewski hinausführt und diesen z.T. korrigiert, gibt BREEzE, Organisation, 263-278, mit einer graphischen Übersicht ebd., 268; außerdem BREEZE, Career Structure (ANRW), 441-445. Letzterer (BREEZE, Organisation, 271-272 mit Anm. 38; und BREEZE, Career Structure (ANRW), 443 mit Anm. 41 und 444 mit Anm. 52) erkennt CIL VIII 17626 (= CBFIR 753) und AE 1932, Nr. 57 (= CBFIR 701; dort aber bereits in das 2. Jhd. n. Chr. datiert) als wahrscheinliche Belege für eine direkte Beförderung vom beneficiarius consularis zum centurio an. Zugleich weist er (BREEZE, Career Structure (ANRW), 444-445) darauf hin, dass die Posten des beneficiarius consularis wie auch des signifer zugleich als „efficiency bars“ dienten (s. auch die ausführlichere Diskussion mit tabellarischer Übersicht in BREEZE, Organisation, 274-276). Hier wurde noch einmal eine Auslese auf dem Weg zum Zenturionat getroffen. Eine Garantie für den weiteren Aufstieg boten diese Posten also nicht. So auch Отт, Beneficiarier, 31, der aber ebd., 31-32, einige Beispiele für einen solchen Aufstieg bietet. 
Tätigkeiten. ${ }^{301}$ Außerdem weist J. Helgeland mit Recht darauf hin, dass sich auf allen gesichert vorkonstantinischen christlichen Soldateninschriften nur ,normale Soldaten', aber keine ,Polizeisoldaten' finden; vergleichbares gilt auch für die Soldatenmartyrien. ${ }^{302}$ Bereits im Kapitel $\mathrm{zu}$ Tertullian wurde darauf hingewiesen, dass der eine Text aus vorkonstantinischer Zeit, den R. Bainton als Beleg für die Existenz christlicher ,Polizeisoldaten' anführen kann, nämlich Tert. fuga 13,5-6, von ihm missverstanden wurde und keineswegs Christen in den Reihen der beneficiarii consularis anführt. ${ }^{303}$

2. J. Cadoux ist der Ansicht, dass „Clemens of Alexandria does not seem ever to have faced the problem of Christianity and war [...].“304 So erklärt er, wie Clemens trotz seines „clear grasp of Christian principles in the abstract“ - was für J. Cadoux natürlich pazifistische Prinzipien sind - Formulierungen gebrauchen konnte, „which concede the compatibility of military service with the Christian faith. “305 L. Swift meint ebenfalls, dass Clemens keine kohärente Position zu den Fragen von Soldatendienst und Gewaltanwendung entwickelt hätte. Vielmehr wäre festzuhalten, „although Clement is sensitive to the need for defending the safety of the state, the moral issue of Christian participation in violent action seems not to have been seriously joined in his mind.“306

Angesichts der besprochenen Passagen zu den kriegerischen Texten aus dem Alten Testament, zu seiner grundsätzlich kritischen Haltung gegenüber dem Krieg und zu den bei ihm vorhandenen Ansätzen zu einer ,Lehre vom gerechten Krieg‘ ist aber zu fragen, ob es möglich ist, dass er das alles wirklich in keiner Weise mit der Frage des Soldatenberufs zusammengedacht hat. Vor allem in einem Werk wie dem Paedagogus, wo er so viele Bereiche des Lebens so gründlich auf ihre ethische Relevanz durchspricht, ist eine solche Leerstelle kaum vorstellbar. So stellt denn auch L. Swift zu Recht fest, dass ,he did not consider as sinful every act of homicide including that on the battlefield“307. Wenn dem so ist, dann ist es umso

301 Vgl. HELgELAND, Christians (ANRW), 794.

302 Vgl. HeLgeland, Christians (ANRW), 794. Ebenso Shean, Soldiering, 76 mit Anm. 11, der auf die Inschrift LECLERCQ, Militarisme, Nr. 29 (= CIL VI 32877 = ILS 9086) verweist, die einen christlichen Soldaten als zur legio II Parthica gehörig ausweist. Man könnte beispielsweise auch noch auf CIL VI 2873 = ILCV 398 B und auf CIL VI 2610 + 32654 = ILCV 2199 verweisen, in denen jeweils ein Zenturio der cohors $X$ urbana und ein Soldat der cohors VI praetoriana nachgewiesen sind. Beide Inschriften sind zugänglich in GuYoт/KLEIN (Hrsg.), Christentum Bd. 2, 66-67, mit Kommentar ebd., 279-280. Eine gute Zusammenstellung eines Großteils des relevanten epigraphischen Materials in englischer Übersetzung bietet SIDER, Killing, 145-151 (die Inschriften CIL VI 2873 = ILCV 398 B und CIL VI 2610 + 32654 = ILCV 2199 fehlen). Außerdem ist an den miles gloriosus aus Tertullians De corona zu erinnern, der sehr wahrscheinlich ein speculator der Prätorianergarde war.

303 Siehe oben S. $168 \mathrm{ff}$.

304 Cadoux, Christian Attitude, 232.

305 Cadoux, Christian Attitude, 232.

306 SwIFT, Views, 284.

307 SwIFT, War (ANRW), 852. 
wahrscheinlicher, dass Clemens Überlegungen zur Verbindung von Soldatendienst und Gewaltanwendung angestellt hat.

Ergänzend muss hinzugefügt werden, dass die in Ägypten stationierten Einheiten, trotz ihres eher ruhig gelegenen Stationierungsortes fern von bedrohten Grenzen, sowohl durch Abordnungen, sogenannte vexillationes, in militärische Auseinandersetzungen als auch in innere Konflikte verwickelt waren. ${ }^{308}$ Es ist nur schwer vorstellbar, dass der Zusammenhang zwischen Heeresdienst und Gewaltanwendung dem Clemens völlig entgangen ist, umso mehr, als dieser ja im Heer dienende Christen kannte.

J. Helgeland vertritt eine mit J. Cadoux vergleichbare Position und denkt, dass Clemens militärische Themen nur beiläufig und unsystematisch anspricht und daher wohl - so wird man ihn verstehen müssen - keine kohärente Position hatte und es auch nicht für nötig hielt, eine solche zu entwickeln. ${ }^{309} \mathrm{~J}$. Helgeland hält allerdings auch fest, dass er den Soldatenberuf nicht für sonderlich problematisch gehalten zu haben scheint. ${ }^{310}$ Mit letzterem Punkt hat er sicherlich Recht, die Bestreitung einer kohärenten Position bei Clemens überzeugt aber ebenso wenig wie zuvor bei L. Swift.

3. Gegen R. Riesner ${ }^{311}$ und J. Helgeland ${ }^{312}$, die beide der Ansicht sind, dass es sich bei christlichen Soldaten nur um einen seltenen Fall im Umfeld des Clemens bezie-

308 Vgl. dazu ALSTon, Soldier, 69 - 79, mit Belegen in den Anmerkungen (ebd., 220 - 223) auf den sich der folgende Überblick stützt. So schreibt er (ebd., 72): ,The army in Egypt played its part in most of the major military expeditions in the eastern half of the empire." Belegt ist die Teilnahme an den Feldzügen des Corbulo (58-63 n.Chr.), am Kampf gegen die jüdischen Aufstände (66-70 n. Chr., 115-117 n.Chr., 132-135 n.Chr.), an der Annexion des Nabatäerreichs und seiner Umwandlung in die Provinz Arabia (106 n.Chr.), am Partherkrieg Trajans (116-117 n.Chr.) und an dem Feldzug des Alexander Severus gegen die Perser (232 n.Chr.). Für die zweite Hälfte des 2. Jhds. n.Chr. ist die Qualität wie die Quantität der Quellen ungleich schlechter, was eine Erklärung dafür bieten dürfte, dass es keine gesicherten Nachrichten über einen Einsatz ägyptischer Einheiten in den Feldzügen dieser Zeit gibt. Eine Teilnahme von Abordnungen kann jedoch für den Partherfeldzug des Lucius Verus (163-165 n.Chr.) ebenso angenommen werden, wie für die Partherkriege des Septimius Severus (194-195 und 197-199 n.Chr.). Im Inneren kann noch einmal das Eingreifen im jüdischen Aufstand 115-117 n.Chr. genannt werden, bei dem es auch zu Kämpfen in weiten Teilen Ägyptens kam, außerdem der große Bukolenaufstand (171-172 n.Chr.) und Caracallas blutiges Vorgehen gegen Unruhen in Alexandria (215 n.Chr.). Zusammenfassend hält er fest (ebd., 78): „Taken together [die Konflikte im Inneren; AG] with the campaigns outside Egypt, a Roman soldier was likely to spend at least some of his career involved in warfare. [...] A soldier must not, however, spend a great deal of time at war, though we must make some allowances for the imperfection of the source material. The soldier could expect to fight at some point in his career but it seems unlikely that many of the soldiers of the Egyptian army were killed while on active service or that, in terms of time, war was a major part of the life of the soldier.“

309 Helgeland, Christians (ANRW), 745.

310 HELgELAND, Christians (ANRW), 744-745.

311 Riesner, Militia Christi, 53-54. Er meint, dass der Fall ,in der besonderen Umgebung des Alexandriners eher selten war“, räumt aber ein, „[i]mmerhin hat Clemens christliche Soldaten gekannt, das machen gelegentliche Bemerkungen in seinen Schriften deutlich.“ 
hungsweise vermutlich sogar um einen wahrscheinlich überhaupt nicht vorkommenden Fall handelt, ist noch einmal ${ }^{313}$ festzuhalten, dass vor allem paed. 3,12,91,2 ein Beleg dafür ist, dass Clemens von christlichen Soldaten als einem Normalfall wusste. Zusammen mit den anderen beiden Haupttexten aus prot. 10,100,4 und paed. 2,11,117,2 zeigt er außerdem, wie H. Brennecke mit Recht festhält, dass zu Clemens Zeiten „bei im Osten stationierten Einheiten mit größeren christlichen Truppenteilen zu rechnen“"314 ist. Die Beiläufigkeit, mit der Clemens den Soldatenberuf in prot. 10,100,4 und paed. 2,11,117,2 als bekannte Gegebenheit bei seinen Adressaten voraussetzt, sowie die direkte Ansprache von Soldaten in der ethischen Ermahnung in paed. 3,12,91,2 machen deutlich, dass Clemens hier sehr direkt auf die Lebenswelt seiner Leser Bezug nimmt. Dazu können noch einige unterstützende Argumente angeführt werden.

\section{Exkurs: Das Heer in der Lebenswelt des Clemens und seiner Leser}

Angesichts der zuletzt angestellten Überlegungen zum eventuellen Vorhandensein christlicher Soldaten im Umfeld des Clemens gilt es, an dieser Stelle noch konkret nachzufragen: Wie nahe war das Heer als erfahrbare Wirklichkeit für Clemens und seine Leser? Wie sehr war es Teil ihrer Lebenswelt?

Zur Beantwortung dieser Fragen muss man zuerst festhalten, dass die wohl seit hadrianischer Zeit als einzige Legion in Ägypten stationierte legio // Trajana nur 30 Stadien (ca. 5,5 km) von Alexandria entfernt in Nikopolis ihr Legionslager hatte. ${ }^{315}$ Dort waren außerdem Hilfstruppen ${ }^{316}$ und die classis Alexandrina ${ }^{317}$ kaserniert. Alles in allem dürften dort zur Zeit des Clemens, gemessen an den Sollstärken der Einheiten, etwa 10000-12000 Mann stationiert gewesen $\operatorname{sein}^{318}$ - von denen aller-

312 Helgeland, Christians (ANRW), 745: „It would seem, therefore, that [...] he was not disturbed by the relationship some Christians had to the military. Possibly he was not aware of any such Christians, although we cannot say for certain.“

313 Siehe dazu auch schon oben S. 217, Anm. 136.

314 BRENNECKE, An fidelis (2007), 200.

315 Zum Folgenden vgl. grundsätzlich Alston, Soldier, 23-52; MiтtнoF, Fritz, Soldaten und Veteranen in der Gesellschaft des römischen Ägypten (1.-2. Jh. n.Chr.). In: Alföldy/Dobson/Eck (Hrsg.), Kaiser, Heer und Gesellschaft, 377-406; Clauss, Alexandria, 131-137; LE BoHEC, Armee, 197-198. 316 Vgl. Alston, Soldier, 24-27, und die Übersicht ebd., 165-191, mit den relevanten Belegen. Zwischen ca. $180-220$ n. Chr. standen dort die folgenden Einheiten: ala Apriana, ala veterana Gallica; ala Heracliana; ala Thracorum Mauretana; cohors I Apamenor (?); cohors I Augusta Praetoria Lusitanorum eq.; cohors I Flavia Cilicia eq.; cohors II Ituraeorum eq.; cohors III Ituraeorum (?); cohors I Pannoniorum (?); cohors scutata civium; cohors II Thracum eq. (?); numerus Hadrianorum Palmyrenorum Sagittorum. Siehe außerdem MAXFIELD, Valerie A., The Deployment of the Roman Auxilia in Upper Egypt and the Eastern Desert during the Principate. In: Alföldy/Dobson/Eck (Hrsg.), Kaiser, Heer und Gesellschaft, 407-442.

317 Vgl. Watson, Roman Soldier, 20 -21; Webster, Army (1998), 157-166, v. a. 159; Le BoHEc, Armee, $30-31$.

318 Vgl. den Überblick bei ALSTON, Soldier, 31-32. 
dings etliche Soldaten über die Provinz verteilt Dienst taten. Verbunden waren Lager und Metropole auf direktem Weg durch die via Nicopolitana. Im Jahr 215 n. Chr. verlegte Caracalla die Truppen dann direkt nach Alexandria. ${ }^{319}$

Für den Zweck dieser Untersuchung ist weiterhin eine Beobachtung zur Rekrutierung des ägyptischen Provinzheeres ${ }^{320}$ wichtig, die F. Mitthof wie folgt zusammengefasst hat:

„Bereits in der frühen Kaiserzeit griff die Militärverwaltung bei der Suche nach geeigneten Rekruten auf Landeskinder zurück. Um die Wende vom 1. zum 2. Jh. waren die in Ägypten liegenden Einheiten mit dem lokalen Element durchsetzt, und spätestens seit dem letzten Viertel des 2. Jh. wird man - abgesehen von frisch nach Ägypten verlegten Einheiten, die selbstverständlich das ethnisch-kulturelle Gepräge ihres vormaligen Dienstortes für einige Zeit behielten - mit einem Provinzheer rechnen dürfen, das sich beinahe ausschließlich aus Personen ägyptischer Herkunft zusammensetzte.““321

Dabei gab es allerdings Unterschiede je nach Truppengattung: Für die auxilia ist schon „seit frühantoninischer Zeit eine provinzinterne Ergänzung anzunehmen“322. Die Legionen dagegen wurden noch weit bis ins 2. Jhd. n. Chr. vor allem aus Syrien, Phönizien, Kleinasien, Cyrenaica und Africa rekrutiert. ${ }^{323}$ Erst gegen Ende des 2. Jhds. n. Chr. scheint auch die legio II Traiana ihre Rekruten mehr und mehr aus Ägypten und hier bevorzugt aus Alexandria ${ }^{324}$ bezogen zu haben. ${ }^{325}$ In der Regel reichten

319 Vgl. Clauss, Alexandria, 133.

320 Vgl. dazu Alston, Soldier, 39-52; Mitthof, Soldaten, 378-383.

321 Miтtнof, Soldaten, 379. Vgl. zu dieser Frage ebd., 378-383 mit Anm. 5-6, für die Belege zu dem angeführten Zitat; vgl. auch kurz CLAuss, Alexandria, 134. Einen guten Überblick über die Herkunft der Legionäre bietet weiterhin ALSTON, Soldier, 41-44, mit Diskussion der Belege und einem tabellarischen Überblick. Und ebd., 165-189, nennt er in seiner Übersicht über die in Ägypten stationierten auxilia bei den Belegen auch Angaben zur Herkunft der Soldaten, soweit diese aus den Quellen ersichtlich ist. Zur Zunahme der lokalen Rekrutierung ab dem 2. Jhd. n.Chr. vgl. Le BoHEc, Armee, 88-95, hier v.a 94-95, für Ägypten.

322 Mitthof, Soldaten, 379 mit Anm. 5, wo er die Angaben aus ChLA X 456 + XI 468 (Rekrutierung in frühflavischer Zeit) mit den Angaben aus ChLA X 410 und ChLA V 283 = P. Mich. III 162 (Rekrutierung in spätantoninischer Zeit) vergleicht. Während in flavischer Zeit die Herkunftsangaben überwiegend auf Gegenden außerhalb Ägyptens verweisen, dominieren in antoninischer Zeit ägyptische Orte oder die Angabe origo castris. Zu ChLA X 456 + XI 468 siehe auch SpeIDEL, Michael A., Rekruten für ferne Provinzen - Der Papyrus ChLA X 422 und die kaiserliche Rekrutierungszentrale. In: Speidel, Michael A. (Hrsg.), Heer und Herrschaft im Römischen Reich der hohen Kaiserzeit, (Mavors Roman Army Researches 16), Stuttgart 2009, 213-234, hier 217-219. Dieser diskutiert auch ausführlich ChLA X 422, bei dem es sich s.E. (ebd., 215) sehr wahrscheinlich um die Auflistung des ,jährlichen Rekrutenzugang[s] einer in Ägypten stationierten Auxiliareinheit“ für die erste Hälfte des 2. Jhds. n. Chr. handelt. MiтTHOF, Soldaten, 379, Anm. 6, dagegen vermutet, es könnte sich möglicherweise um Legionäre handeln.

323 Vgl. Alston, Soldier, 41-44; Mitthof, Soldaten, 379-380 mit Anm. 6; Speidel, Rekruten, 219. Relevant sind hier v. a. CIL III 6627, BGU IV $1083=$ ChLA X 426.

324 Vgl. Dietze-Mager, Gertrud, Die Beziehung zwischen römischem Bürgerrecht und alexandrinischem Stadtrecht bis zur Constitutio Antoniniana (212). In: van Nuffelen, Peter (Hrsg.), Faces of Hellenism - Studies in the History of the Eastern Mediterranean (4th Century B.C. -5th Century A.D.), (Studia Hellenistica 48), Leuven 2009, 217-275, hier 264-265 mit Belegen. Sie schreibt zusammenfassend: „Alexandriner wurden offensichtlich nicht nur bei der Einziehung in die Legionen [...], sondern auch in die Hilfstruppen und vor allem in die misenatische Flotte bevorzugt." Siehe auch Mitтhof, Soldaten, 380, Anm. 7, mit weiteren Belegen. 
dabei für den Bedarf des Provinzheeres die Freiwilligen aus - folgt man F. Mitthofs, waren das durchschnittlich zwischen 500 und 1000 Rekruten pro Jahr ${ }^{326}$-, so dass Zwangskonskriptionen, wenn überhaupt, nur in Ausnahmefällen vorkamen.

Daraus lässt sich zweierlei folgern: Zum einen zeigt die reine Anzahl an Soldaten, die in oder bei Alexandria stationiert waren, dass unter den Christen der Gemeinde Alexandrias mit einer gewissen Zahl konvertierter oder zumindest am Christentum interessierter Soldaten gerechnet werden kann. Zum anderen zeigt die weitgehende Rekrutierung aus der Provinz und gerade auch aus Alexandria, dass zur Zeit des Clemens der Dienst entweder in der in Nikopolis stationierten Legion oder in einer der dortigen Auxiliareinheiten für Alexandriner und damit zumindest grundsätzlich auch für alexandrinische Christen eine Option war. Gerade den vielfach aus den gehobenen Schichten Alexandrias stammenden Hörern und Lesern des Clemens, die zumindest zu einem Teil auch römisches Bürgerrecht besessen haben könnten ${ }^{327}$, stand im Fall des tatsächlichen Besitzes dieses Bürgerrechts auf jeden Fall die Legion offen ${ }^{328}$.

325 Vgl. Alston, Soldier, 42-43; Mitthof, Soldaten, 379-381; Le Bohec, Armee, 94-95; Speidel, Rekruten, 219-221. Das gilt v. a. dann, wenn man annimmt, dass die Soldaten, die castris als Herkunft angeben, aus der Provinz selbst stammen. ALSTON, Soldier, 43 steht dieser Vermutung skeptisch gegenüber. Zur Problematik vgl. auch Mitrhof, Soldaten, 379, Anm. 3; und Le BoHEC, Armee, 88. Aber auch so zeigt sich dieser Sachverhalt durch den Vergleich der zwei wichtigsten Belege für das 2. Jhd. n. Chr.: Zum einen die zusammengehörenden Entlassungsinschriften AE 1955, Nr. 238 + AE 1969, Nr. 633 aus dem Jahr 157 n.Chr., was auf eine Rekrutierung in den Jahren 132-133 n.Chr. hinweist. Zum anderen die Entlassungsinschrift CIL III 6580 = ILS 2304 aus dem Jahr 194 n.Chr., was auf eine Rekrutierung im Jahr 168 schließen lässt. Der Vergleich zeigt, dass der Anteil der Legionäre, die Ägypten als Herkunftsort angeben, von 1\% auf 21\% ansteigt. (Derjenige der Soldaten mit der Angabe castris steigt von $0 \%$ auf $62 \%$.) Siehe zu den genannten Inschriften die tabellarische Übersicht und Auswertung bei Alston, Soldier, 43-45. Sowohl Alston, Soldier, 44, als auch MitTHoF, Soldaten, 379, Anm. 6, halten beide Listen für repräsentativ. SPEIDEL, Rekruten, 220, dagegen meint, dass die Zahlen der früheren Inschrift aufgrund einiger Besonderheiten auf eine unübliche Rekrutierung hinweisen, die er mit dem Beginn des Bar Kochba-Aufstandes in Verbindung bringt. Dennoch weise auch diese Liste in den großen Linien markante Parallelen mit dem gängigen Rekrutierungsmuster der ägyptischen Legionen auf.

326 Vgl. Mitтhof, Soldaten, 382 mit Anm. 17, wo er im Anschluss an die Berechnungen u. a. von ALston, Soldier, 45-48 (ca. 250 Rekruten für eine Legion von ca. 5000 Soldaten) von 1000 neuen Rekruten für eine 20000 Mann starke Truppe ausgeht. Für die 10000-12000 Mann zur Zeit des Clemens sind die Zahlen dann entsprechend etwas niedriger anzusetzen.

327 Vgl. zum Verhältnis von alexandrinischem und römischen Bürgerrecht ALSToN, Soldier, 61; Clauss, Alexandria, 126-128; sowie ausführlich DieTzE-MAgER, Bürgerrecht; und jetzt auch Marotta, Egyptians and Citizenship from the First Century AD to the Constitutio Antoniniana. In: Cecchet, Lucia, Busetto, Anna (Hrsg.), Citizens in the Graeco-Roman World - Aspects of Citizenship from the Archaic Period to AD 212, (Mneomsyne Supplements 407), Leiden 2017, 172-198, der auch die weiteren rechtlichen Status der Bewohner Ägyptens diskutiert. Der Briefwechsel zwischen Plinius und Trajan in Plin. epist. 10,5-7.10 belegt, dass Bewohner der Provinz Ägypten zuerst das sehr exklusive alexandrinische Bürgerrecht erringen bzw. vom Kaiser verliehen bekommen mussten, ehe sie das römische Bürgerecht erhalten durften. Diese Abfolge ist ein Ausdruck der privilegierten Stellung der Alexandriner gegenüber den einfachen Provinzbewohnern und zeigt, dass diese die „most priviledged non-Romans“ (ALSTon, Soldier, 61) Ägyptens waren. Zur privilegierten Stellung der Alexandriner vgl. ausführlich DiETZE-MAGER, Bürgerrecht, 237-268 und 225-231 zu den Pliniusstellen, wo auch abweichende Interpretationen diskutiert werden; MARotTA, Citizen- 


\title{
3.4.4 Fazit
}

Diese Folgerungen unterstützen die schon bei der Textinterpretation geäußerte Annahme, dass Passagen wie prot. 10,100,4 sowie paed. 3,12,91,2 und 2,11,117,2 tatsächlich die Lebenswirklichkeit des Clemens und seiner Leser widerspiegeln. Clemens kannte mit Sicherheit christliche Soldaten in seinem Umfeld. Seine Äußerungen zeigen zudem, dass er sich mit ihrer Existenz in ethischer Hinsicht befasste - zwar nur knapp, aber deutlich genug, um seine Haltung erkennen zu können - und ihren Dienst im Heer mit ihrem christlichen Bekenntnis für vereinbar hielt. Prägnant hat das A. von Harnack auf den Punkt gebracht: „Deutlich hat Clemens von Alex. die Vereinbarkeit des militärischen Standes mit dem christlichen Bekenntnis vorausgesetzt. “329 Das gilt mit Sicherheit für Soldaten, die während ihres Dienstes zum Christentum konvertierten, und mit einer gewissen Wahrscheinlichkeit auch für Christen, die dem Heer beitraten.

Eine interessante Leerstelle bildet die Frage der Heeresreligion beziehungsweise aus christlicher Sicht diejenige der Idolatrie, die im Heer ja allgegenwärtig war. Gerade wenn man im Blick hat, dass für Tertullian die Gefahren des Götzendienstes das

\begin{abstract}
ship, 174-183 und 190 sowie 176-181 zu den Pliniusstellen. G. Dietze-Mager interpretiert die Koppelung der Vergabe des römischen Bürgerrechts an die vorherige Verleihung des alexandrinischen Bürgerrechts als eine Analogie zur entsprechenden Koppelung an das ius Latii im Westen des Reiches (ebd., 231-237). Zusammenfassend hält sie fest (ebd., 269-270): „Die Quellen zeigten eine relativ starke Präsenz von römischen Neubürgern mit hellenischem Hintergrund im frührömischen Alexandria. [...] Zumindest anfänglich konzentrierte sich die römische Präsenz im Wesentlichen auf Alexandrien, dessen Bürger aus der Gesamtheit der ägyptischen Bevölkerung klar herausgehoben und in die Nähe der Römer gerückt wurde. Wenn wir auch keine rechtliche Konditionalität zwischen römischem Bürgerrecht und alexandrinischem Stadtrecht nachweisen konnten, so legten die Quellen doch nahe, daß die Alexandriner bei der Verleihung römischen Bürgerrechts in Ägypten bevorzugt wurden. [...] Auch im 2. Jh. begegnen uns Personen, die eine Verbindung zwischen römischem und alexandrinischem Bürgerrecht erkennen lassen, schon allein auf Grund der Tatsache, dass alexandrinische Bürger bei der Rekrutierung für die ägyptischen Legionen, die Hilfstruppen und die misenatische Flotte bis Ende des 2. Jh. bevorzugt wurden." Siehe auch MARotTA, Citizenship, 176 und 181.
\end{abstract}

328 Das Bürgerrecht konnte aber auch direkt beim Eintritt in die Legion verliehen werden, war also nur in dem Sinn zwingende Voraussetzung, dass man es beim Eintritt selbst besitzen musste. Vgl. DiETZE-MAGER, Bürgerrecht, 257-258 und 264- 265 mit Belegen, so verweist sie z. B. (ebd., 257-258) auf CIL III 6627 = ILS 2483 und P. Oxy. XXII 2349. Siehe auch WesCH-KLEIN, Soziale Aspekte, 157-158 mit Anm. 63. Diese Möglichkeit stand allerdings nur Alexandrinern offen, da ,Ägyptern' der direkte Weg zum römischen Bürgerrecht - außer durch einen kaiserlichen Gnadenakt - verschlossen war. Vgl. dazu MAROTTA, Citizenship, 175-187, der u. a. auch die Bestimmung des Gnomon des Idios Logos 55 diskutiert. Letztere konnten nach MAROTTA, Citizenship, 183-186, über den Dienst als Flottensoldaten nach ihrem ehrenvollen Ausscheiden das römische Bürgerrecht erlangen.

329 HARNACK, Mission und Ausbreitung (1924), 581. Ebenso BigELMAIR, Beteiligung, 181; SCHÖPF, Tötungsrecht, 220; Helgeland, Christians (ANRW), 745 - 746; RIESNER, Militia Christi, 55; BRENNECKE, An fidelis (2007), 200. Ähnlich sehen das auch KaRPP, Stellung, 506; und CAMPENHAUSEN, Kriegsdienst, 257, wenn auch mit einer gewissen Reserve. 
hauptsächliche Übel des Militärdienstes darstellten, verwundert das völlige Fehlen dieses Themas bei Clemens doch sehr. ${ }^{330}$ Zumindest für den Paedagogus passt diese Lücke allerdings ins Gesamtbild, da dort, wie Chr. Mühlenkamp zusammenfassend festhält, „von Abgrenzung zum Heidentum nur wenig die Rede“331 ist. $^{332}$ Sie erklärt das vor allem mit dem „sozialen Milieu der Adressaten des Paidagogus“333. Diese Antwort mag auch für die hier behandelte Fragestellung zumindest grundsätzlich in die richtige Richtung weisen. Dennoch bleibt das völlige Fehlen der Idolatrieproblematik eine bemerkenswerte Lücke in der Position des Clemens.

Angesichts der Nähe des Clemens zur alexandrinischen Gemeinde, in deren Rahmen die Lehrtätigkeit, die sich im Protrepticus und Paedagogus sowie wohl auch teilweise in den Stromata spiegelt, durchgeführt wurde, lässt sich annehmen, dass die Haltung des Clemens nicht allzu weit von derjenigen der Gemeinde entfernt gewesen sein dürfte. Auch dort wird man zumindest konvertierte Soldaten willkommen geheißen und zur Taufe zugelassen haben, ohne dass diese ihren Beruf aufgeben mussten.

Außerdem ist Clemens ein wichtiger Zeuge dafür, dass es um das Jahr 200 n. Chr. bereits eine substantielle Zahl von Christen in den im Osten stationierten römischen Einheiten gab. Diese Zahl muss zumindest so groß gewesen sein, dass die Behandlung des Themas Eingang in die präkatechumenale und die katechumenale Unterweisung der Gemeinde gefunden hat, wie sie sich im Protrepticus und im Paedagogus widerspiegeln.

330 So fehlt, darauf macht Helgeland, Christians (ANRW), 745-746, aufmerksam, bei der Diskussion der Kränze in paed. 2,8,70-76, die Clemens ebenfalls als für Christen untragbar bewertet, jeder Hinweis auf den Soldatenkranz. Diese Lücke fällt umso mehr auf, als die weiteren Beispiele sowie die Argumente des Clemens denen in Tertullians De corona durchaus ähneln.

331 MÜHLENKAMP, Heiden, 166-167.

332 Auch RiEsner, Militia Christi, 62-63, hält fest, dass die nichtrigoristische Auffassung zum Wehrdienst den ebenso nichtrigoristischen Stellungnahmen des Clemens zu anderen Themen wie Philosophie, Sexualität, Familie, Wirtschaft und Sport entspricht. Vgl. auch VöLKER, Gnostiker, 195-219; sowie CHADWICK, Clement, 174-176.

333 MÜHLENKAMP, Heiden, 167. 